\title{
Outdoor Education and Meaningful Learning: Finding the attributes of meaningful learning experiences in an outdoor education program
}

Stacy Tooru Taniguchi

Brigham Young University - Provo

Follow this and additional works at: https://scholarsarchive.byu.edu/etd

Part of the Educational Leadership Commons

\section{BYU ScholarsArchive Citation}

Taniguchi, Stacy Tooru, "Outdoor Education and Meaningful Learning: Finding the attributes of meaningful learning experiences in an outdoor education program" (2004). Theses and Dissertations. 164.

https://scholarsarchive.byu.edu/etd/164

This Dissertation is brought to you for free and open access by BYU ScholarsArchive. It has been accepted for inclusion in Theses and Dissertations by an authorized administrator of BYU ScholarsArchive. For more information, please contact scholarsarchive@byu.edu, ellen_amatangelo@byu.edu. 
OUTDOOR EDUCATION AND MEANINGFUL LEARNING: FINDING THE

ATTRIBUTES OF MEANINGFUL LEARNING EXPERIENCES IN AN OUTDOOR

EDUCATION PROGRAM

\author{
by \\ Stacy T. Taniguchi
}

\begin{abstract}
A dissertation submitted to the faculty of
Brigham Young University

in partial fulfillment of the requirements for the degree of
\end{abstract}

Doctor of Philosophy

Department of Educational Leadership and Foundations

Brigham Young University

April 2004 
BRIGHAM YOUNG UNIVERSITY

GRADUATE COMMITTEE APPROVAL

of a dissertation submitted by

Stacy T. Taniguchi

This dissertation has been read by each member of the following graduate committee and by majority vote has been found to be satisfactory.

OS APR 04

Date

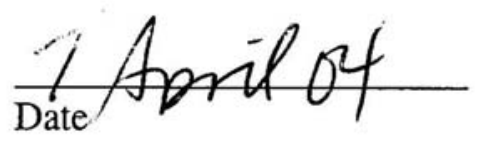

12 April on

Date
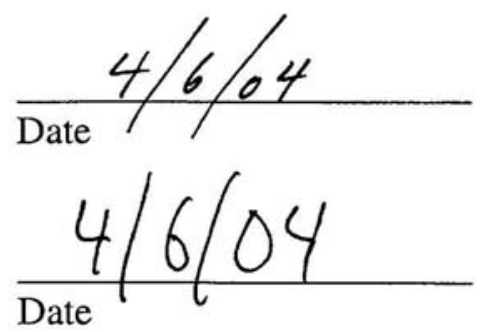
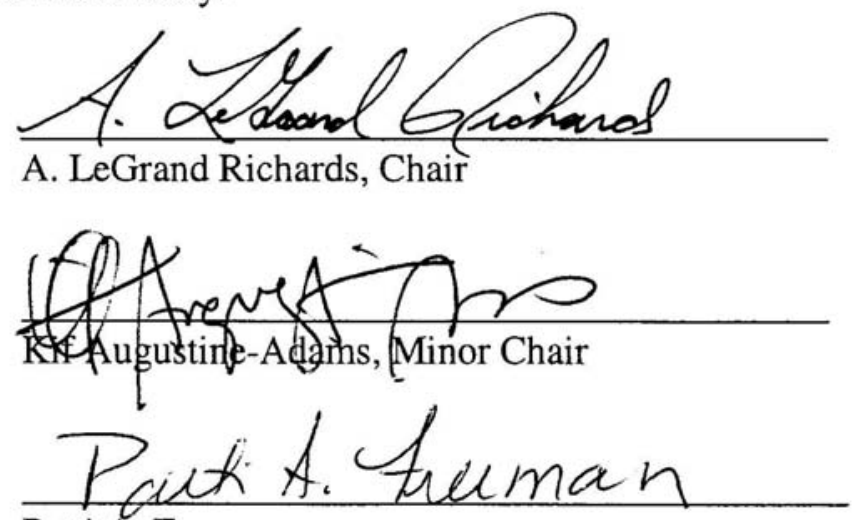

Patti A. Freeman

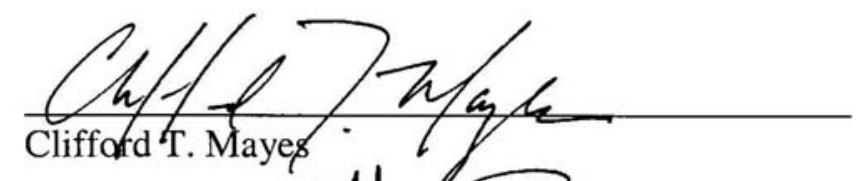

0 (the

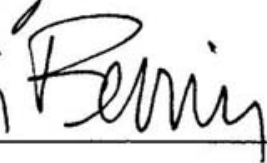

Scott E. Perrin 


\section{BRIGHAM YOUNG UNIVERSITY}

As chair of the candidate's graduate committee, I have read the dissertation of Stacy T. Taniguchi in its final form and have found that (1) its format, citations, and bibliographical style are consistent and acceptable and fulfill university and department style requirements; (2) its illustrative materials including figures, tables, and charts are in place; and (3) the final manuscript is satisfactory to the graduate committee and is ready for submission to the university library.

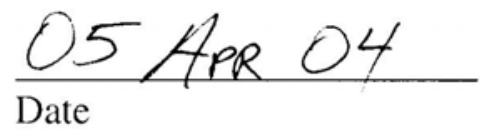

Date

Accepted for the Department

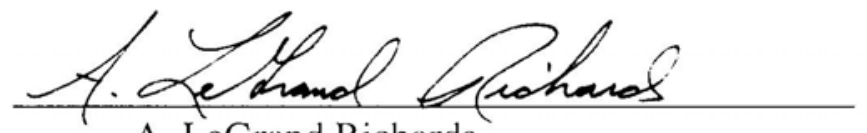

A. LeGrand Richards

Chair, Graduate Committee

Accepted for the College

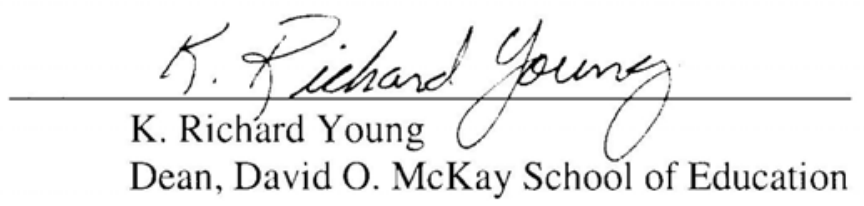




\begin{abstract}
OUTDOOR EDUCATION AND MEANINGFUL LEARNING: FINDING THE ATTRIBUTES OF MEANINGFUL LEARNING EXPERIENCES IN AN OUTDOOR EDUCATION PROGRAM

\author{
Stacy T. Taniguchi \\ Department of Educational Leadership and Foundations \\ Doctor of Philosophy
}

This phenomenological study sought to identify the common attributes of meaningful learning experiences as found in an outdoor education program. The pragmatic educational philosophy of John Dewey provides the rationale for the essence of meaningful learning in our schools and this research identifies the attributes of educative reflective experiences that are also meaningful learning experiences. Thirteen students enrolled in the Wilderness Writing Program, offered during the fall semester of 2003 at Brigham Young University in Provo, Utah, made up the focus group of this study. Their participation in four outdoor recreational activities and their reflections about their experiences became the basis of this research. Through written journal entries, focus group discussions, observations, and writing assignments, this study took a qualitative approach to identifying patterns of attributes that appeared to occur in meaningful 
learning experiences. This study found that meaningful learning experiences were identified by participants who experienced a period of awkwardness followed by a purifying process, or sublimation. A reflective period allowed for reconstruction of a person's view of himself or herself and this was closely tied with feedback from others in the group. The findings of this study can give educators specific components that appear to be crucial ingredients to meaningful learning experiences. 


\section{ACKNOWLEDGMENTS}

The completion of this doctoral dissertation was made possible through the support of many people. I am eternally grateful to my wife LuAnn Taniguchi who provided encouragement, labor, and support through the years of school leading to and including the time during which this work was completed. I want to thank my children, Jared, Amy, Ryan, and Maili for their support. I am grateful to Dr. A. LeGrand Richards, my doctoral committee chair, for entrusting me with his time and effort to mentor me through the years of my study and to my doctoral committee members, Dr. Patti A. Freeman, Dr. Kif Augustine-Adams, Dr. Cliff T. Mayes, and Dr. Scott E. Ferrin for their expertise and support. I wish to thank Dr. Patti A. Freeman and Dr. Brian J. Hill for their valuable mentorship, encouragement, and support in preparing me for my future. I am grateful to Dr. Burton K. Olsen and Dr. John S. Bennion for their interest and support in sharing their Wilderness Writing Program with me for the collection of my data for this dissertation and to the participants of this research study for helping me find what I was looking for. I also want to thank Alexis Palmer for her insight and help on the data analysis. Finally, I am grateful to my parents, Joichi and Misako Taniguchi, my sister Grace, and her husband, Kenzo Shinsato, who taught me to never stop asking questions and never stop learning because wisdom comes with age. 


\section{TABLE OF CONTENTS}

Abstract

iv

Acknowledgements

vi

Table of Contents

vii

List of Figures

$\mathrm{X}$

Introduction

1

The Problem Statement $\quad$.................................... 9

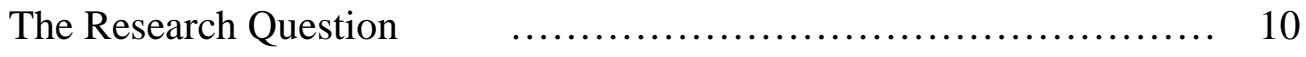

Definition of Terms $\quad$...................................... 10

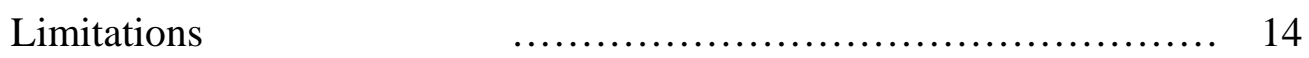

Delimitations $\quad$....................................... 14

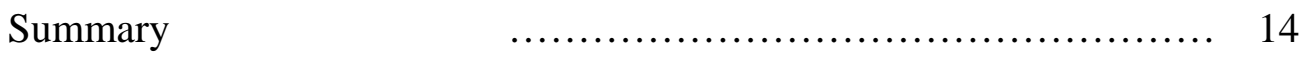

Literature Review $\quad$............................................. 18

Philosophical Works $\quad$.................................... 18

Pragmatic Educational Philosophy of John Dewey $\quad \ldots . \ldots \ldots \ldots . .18$

Existentialism $\quad$...................................... 24

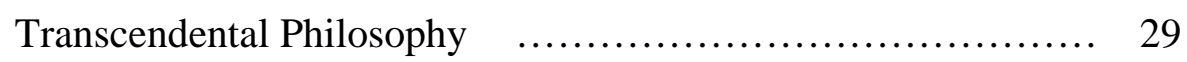

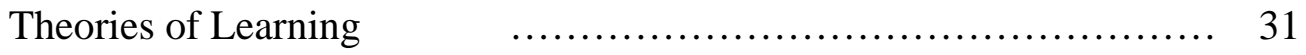

Cognitive Learning Theory $\quad \ldots \ldots \ldots \ldots \ldots \ldots \ldots \ldots \ldots \ldots \ldots \ldots . \ldots \ldots$

Cognitive Constructivism $\quad \ldots \ldots \ldots \ldots \ldots \ldots \ldots \ldots \ldots \ldots \ldots \ldots \ldots$

Social Constructivism $\ldots \ldots \ldots \ldots \ldots \ldots \ldots \ldots \ldots \ldots \ldots \ldots \ldots$

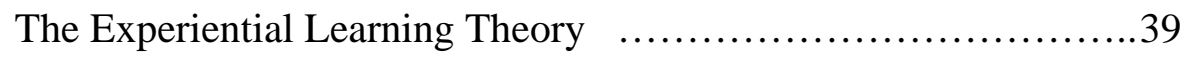

Outdoor Education Literature $\quad$..................................... 45 


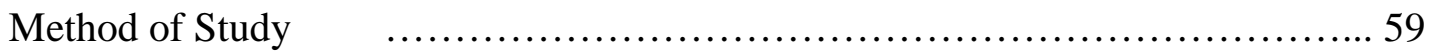

Phenomenological Study $\quad$....................................... 59

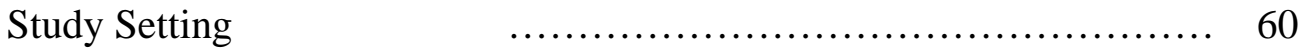

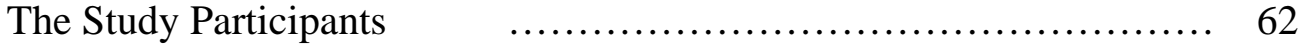

Consent to Participate $\quad$........................................ 62

Introduction to Outdoor Recreation Course $\quad \ldots \ldots \ldots \ldots \ldots \ldots \ldots \ldots \ldots \ldots . \ldots . \ldots . \ldots$

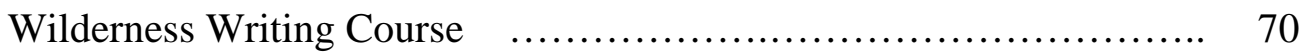

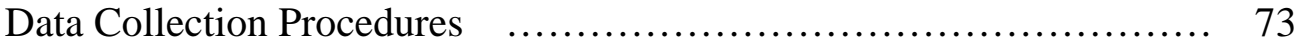

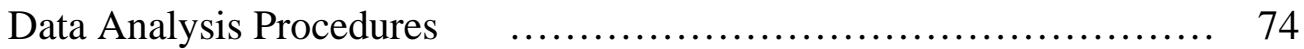

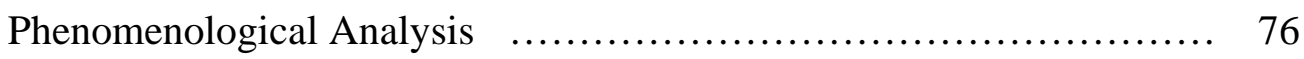

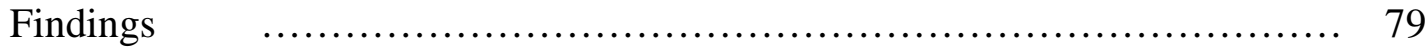

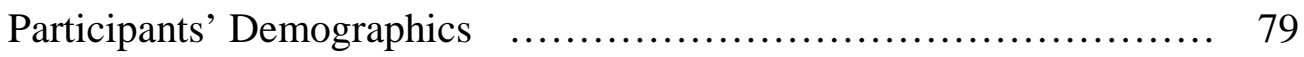

Themes of Meaningful Learning Experiences $\quad$...................... 81

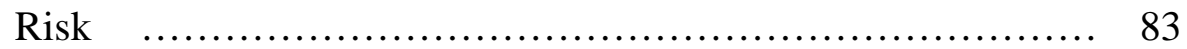

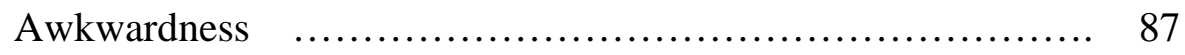

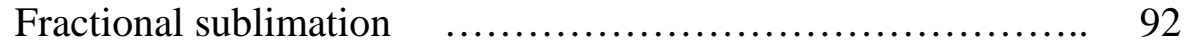

Reconstruction $\quad$............................................. 99

Reflection $\quad$...................................... 101

Reformation .............................................. 102

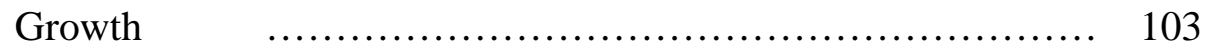

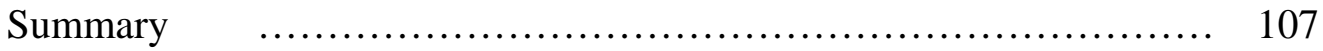

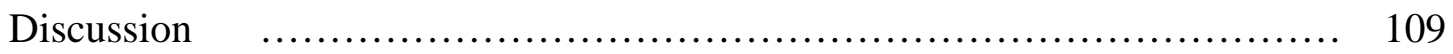

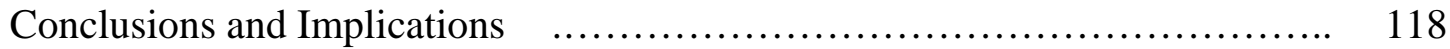




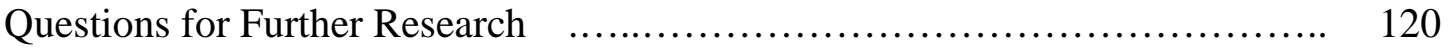

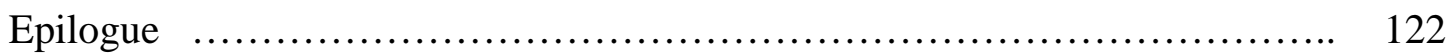

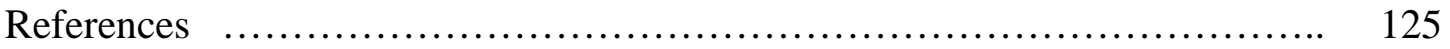

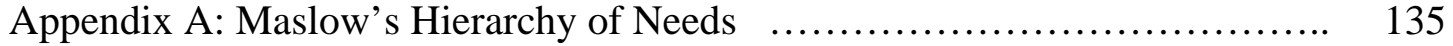

Appendix B: Written Purpose and Expectations of Research Study $\quad \ldots \ldots \ldots \ldots . .136$

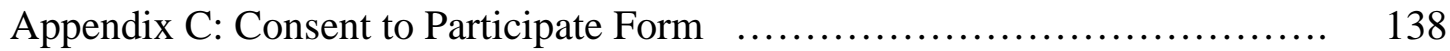

Appendix D: RMYL 123 Class Schedule for 2003 Winter Semester $\quad \ldots . \ldots \ldots \ldots . \quad 140$

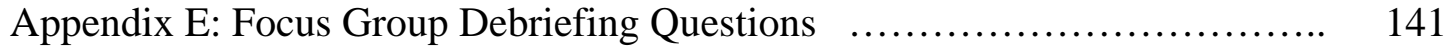

Appendix F: Triangulation: Supporting Sources for Validity and Reliability .... 143

Appendix G: Additional Comments from Participants Relating to Themes $\ldots . .146$

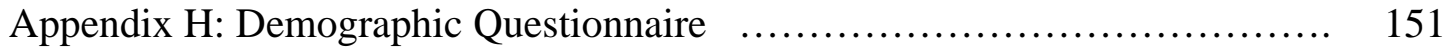

Appendix I: Research Participants’ Demographic Parameters .............. 152

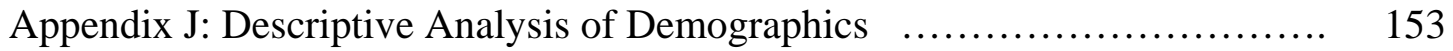

Appendix K: BYU Online Student Ratings Report ........................ 155 


\section{LIST OF FIGURES}

Figure

Page

1. The gap between an educative and meaningful experience $\quad \ldots . . . . . \quad 17$

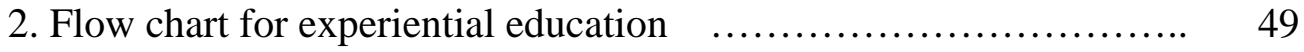

3. Yerkes-Dodson Curve $\quad$........................................... 52 
Outdoor Education and Meaningful Learning: Finding the Attributes of Meaningful Learning Experiences in an Outdoor Education Program What avail is it to win prescribed amounts of information about geography and history, to win ability to read and write, if in the process the individual loses his own soul: loses his appreciation of things worth while, of the values to which these things are relative; if he loses desire to apply what he has learned and, above all, loses the ability to extract meaning from his future experiences as they occur. (Dewey, 1938, p. 49)

At 20,320 feet, Mt. McKinley stands as the highest geographical point on the North American continent. Situated in a mountain range which spans the interior of Alaska, this feature alone is the number one tourist attraction for the State. In 1988 as a climbing guide on Mt. McKinley, I was responsible for taking a group of nine climbers up this huge mountain massif. Taking nineteen days to reach the high camp at 17,200 feet, this group of climbers was posed to make an eight-hour climb to the summit and back to their high camp with me. As if the exertion of climbing upwards was not enough, the lack of oxygen in the blood to fuel the body’s system and the freezing cold temperatures made this summit effort a very demanding and difficult task. Taking five steps and catching one's breath for five minutes was typical, and this effort made the summit climb long and painstakingly slow. Most of the group moved along steadily, working their way closer and closer to the summit. This summit day was sunny with little wind, but temperatures were around $-10^{0} \mathrm{~F}$. About 500 feet from McKinley’s peak, one client just sat down and called it quits. He was exhausted and felt that he could not push 
on. We could see the summit from where he sat. I knew that if he rested and then replenished his fuel reserves with hot liquids and an energy bar, he could continue and make it to the summit. I encouraged him to think positively and to reconsider his position. He had carried heavy loads to each new camp, endured cold temperatures and little oxygen to breathe, exerted a lot of energy, and yet, he had made it this far. I pointed out that within another couple of hours, he would be able to stand on the highest point of North America, his goal for the last nineteen days. After much coaxing, a short rest, some liquids, and a bite to eat, he did reconsider, got back on his feet, and pushed on to the summit.

Five days later, we all were back in civilization. We congratulated each other and departed on our separate ways. I would probably not see any of these climbers again.

About a year later, I received a phone call from a family member of my client who had almost given up on his summit bid on Mt. McKinley. The call was to give me a personal invitation to this climber's funeral, for he had succumbed to lung cancer. Unbeknownst to me at the time, this client had been diagnosed with cancer less than a month before the climb.

As I entered the church where the funeral was to be held, I was taken aback with the enlarged photos of our McKinley climb that lined the entire perimeter of the chapel room. There must have been over forty pictures, many in an 11 ” x 14 ” format, matted and framed, on easels. The memories of that climb came flooding back as I looked at each one, especially the one in which the two of us were standing together on McKinley's summit. During the eulogy, a brother of this deceased climber related how this McKinley climb was the experience that gave meaning to his deceased brother's final year. It was a 
frequently mentioned experience during his brother's conversations. The climb gave him courage and purpose to face the reality of his immanent death. This climbing experience appeared to be one of his culminating life experiences that, for him, defined who he was. As I sat in that church that day, listening to this account of how this McKinley experience gave so much meaning, a focus, and purpose to an individual's life, I wondered...

As a wilderness adventure guide for over 20 years, I heard many of my clients express feelings of discovery and self-awareness after a trip, whether they were climbing a mountain, sea kayaking across pristine fjords, or hiking through the wild backcountry. The expressions were more than just a sense of accomplishment; they were excited about what they learned because there was meaning for them in the experience.

The interesting, yet sad, contrast is that as a public school educator for almost the same amount of time, I rarely heard the same expressions of discovery and selfawareness about our experiences in the classroom.

For 23 years, I taught high school courses in the biological sciences. On average I saw approximately 160 students each school day and my responsibilities to them included the teaching of the scope and sequence of information that was outlined by the school administrators for the courses I taught. Certain constraints, such as time, policy, and resources, limited me in what I taught and how I taught. My focus became the dissemination of knowledge, the knowledge that myself and school administrators felt was important for students to know. I hoped that this information was meaningful to my students, but my utilitarian approach to teaching (getting the maximum amount of information out to as many students as I could) became my focus. My teaching style was 
taking on a Darwinian sociological purpose: survival of the smartest (or, maybe, the fittest). The educational environment and process was set, and I molded students to it.

During my years of experience, I could see that not all of my students were surviving the educational experience, at least in my classes. I could see boredom in their eyes, an apathetic attitude towards achieving success in the course, and in many cases an automaton response to my questions and requirements because they knew they had to, not because they wanted to. In some cases, students were just failing the course and/or school. I could see that disseminating the information was not all there was to learning. I began to realize that education was about teaching and learning together, not just teaching. My responsibility as an educator was to accomplish both, and I was only focusing on one. By providing the teaching aspect of education and leaving it up to my students to learn, I was not necessarily improving the lives of my students. I was missing something very important in their education, something meaningful.

Ask any adult if he or she has had experiences that made an important impact on his or her life. Just about everyone you ask the question to will probably be able to give accounts of such experiences. Many of them can tell you the actual events of the experiences and reminisce about the outcomes and the experiential influences. The events and outcomes can vary, but the feelings from those experiences seem to have an inexpressible common ground that many may describe as a meaningful experience. As a person thinks about such experiences in life, especially the memorable experiences that have had an impact on helping that person attain a higher level of what Abraham Maslow (1971) calls self-actualization, these experiences seem to lead to the shaping of an ontological view of the world, and, in some instances, direct the life he or she currently 
lives. The question that begs to be asked is what made those experiences so meaningful? Are there some common attributes to such experiences?

The importance of asking this question is to scrutinize one of the key systems that carries the responsibility to have such meaningful experiences: the educational system. The educational system should be designed to teach people about the world they live, how they fit in with that world, and hopefully, give the students the tools to see how they can make contributions to that world. To accomplish that design, education must create interests and meaning to what is presented; otherwise, education provides experiences, but not educative ones (Dewey, 1916).

Education has taken on the responsibilities of collecting information, both old and new, deciding on which information is important enough for students to know, and disseminating it to them. Education has focused on these responsibilities and educators have become somewhat efficient at fulfilling them. The world today is dealing with a flood of information that not only is being discovered and developed at a pace hard to keep up with, but is also available almost as quickly as the information is being discovered (Clawson, 1999). Clawson (1999) refers to this current state of the world as the Information Age. Getting this information, deciding on which information is important to know, and providing it to students is an important aspect of education, but does this make up meaningful learning experiences? In order to keep up with the fastpaced world, have educators focused too much on the information and not enough on the learning process? Has education’s focus been mainly directed towards premeditated results and empirical tests and measurements to determine how successful education is? Have educators become inefficient in providing their students with meaningful 
experiences, which is the essence of learning about themselves (Wurdinger, 1994)? Do students learn who they really are; what their weaknesses and strengths are? What their potential is?

To provide a foundation and focus to education's purpose, John Dewey, the wellknown American educational philosopher, advocated a pragmatic educational philosophy. He believed that a democratic society can only exist and function well if the citizenry was well-educated and contributing to its improvement (Dewey, 1916). A democracy is based on the philosophical foundation that all members of the citizenry have a voice to be counted, and they all contribute to the success of the society. If the members of that democratic society are not contributing ideas and opinions, then those who are contributing will eventually have the power to govern those who do not. Dewey suggested that an educated member of society was the key to making the democracy weather the tyrannical interferences that may try to destroy the society. So Dewey advocated an educational system that provides the experiences which teach the knowledge and skills that members of the democratic society need. His pragmatic philosophy points to an education that provides the experiences that help citizens to think, problem solve, communicate ideas and have the interest to better themselves and their society. He advocated the notion that the only system of education that can deliver such expectations is one based on meaningful experiences (Dewey, 1916). Schools need to be the models of the very society in which the students are a part. As models, schools need to provide experiences that allow students to learn how to cope with, adapt to, and contribute to the improvement of their society (Dewey, 1916). These experiences must have personal meaning to the students. 
Most educational systems tend to take a utilitarian view because of large student bodies and limited resources. Learning is approached from an efficiency objective where the emphasis is on acquisition of associations. This tends to be external in nature and not intrinsic to the human character (Maslow, 1971). Such educational systems are many times tedious and irrelevant to students. When was the last time you needed to use a quadratic equation? Do you remember what a dangling participle is? How have the chemistry lessons on molarities changed or directed your life? These questions are not meant to belittle the lessons or the subject matter, but to stimulate feelings and recall of the experiences in which these lessons were taught. Why is it that you cannot remember what a dangling participle is? Was it something about the classroom setting? Was it the teacher? Was it the subject matter? Was it because of the way it was taught? The summation of education should not be characterized by the recall of knowledge itself, but also by the experiences from which the lessons were learned. The educated citizen that Dewey advocates must be exposed to more than such expendable knowledge of associations. Student comments about lessons, such as “this is boring," "I don't see the point in this class," "this stuff is dry," etc., illustrate the failure of education to provide meaningful experiences. Dewey saw the educational system of the American society lacking meaningful experiences for students because it relied on extrinsic motivation to teach the lessons educators felt needed to be learned, and that has not changed much since Dewey’s time (Wurdinger, 1994).

The current American educational trend is to attempt to reach all students with the information they need to succeed in their society and to verify that goal through efficient tests and measurements (Paige, 2003). This is not a new trend, but a recurring one whose 
proponents hope to create a more contributing citizenry in the American society. The American government holds educators responsible for this accomplishment through the No Child Left Behind Act of 2002 and expects that educators perform (Paige, 2003). This new federal legislation has made testing the official driving force in the reform of education today (Hillocks, 2003). A concern for educators is that the focus is on their efficient practices to fulfill the objectives of this Act and not on how this will create citizens that know their strengths, weaknesses, and potentials. Standardized tests cannot measure the personal meaningfulness of learning experiences in school; they simply acknowledge that something was remembered long enough for a student to answer some, or maybe all, of the questions correctly.

This is a crucial time in American democracy. We are faced with problems that demand critical thinking of all citizens. We need to help students examine specious arguments and know them for what they are. Our tests encourage the opposite. (Hillocks, 2003, p. 70)

Central to the phrase "meaningful experiences" is the word meaningful, which implies that there must be an influential impact on the person having the experience. We usually remember those experiences as turning points in our lives, compass points that give us direction, or insights to our ontology.

From 25 years of personal experiences in education and 20 years of wilderness guiding experiences, I have seen learning experiences at both ends of the spectrum. In the formal classroom, experiences were aseptic and devoid of all but the stimuli that the teacher wanted to introduce. Exploration of self was very limited because directions were given by someone else, and meaningful learning was not a focus objective of the courses 
I taught. In the outdoor setting, experiences were haphazard and full of stimuli, both desired and unwanted. Individuals had to decide for themselves what to make of these experiences and their comfort zone was disrupted, forcing them to make relevant meaning out of the experiences. In these two educational settings, I found that the traditional classroom course lacked meaningful learning experiences, while the outdoor experiences provided meaning for the individual clients.

If we want education ultimately to be the “'self-actualization’ of a person, the becoming fully human, the development of the fullest height that the human species ... can become” (Maslow, 1971, p.169), then we need to make learning meaningful, to make learning relevant, and to create events that make a difference in a person's life.

\section{The Problem Statement}

Everyone has a myriad of experiences everyday, but not all of these experiences are educative and fewer still are the meaningful ones. Dewey (1938) has argued that reflection needs to be incorporated into the learning process if an experience is to be educative. But reflection alone does not transform educative experiences into meaningful learning experiences. There exists a gap between these two types of experiences. In order to bridge this gap, one needs to identify those characteristics of an experience that repeatedly appear as attributes of meaningful learning experiences, but may not be apparent in other educative ones.

This research attempts to explore particular experiences in a university-level outdoor education course that individuals have found meaningful (Olsen \& Bennion, 1996). Through a qualitative phenomenological study, this research hopes to identify common attributes of meaningful experiences. 


\section{The Research Question}

Thus, we return to the question: what makes a meaningful learning experience? It would be useful to educators if we could identify factors common to all meaningful experiences. If schools are to be the models for preparing individuals to think, problem solve, and communicate ideas, Dewey (1916) proposes that we should help provide more meaningful experiences in education. If we can identify the essential attributes of meaningful learning experiences, then teachers can become more helpful in facilitating meaningful lessons. To know what those factors are should be important to any pedagogy that strives for an educated society.

\section{Definitions of Terms}

The following terms and phrases are used throughout this research and will be essential to this study:

1. Awkwardness is the state of being uncomfortable due to the unfamiliarity of the situation and having a difficult time changing this state in a timely manner. This state may involve a sense of inconvenience, ignorance of what is happening and/or what to do, a lack of ability to perform necessary actions, feeling out-ofplace, being in a situation that is unmanageable and/or out of personal control (Guralnik, 1966).

2. Experience is the interaction of a person and that person's perceived environment (Bigge \& Shermis, 1999). The environment can be the human and/or non-human other(s).

3. Experiential education is a process of enhancing the quality of the learning experience by deliberately providing experience(s) in which a person can actually 
act out what is taught or emphasized in a lesson, along with having the opportunity to reflect on the experience (Joplin, 1995). It can be used with a variety of subject matters, but the focus is on a participatory interaction with the subject matter in a way that produces a sense of relevancy for the learner (Wurdinger, 1994; Dewey, 1938; Beard \& Wilson, 2002; Henry, 1989). This relevancy is a precursor to a meaningful learning experience.

4. Experiential learning is "the insight gained through the conscious and subconscious internalization of our own or observed interactions with the perceived environment, built upon our past experiences and knowledge” (Beard \& Wilson, 2002, p. 16). All learning is experiential, but the use of this term, in this research, is specific in that experiential learning was produced by deliberate and purposeful planning of opportunities to participate in relevant activities and is experienced first hand and not through a review of others' experiences (Joplin, 1995).

5. Fractional sublimation, a term coined from this research, is a process of shedding some of the facades a person has created as part of his or her societal persona. Since this process does not totally expose and shed all of the facades an individual has created in one sublimation process, it is a fractional process or a process done in stages.

Unlike Freud's use of the word sublimation in his studies, this research borrows the meaning of sublimation from chemistry, which is the process of changing a substance from its solid state of matter directly to a gaseous state of matter, without passing through its liquid state (Smoot, 1995). Through this 
transformation process, a purification process also occurs whereby impure substances that are not a part of the purity of what is being sublimated are shed. In its gaseous state the substance's true essence (or in chemistry, its true molecular structure) is found (Smoot, 1995). As an example, dry ice or frozen carbon dioxide in its solid state of matter will sublimate to a gas at room temperature because of its high vapor pressure. When the dry ice sublimates to the gaseous state, usually a white film is left behind where the solid dry ice once existed. The white film is made up of the impure substances that were a part of the solid piece of dry ice, but not the pure carbon dioxide that is released as a gas.

For people, the fractional sublimation process involves exposing them to situations that can reveal portions of their real self, some of their weaknesses and possibly their strengths, while they leave behind their facades that previously covered up who they really are.

6. Learning can be "a systematic change in behavior or behavioral disposition that occurs as a consequence of experience in some specified situation” (Estes, 1975, p. 9) or a realization of a perceived state of reality.

7. Meaningful is a term that describes the perception of the value of an experience by the individual having the experience. The reference point of this term is not the educator or the researcher, but the individual participants. The term "meaningful" is concerned with personal development (Henry, 1989). In this research’s context, the implication of meaningful is that a person engages in an experience from which is produced, for that person, an insight to his or her reality and/or a motivational arousal of interest to learn more about oneself and one's potential 
(Beard \& Wilson, 2002; Dewey, 1938; Maslow, 1972; Chaplin, 1985). Thus, the experience is important to the individual and defined, by that individual, in a very subjective manner. An experience that provides a chance for a person to view himself without the facades that he creates becomes a meaningful experience when he can reconstruct himself from this naked view.

8. Outdoor education is the pedagogy that utilizes challenging activities in an outdoor environment (usually meaning an environment not enclosed by manmade structures) for the personal, social, and educational development of the student (Gair, 1997).

9. Risk is the chance that a state of awkwardness may result. Unlike the usual use of this word implying a situation of danger, possibility of harm or injury, or loss, the use of this word in this study does not necessarily imply such drastic factors (Guralnik, 1966). Risk is a perception, and therefore, can be psychologically threatening.

10. Reconstruction is the process of forming a different perception of oneself based on the experience of the sublime of that particular individual and the knowledge of what weaknesses, strengths, and potentials were learned from the experience.

11. Sublime is the non-sensory realization of the essence of something or the potential power someone or something possesses. It is the a priori nobility of an object that overwhelms the rational man; an awareness that is critical to the $a$ posteriori knowledge of reconstruction through sensations and experience (Kant, 1892 [1790]). 


\section{Limitation}

A limitation of this research study was the possible influence of the participants' knowledge of the purpose of this study, which was made known to the participants before the actual data collection began.

This study recognizes the limitation that the findings from this study are statistically not generalizable to other populations, but refers to Hammersley (1992) who proposes an apology that qualitative studies may still have implications for larger aggregates if anyone is interested in the similarities.

\section{Delimitation}

A delimitation of this study is that this research did not distinguish between a positive meaningful learning experience (i.e. an experience that uplifts and generates the desire to improve the quality of one's life) and a negative one (i.e. an experience that disturbs an individual and generates feelings of depression, withdrawal, hatred, apathy, etc.).

\section{Summary}

The current and predominant utilitarian approach to educating the citizenry is not the humanistic pedagogy Maslow (1971) or Dewey (1916) advocated. Peter Drucker (1999) makes the point that the goal of most organizations today is not just to deliver a service but to also foster change that will improve lives. This change or innovation does not come from brilliance, but from being conscientious. Innovations that matter should be created out of concern for those individuals the innovation will affect. These innovations should influence the way people will look at themselves and their environment. These 
innovations need to be implemented because good intentions are no longer good enough (Drucker, 1999).

Drucker was addressing his comments to the entrepreneurial business world, but education is an organization that is in the business of changing lives for the better. If educators want to shift focus from collecting and disseminating information to providing meaningful learning experiences, then innovative ideas that produce meaningful learning experiences will be needed.

The problem that education has with innovations is that innovations require a willingness to take a chance on success or failure, a change of techniques, and an investment of time and effort (Senge, 1999). The status quo is comfortable and safe; therefore, when innovative educational programs should be sought for, educators typically resist change (Bacharach \& Mundell, 1995). This reluctance to accept core innovations will often create a dilemma for those citizens trying to cope in this period of time called the Information Age (Elmore, 1996).

What education needs to strive for is intrinsic value to what is being learned. Maslow (1971) suggests that the relevancy of an experience for an individual is a precursor to developing intrinsic value of a lesson learned. If a person does not see the application or association of the information given, even at that immediate moment, there is a likelihood that there will be no reason to remember or learn the lessons that are being presented. Education then becomes nothing more than external associations (Maslow, 1971).

Dewey (1916) advocated that only through the actual experiences of situations, both past and present, can an individual think for himself. Therefore, education must 
become the vehicle to use those experiences and create new ones that matter for enhancing that quality. Democratic societies will progress with contributing citizens who think for themselves and are not molded by preconceived templates of others (Dewey, 1916). This pragmatic philosophy, proposed by Dewey, establishes the philosophical foundation on which the legitimacy for a pedagogy that produces meaningful learning experiences can be argued. Maslow (1971) stated that there are experiences that are far more important than classes, lectures, memorizing, and book learning. "The most important social science observation here is that experiences are more effective teachers than lectures [sic]” (Etzioni, 1993, p. 103).

As education continues to focus on teaching the masses, is our society losing the perspective of what embodies learning? Are educators helping students to experience what is relevant in their lives? Are students being exposed to experiences of both failure and success, without time to reflect on what constructive things they can learn from such experiences? If educators ignore the individual student's emotional, intuitive, and situational learning, then we can lose, what Hubert Dreyfus (2001) claims as ...our ability to make sense of things so as to distinguish the relevant from the irrelevant, our sense of the seriousness of success and failure that is necessary for learning, and our need to get a maximum grip on the world that gives us our sense of the reality of things. Furthermore, we would be tempted to avoid the risk of genuine commitment, and so lose our sense of what gives meaning to our lives. (p. 7)

The problem area for this research question is centered on the lack of a connection between reflective experiences, created by Dewey’s pragmatic educational philosophy, 
which are essential to an educative experience, and the meaningful learning experiences that are so essential to the development of an educated individual. This creates a dilemma that progressive educators view as a critical failure of the educational system to produce educated and motivated citizens (Dewey, 1916). If meaningful experiences educate an individual to be a productive and a contributing member of society, then what makes those kinds of experiences meaningful, and can educators produce those kinds of experiences for their students? Education must embrace innovative ideas that enhance the pool of meaningful experiences for its students. In order to have such innovative ideas and for administrators to recognize them, it would be helpful to identify what factors seem to be common in meaningful experiences (see Figure 1).

The purpose of this research study was to find the attributes of an outdoor education program's meaningful learning experiences. The identification of such attributes may give educators the tools to go beyond just the dissemination of information.

Figure 1. The gap between an educative experience and a meaningful learning experience.

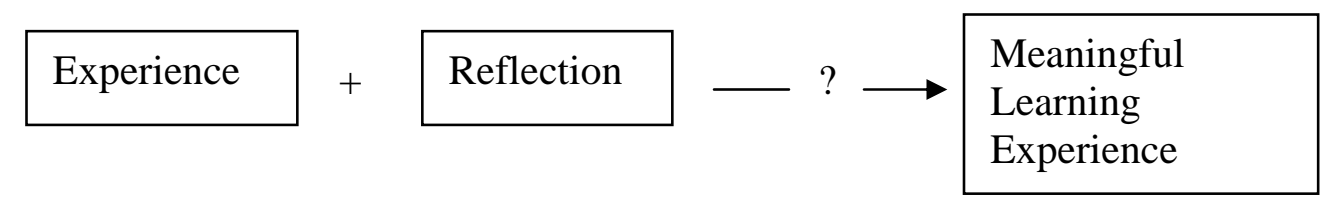




\section{Literature Review}

The search for the attributes of meaningful learning experiences is based on the understanding of current and relevant views of education. This review of literature focuses on those relevant philosophical, theoretical, and research works that establish the purpose and foundation for this research study.

\section{Philosophical Works}

The focus of this study requires a brief review of John Dewey’s perspective of education in a democracy in order to establish the importance of an educated citizenry. Dewey’s pragmatic philosophy gives a foundation to the experiential approach in both learning and teaching.

The brief overviews of existentialism and the transcendentalism of Immanuel Kant, two philosophical views of man's approach to reasoning and understanding his existence and his nature, sets the stage for this study’s rationale for its findings and resulting interpretations.

\section{Pragmatic Educational Philosophy of John Dewey}

The philosophy on which experiential education and learning is grounded is the pragmatic philosophy of John Dewey. Dewey argued "that the traditional quest for truth, based on certain permanent and unchanging knowledge, is a futile activity” (Oliver, 1999, p. 138). For Dewey, the world was a constantly changing one and the criterion of truth was not given by permanent structures of reality, but by the multitude of diverse experiences (Oliver, 1999).

Dewey wanted to redirect the focus of philosophy from a discipline that attempts to define what truth is to a discipline that actually tries to advance our well-being (Oliver, 
1999). Dewey deemphasized the pursuit of an ontological truth in education (Posner, 2003). He proposed that most people are only interested in and capable of getting better control over their environment, broadening their horizons, and improving their lives (Posner, 2003). Therefore, education's goal should be to improve the lives of the students it educates (Dewey, 1938). To accomplish this, Dewey advocates an epistemic democratic process, whereby there is a cooperative approach for gaining this educational goal (Posner, 2003). This cooperative approach includes challenging the current system, by all who have a vested interest in it, to open itself up to innovations and see if others have a better way. Constant scrutiny and challenge can only test current methodologies for their effectiveness and practicality (Posner, 2003).

His best examples of this philosophy were his views on social and political issues. Dewey believed that societies needed to base their political agenda on what ideas offered the best possibility of widespread agreement instead of what traditional philosophers argued should be the truthful accounts of human nature and human needs (Dewey, 1960). "The best political system must be one which provides the conditions for widespread agreement about the way forward” (Oliver, 1999, p. 139). For Dewey (1916) this political system was a democratic one; however, the assumption is made that agreement on the way forward can only be valid if all those affected by such an agreement can participate in its establishment. Dewey believed that a liberal democracy was the best political system available, but most fell short of offering equal participation and, therefore, widespread agreement (Oliver, 1999).

The primary reason for this shortfall is focused on the education of the citizenry. Dewey argued against the existence of dualisms that are embedded in the philosophical 
systems of education, which dichotomize certain relationships, such as the mind and the body, the mind and nature, and the individual and society (Dewey, 1916). He argued that they are inseparable and it is irrational to keep them separate. From his early interests in Hegel, Dewey argued for a philosophy of education that nullified these dualisms and was centered on the freedom of the mind and thought in directed, social activity (Dewey, 1916). Only through the actual experiences of situations both past and present could an individual think for himself. Therefore, Dewey believed education must become the vehicle to use those experiences and create new ones that matter for enhancing that quality. Democratic societies would only progress with contributing citizens who think for themselves and are not molded by preconceived templates of others (Dewey, 1916).

Dewey defined education as a process of growth, and it is through this concept that he links education with democracy. Democracy, understood as a mode of associated, conjoint, and communicated living, is the only type of society in which individuals are able to grow and socially participate in a manner that allows for the realization of their unique interests and gifts. Conversely, a flourishing democracy requires individuals who will maximize their potential with others. Learning in isolation perpetuates the belief in a duality of mind and action, and of the individual and society. For Dewey, reality consisted of these as an inseparable whole.

Dewey emphasized that a democracy should embrace the concept of freedom, which is not just the ability to move or act as one pleases, but also "means intellectual initiative, independence in observation, judicious intervention, foresight of consequences, and ingenuity of adaptation to them” (Dewey, 1916, p. 352). Freedom entails the 
participation in group activities. Dewey argued that certain essential capacities can only be learned in a group. He claimed that

this type of free social and intellectual interaction, in which each member of the group considers the actions and interests as information for informing their own actions, dissolves the artificial social barriers of race and class by allowing for free communication of interest between varied social groups. (Dewey, 1916, pp. 100-01)

The method of Dewey’s democratic education is an experimental and experiential process in which thought and reason are applied to activity to find the best answer to a problem at a particular time and place. Thus, one of the great themes in his work is the scientific method and his applications of it to the field of education. The scientific method shows that knowledge does not exist statically or separate from action. Knowledge that is isolated from action and is acquired passively prevents the formation of new habits and the reconstruction of experience, thereby preventing growth and learning. The experimental method unites mental activity and experience and allows for the creation of new knowledge. This presupposes that knowledge is not a body of universal truth waiting to be uncovered by rational, objective thought. Experimental science has shown that "there is no such thing as genuine knowledge and fruitful understanding except as the offspring of doing” (Dewey, 1916, p. 321). In seeking to overcome the idealization and remoteness of reason and making it experimental and practical, Dewey called for a curriculum that combines liberal and vocational education "by furnishing their context, their background and outlook" to the present community life (Dewey, 1916, p. 247). This would enlarge the personal experience. 
Dewey emphasized the association and communal aspects of democracy and found that conscious, directed education is necessary to establish these conditions and form democratic character in children. Growth, experience, and activity are the preferred terms by Dewey to describe the tying of learning to social, communicative activity and this allows for the flourishing of democratic community.

Dewey’s philosophical approach is pragmatic and its value is found in its usefulness. Thus, he argued for the application of his philosophy by emphasizing the education of the citizenry. In the early 1900’s, the Progressive Education Movement promoted the idea that students be encouraged as independent thinkers, creative beings, and individuals who are expressive about their feelings. This was a sharp contrast from prevalent educational approaches rooted in social efficiency in the early 1900s in the United States. Such approaches did not foster the importance of individualism and creativity. Instead they emphasized classroom control, management, and a structured curriculum that focused on basic skills. The advocates for this Movement looked to Dewey as an important influence and motivator, although Dewey later became critical of their interpretations of his own philosophy (Dewey, 1920).

Two basic principles fostered in the Progressive Education Movement were continuity and interaction. Continuity is the principle that each learning experience be nurtured by the previous experience. Therefore, from a progressive standpoint, the learning process is gradual. The organizational thought process that relates all experiential processes is something Dewey named the "Progressive Organization of Subject Matter” (Dewey, 1938). The second principle, interaction, denotes the concept that what was learned may possibly need revisions, adaptations, or be discarded all 
together because further research has claimed it to be false. Essentially, from this standpoint, assumptions need to be challenged in the continual search for truth. Thus, the interaction principle encouraged experimentalism, verification, and reconstruction (Fink, 1995).

Dewey (1938) emphasized several points: the “either-or” mentality, the theory of experience, the continuity or experiential continuum, the nature of freedom, and the need for organization in the subject matter. He pointed out that the tendency to accept and reject ideas that seem to oppose one another is a pitfall to progressing from learning from past experiences. The paradigm may shift when a student looks at the world through new and different lenses, but he only modifies, he does not abandon, what exists to fit the new paradigm. The utilitarian way of teaching is not all wrong and therefore rejecting it means to abandon all of what has been learned from it. Experience is a key component to Dewey’s educational philosophy and the traditional way is still an important past experience that adds to the continuity of experiences. Freedom is not the concept of movement or anarchy, but the idea of control to experience what is meaningful to each individual. Based on this freedom of experiences, there is a need to organize them into a learning continuum (Dewey, 1938).

This education is based on the emphasis of experiences because experiences shape what truth is for individuals. The knowledge of what is real comes from the experiences each individual has and the more experiences one has with the opportunity to reflect on them, the more educated one becomes, thus increasing the potential of that individual to become a productive and contributing citizen. 
Dewey recognized that not all reflected experiences are meaningful ones that lead to an understanding of truth, yet Dewey did not adequately identify the factors that made some reflective experiences meaningful and others not.

In addition to Dewey’s pragmatic philosophy of education, this research found two other philosophies that help create a basis from which to build the findings of this research. Existentialism can provide a foundation for the rationale of using outdoor programs as a setting for meaningful learning experiences and Immanuel Kant’s transcendental philosophy, especially his judgment of the sublime, gives us insight to what may be happening during an experience that transforms it to a meaningful learning one.

\section{Existentialism}

Existentialists provide a rationale for outdoor settings as a means to create meaningful learning experiences. Existentialism views the natural environment as a place where awkward and uncomfortable conditions can exist. These conditions provide the impetus of our confrontation with the seemingly timeless nature of the world and our own fragile mortality within it. Our existence, at least on this earth as a mortal being, is only a temporary one, but existentialists see that man avoids facing that fact until he confronts a situation that exposes his fragile state. The natural environment, which is usually the stage for outdoor educational programs, provides a backdrop that can present physically uncomfortable situations which in turn force us to confront our mortality straight on. As in such stories as "The Snows of Kilimanjaro” and "The Short Happy Life of Francis Macomber” by Ernest Hemingway (Hemingway, 1964), when man finds himself exposed 
to the natural environment and, in it, realizes his own mortality, he tries to find meaning in that experience for his own existence.

Existentialist philosophy concentrates upon one’s being in the world. To make full sense of one's existence, a person needs to actively create meaning for his life, rather than allow it to be imposed by others (Oliver, 1999). For the existentialist, choice, involvement, and personal discovery are essential to the process of finding meaning. Contrast the existentialist view with the American trend in education today, which supports the approach of imposing what others want to be taught.

Soren Kierkegaard (1813-1855), considered by some as one of the first publicly known existentialists, once said that if God offered him well-being in the right hand and a life of struggle and eternal striving in the left, he would not hesitate to choose the left (Oliver, 1999). For Kierkegaard, the freedom of choice was important, but even more essential was the ability to face the fears and challenges that verified a person's mortality and characterized one’s existence (Oliver, 1999). A life without challenges and struggles offers few experiences where choices can be made, and without opportunities to choose, there are no references from which a person can define who he really is and what he is capable of accomplishing.

Jean-Paul Sartre (1905-1980) made an important contribution to modern existentialism by suggesting that all of us have an unavoidable sense of the fact of our existence (Oliver, 1999). “This sense can be vague and ignored, but it is unshakeable” (Oliver, 1999, p. 129). This factuality is that each human existence will come to an end at some time; earlier for some and later for others, but it is inevitable. As much as man tends to ignore this fact of existence, the fact actually defines each individual. Each 
person should confront this reality in order to create meanings to one's existence (Sartre, 1993). Sartre points out that this meaning is centered on our freedom to choose and it is consciousness of this freedom that can give meaning to our existence (Sartre, 1993).

On a practical level, Viktor Frankl (1984) explains this search for meaning. As a Jewish prisoner in a World War II Nazi concentration camp, Frankl had to come to terms with his own mortality as many of his fellow prisoners were put to death on a daily basis. These prisoners were stripped of almost everything. They were taken from their homes, family members were separated, all their possessions were taken away, including their clothes, and even their identities were replaced with numbers. Under these atrocious circumstances, Frankl had to find meaning for his own mortality. His existence had to be for some reason. His fellow prisoners, who were being executed, were not just numbers. He was not just a number and a possible casualty of war to be forgotten. In such a dire setting, after being stripped of his former identity, he was still a person and that recognition had meaning (Frankl, 1984). Frankl implies that finding meaning requires a shedding of facades that a person builds up around himself. This implication is supported by the findings of this research study.

Frankl found meaning in his existentialist view concerning his own freedom to choose. As many of his fellow prisoners succumbed to hopelessness and despair, Frankl noticed that suicide was a frequently entertained idea, but only briefly, because suicide would only mean submission to the Nazi objective.

Every day, every hour, offered the opportunity to make a decision, a decision which determined whether you would or would not submit to those powers which threatened to rob you of your very self, your inner freedom; which determined 
whether or not you would become the plaything of circumstance, renouncing freedom and dignity to become molded into the form of the typical inmate. (Frankl, 1984, p. 74)

Fundamentally, this decision-making process is what makes an individual into what he becomes. Through this freedom of choosing what his attitude will be, man finds meaning to his existence through the conditions that he faces (Frankl, 1984).

This recognition of having this agency to choose arouses a consciousness within a person. William James, Jean-Paul Sartre, Maurice Merleau-Ponty, Alfred Schutz, and many others propose that this consciousness of being is not simply inwardness or an arousal of essence, but a provocation of being alive and being unique. Consciousness brings us toward the world, not away from it. Consciousness is the way we encounter the natural and human world (Greene, 1978). The perception of our existence and the worth of our existence are defined in the context of the natural world we live in.

As we recognize this relationship between our existence and our natural environment, what we encounter is a confrontation of this consciousness of the timeless nature of the natural environment and our own temporary existence. The natural outdoors thrust us into the consciousness of our being and the relationship we have with the natural order of the outdoor environment, just as Frankl's experiences in a Nazi concentration camp did. We encounter our fragile and temporary state in contrast to the ever-present existence of the natural environment. The outdoors existed long before us, and will continue to exist long after we are gone. This forces a consciousness of our mortality and we can find meaning in it. Learning must be a process of discovery and recovery in response to this consciousness one encounters. Through this process, there is a form of 
emancipation in which one can find meaning through the reflection of experiences accumulated in the setting which triggered this consciousness (Greene, 1978).

Existentialism gives a philosophical basis to experientialists who advocate that experiences help define one's reality, especially experiences that expose a person to the brute fact that his or her existence is fragile. Such experiences lead a person to confront his mortality and find meaning in his existence. These experiences can be found in the outdoors where one confronts the consciousness of mortality and, therefore, looks for meaning in one's existence. Kaplan and Talbot (1983) suggest that this is attributable to the realization that one cannot control the wilderness environment.

Although often not a conscious priority, the need for control nonetheless can be an important factor in the way an individual attempts to relate to an environment. Yet the assertion of individual control is incompatible with much of what wilderness offers and demands; rather than struggling to dominate a hostile environment, the participants come to perceive their surroundings as quite safe as long as one responds appropriately to the environmental demands. Thus there is the tendency to abandon the implicit purpose of control because it is both unnecessary and impossible. (Kaplan \& Talbot, 1983, p. 194)

By relinquishing this control over the environment, the participant in the outdoors then confronts his place in this outdoor environment and realizes his own mortality. He, paradoxically, can acquire an internal control by rationalizing his own fate in such an environment (Miles, 1987). 


\section{Transcendental Philosophy: The Judgment of the Sublime}

Immanuel Kant would have agreed that knowledge is gained from experience, but not all knowledge is gained that way. He advocated the philosophy that there is a structure of knowledge that transcends experiences and, therefore, is a priori (Oliver, 1999). This structure of knowledge is what Kant refers to as analytic judgment and is an essential part of man's understanding of truths (Zammito, 1992). Kant implies that there is knowledge that exists which depends on a level of comprehension beyond the empirical senses. Only by analytical judgment do we make this comprehension.

The following example illustrates Kant’s view of knowledge based on analytical judgment and knowledge based on experience. In a court of law, there is the assumption that justice and the truth exists. The judicial system of every developed country in the world is based on this assumption. There is no empirical evidence that both exist, but all who enter into a court have some understanding of what these two terms mean and trust that justice and truth exist. This judgment transcends the experience and, therefore, is $a$ priori. This is Kant's analytic judgment. Using this understanding and knowledge, those in the court rely on the judicial system to discover the truth and apply justice properly to the case before the court. The application of this knowledge is accomplished by experiences that occur in the courtroom. This is what Kant refers to as synthetic judgment. Synthetic judgment requires that more validation is necessary and this validation is sensory through experiences.

This research study focuses on Kant's notion of knowledge that transcends experiences, but does not deny that experiences help define this knowledge's application. Kant (1892) provides the concept of the dynamically sublime which implies that there is 
a feeling brought about by powerful objects or experiences. The sublime is associated with the formless, meaning that it cannot be explained by sensations (Audi, 1999). The sublime is not a description, but is the essence of an object. Unlike a person's description of the beauty of something, which is sensual and descriptive, the sublime is the nobility of the object or person, which cannot be sensed nor described. The sublime is an awareness that transcends the experience to a level of understanding and judgment (Zammito, 1992).

Once comprehended, the beautiful and the sublime both share the quality of pleasure, (Kant, 1892). The former's comprehension is based on the synthetic judgment of sense, while the latter is based on the analytic judgment of reflection (Kant, 1892). Kant (1892) explains this difference as beauty being "connected to the form of the object, which consists in having [definite] boundaries” (p. 102) and is based on an indefinite concept of understanding, while the sublime is boundless, representing more of the quality, and is based on a concept of reason. Beauty is the discovery of shape and a purposiveness in the form of the object, fit in its surroundings, and what Kant (1892) refers to as charm (Zammito, 1992). On the other hand, sublimity is an arousal of the mind of the purposiveness to the object of nature (Zammito, 1992). "The sublime is an experience which occasions self-consciousness through aesthetic reflection" (Zammito, 1992, p. 278).

There is a reference to a supersensible subjectivity that is needed to discover the sublime. Kant (1892) implies that the reasoning process relies on an individual's supersensibility to the existence of the sublime. This supersensibility goes beyond the empirical notion of the senses and revolves around a process that Kant refers to as 
subreption (Zammito, 1992). For Kant (1892), subreption was a process of looking at an object from within ourselves and discovering respect for it. This respect is for the sublimity of the object.

The discovery of the sublime does come with a price. The sublime is grounded in initial disappointment because of the overwhelming recognition of the immensity of what is boundless and formless. The discovery of the sublime is a very complex experience because the emotions must deal with what is discovered and make sense of what is the sublime in relation to what was the perception before the discovery. The possibilities are infinite and, therefore, the process of discovery is frustrating, disappointing, and even humiliating as the reality of what is the essence of something or someone comes into formation (Kant, 1892). But the realization of a higher purpose also brings about the good and pleasurable feelings that come with the discovery of the sublime.

This research study proposes that there is sublimity to each person. The sublime of an individual transcends the senses and cannot be empirically discovered, but the realization of the sublime is personal and meaningful.

\section{Theories of Learning}

Learning theories have gone through a history of changes based either on the cultural emphasis placed upon society in that particular time period or a reactionary movement to some failure of learning. From a historical perspective, prior to the twentieth century in our western cultural heritage, education was based on a theistic mental discipline. That gave way to a more secular approach to mental discipline which was followed by a reactionary theory of natural unfoldment or self-actualization, and eventually we came to an apperception theory that seemed to balance the earlier theories 
of learning (Bigge \& Shermis, 1999). The current theories of learning still embrace parts of these earlier approaches, but with more psychological explanations as to why each works.

This research identifies the current and relevant theories of learning to try to determine how well they address the question of what makes meaningful learning experiences. The understanding of learning theories is crucial for any pedagogy that hopes to bring about meaningful learning. These theories give foundation to the purpose of the methodology chosen by an educator. Without a theoretical orientation, an educator will lack a long-range rationale and plan for his or her teaching. Thus, such an educator will usually intend to do little more than provide busy work rather than focus on providing opportunities for meaningful learning experiences (Bigge \& Shermis, 1999).

The current leading theories of learning are classified into three groups: the behaviorists' stimulus-response conditioning theory, cognitive theory, and experiential theory (Priest \& Gass, 1997). The first group views learning as a process of molding individuals into what others want them to be by using selective environmental stimuli that produce predictable responses. This paper will not address this behaviorist group because this stimulus-response conditioning theory focuses on training students to produce specific pre-determined behavior due to specific stimuli given. The personal exploratory nature of finding meaningful learning experiences, in contrast to what someone else wants you to find, and the introspection that is a crucial part of such experiences are not emphasized in the stimulus-response conditioning theory. The second group sees learning as a developmental process of collecting mental patterns that offer insight to one's interaction with his environment. This insight leads to an understanding 
of particular patterns that one comes across in life and, hopefully, increased capability to deal with them. The third group advocates a theory of learning that is enhanced by planned experiences, directed by a facilitator, and, through participation in these experiences, allows for personal conflicts which provide opportunities for successes and failures that are relevant due to the personal involvement and repercussions from the experiences.

Cognitive Learning Theory

Cognitive learning theory views learning as a psychological phenomenon that synthesizes a pattern of interdependent factors of the person and his or her psychological environment. There are two major positions within the cognitive theory, the cognitive constructivists and the social constructivists.

Cognitive Constructivism. The cognitive constructivism theory is based on the individual and his cognitive view of the world he lives in. This view is established over time as one recognizes patterns that will provide insight to whatever is being learned (Mayes, 2002). This cognitive insight leads to a progressive construction of one's understanding of meanings and the accumulation of these understandings becomes the so-called life space of an individual. The life space becomes the reality of the individual and the more understanding that one gains of the different psychological environments encountered, the more the life space grows and helps the individual attain his or her goal(s) (Bigge \& Shermis, 1999).

An example of cognitive constructivism is in the following example:

A teacher has been teaching lessons on multiplication to third graders. Today, she is introducing her students to the concept of multiplying numbers by tens. She 
demonstrates, on the blackboard, the following multiplication problems with their respective answers:

$$
\begin{aligned}
& 1 \times 10=10 \\
& 2 \times 10=20 \\
& 3 \times 10=30
\end{aligned}
$$

She then asks questions about these problems.

Teacher:

"Does anyone notice anything about these problems and answers that could help us learn about multiplying numbers by tens?”

Student A: "The answers increase by ten in each problem."

Student B:

"The answers use the same numbers as the one in the problem being multiplied by ten and adding a zero to it.”

Teacher: "So, if I write the next problem on the board as $4 \times 10=$ What would be the answer?”

Many Students: "Forty!"

Teacher: "How do you know that?"

Student A:

"Because it must be ten more than the thirty."

Student B:

"Also because you used the number four in the problem and we just add a zero to it to get the answer like in the other problems.” 
Teacher: "Okay, so what would the answer be to this problem:

$$
8 \times 10=? ”
$$

(After a short period of silence)

Some Students: "Eighty!”

Teacher: "And how do you know that?”

Student B: $\quad$ "Because you used the number eight in the problem and we just added a zero to it for the answer.”

In this example, the learning process was the recognition of a pattern and this recognition lead to an insight of how to solve similar problems. The future application of this insight is dependent on the individual's ability to recognize experiences that have similar patterns. This gives cognitive constructivism a personal phenomenological aspect.

The basis of the cognitive constructivism learning theory is Gestalt psychology. Gestalt is a German word that lacks an English equivalent for a literal translation, but the idea is that Gestalt refers to patterns or the form of something (Chaplin, 1985). The pattern is made up of the components of a particular thing, situation, event, idea, or whatever is being learned. Gaining insight to the whole is the objective of Gestalt psychology because the components individually have their own separate meanings. Therefore, in cognitive constructivism, the emphasis is on the pattern of one's life space and how that life space as a whole changes with new insight and understanding (Bigge \& Shermis, 1999). 
Thus, for a cognitive constructivist, knowledge is an ongoing gathering of experiences to recognize the patterns within one's environment and synthesizing a reality based on the phenomenon of that experience (Mayes, 2002).

It is important to point out that the cognitive constructivism process is dependent on maturational stages that are genetically defined within the human species. Jean Piaget identified and defined these stages as the basis of his genetic epistemology (Schwartz, 1986). A human being begins as a microscopic fertilized zygote and progresses in stages to become a full grown adult. The human's cognitive development could be viewed in a similar way. The learning process is guided by an innate ability to receive and assimilate information in varying degrees, based on maturational and physiological age. Piaget labeled these maturational stages as the sensorimotor, the pre-operational, the concrete operational, and the formal operational stages (Schwartz, 1986).

The sensorimotor stage begins at birth and lasts until about age two. During this stage, infants learn that there is a relationship between actions and consequences. Infants learn to control their hands, how to propel themselves from place to place, to recognize that objects have physical characteristics they can manipulate, and to foresee what happens if they tip over a container of liquids. What they do lack is the concept of object permanence. If an object is hidden or taken away, infants in this first stage of cognitive development act as if it does not exist anymore (Schwartz, 1986).

The pre-operational stage is signified by the cognitive development of object permanence. This stage usually begins at age two and goes through age seven. The child recognizes that if an object disappears from sight, the object still exists somewhere. 
During this stage, the child learns to use mental images in a concrete way (Schwartz, 1986).

The concrete operational stage follows and lasts until the age of about eleven. During this stage, the child learns to manipulate visual images as if they were symbols of real things. They still think in concrete terms, and abstract constructs are problematic for them (Schwartz, 1986)

The final stage is the formal operations stage. At this point, the individual can learn abstract concepts such as love, liberty, rules of logic, etc. This is the highest cognitive development level and signifies the adult level of learning (Schwartz, 1986).

For the classical cognitive constructivists, the stages cannot be changed, rushed, or taken out of sequence. Because it is genetically determined within the human species, learning must be guided by this model.

Social Constructivism. Social constructivism is rooted in Vygotsky’s notion that the reality of things is dependent upon where those things are in relationship to their environment (Mayes, 2002). The individual is defined by the social forces acting upon him. Vygotsky (1978) would point out that no individual exists in isolation and the phenomenology of an experience is closely intertwined with the situational environment in which the experience occurred. As with Heisenberg's Uncertainty Principle, all things in the universe are affected by the situation in which they exist (Kuhn, 1996).

Jerome S. Bruner, an American psychologist, recognizes the importance of cultural and narrative experiences in learning (Bigge \& Shermis, 1999). Bruner's learning theory is based in social constructivism and meaning for individuals who live together in a culture. Instead of emphasizing information processing, Bruner emphasizes that the 
causes of human learning lie in a given culture and the quest for meaning in that culture. Mankind's genetic inheritance does not direct or shape human action or experience, but it imposes constraints upon people’s experiences (Bruner, 1990). “Most learning, in most settings, is a sharing of culture” (Bigge \& Shermis, 1999, p. 134). Dewey’s influence on Bruner's view of education comes through when Bruner states that education should emphasize student skills on handling things and performing symbolic operations pertinent to one's culture (Bruner, 1973). The social constructivist begins to bring one closer to the experiential nature of learning and what Dewey was advocating in his pragmatic philosophy.

It is important to note that cognitive theorists today will admit that the developmental approach to explaining learning has variations and we will continue to discover variations. Development is a tricky concept to explain in a nice and neat package. As the social constructivists suggest, there are "many cultural, historical, socioeconomic, psychological, and biological differences in how people 'unfold'” (Mayes, 2003, p. 8). Individuals do not necessarily follow a linear pattern in all cases, going from one stage of development to a pre-assigned second and third. Circumstances may provide instances of skipping certain stages, or interesting to this study, revisiting stages that have already been experienced (Mayes, 2003).

John Dewey enters into the picture as a contributor to the cognitive view of learning. Dewey proposed that education was a process of reconstruction of experiences as one learns the meaning of the experiences (Dewey, 1916). Thus, he implies that learning involves the reconstruction of one's life space as one learns what life experiences mean. He also wrote that an experience is a transaction "between an 
individual and what, at the time constitutes his environment” (Dewey, 1916, p. 41). This becomes the source for insightful reflection that gives meaning to an experience, thus changing the life space that one views as his reality and his goals. For Dewey, this was education.

Thus, Dewey makes a case for synthesizing a third learning theory. Such a theory would propose that experiences provide the behaviorists' environmental stimuli that produce responses and these responses, in the context of an experience, mold the cognitive constructivists' life space (Dewey, 1938). This Dewey approach illustrates his recognition of contributions of other theories and avoiding the either-or mentality. The synthesis of the experiential learning theory came from such a view.

\section{Experiential Learning Theory}

Experiential learning is a theory of learning which emerges out of the literature that focuses on providing such meaningful learning experiences (Beard, 2002; Coleman, 1979; Henry, 1989; Itin, 1999; Joplin, 1995; Phipps, 1988; Prochazka, 1985; Proudman, 1995; Wurdinger, 1994). Experiences can take on many meanings, but the experiences that this research is most interested in are the educative ones. This research pre-supposes that educative experiences are insightful and go beyond the experience that is just the transaction of a person and the person's perceived environment. What makes the experience a possible educative one is that this experience provides the student with the opportunity to have an inherent interest in what happens in the experience and the student has a chance for reflection. This reflection should center the experience into the context of what has previously been learned. Therefore, education would be based on a continuous process of added reflected experiences. But Dewey sought for a more 
definitive educational process that goes farther and provides for meaningful learning experiences (Dewey, 1916).

Experiential theories tend to be holistic and incorporate ideas from the cognitive learning theory. There is a need to lay basic knowledge down as the foundation on which meaningful learning experiences can grow. Using a stimulus-response theoretical approach and/or a cognitive approach can appropriately accomplish this, but experientialists support the fact that the learning really begins at that point and needs to be carried on through relevant experiences where application and use can make the learning meaningful (Wurdinger, 1994). Coleman (1979) describes experiential learning in terms of children learning a language. The child is exposed to a linguistic environment, tries and fails to communicate, tries and fails again, but at some point, he will succeed in making himself understood and in understanding others. "It is a painful, time-consuming, and emotion-producing experience, but an effective one" (Coleman, 1979, p. 7) that is meaningful for the child. This learning process

...grounds each word, each phrase in a rich bed of experience. One remembers a word, a phrase, because of the very emotions it provoked when it was not understood by another or when it was not understood and evoked a response from another. One cannot forget it, because its usage is an intrinsic part of the fabric of experience that constitutes one's life. (Coleman, 1979, p. 8)

Many experiential learning advocates recognize that the learning process occurs at different levels, as Piaget (Piaget, 1952) points out, and see these learning levels as a sequential process, but they want to push the process beyond just knowing and include additional levels that can lead to a meaningful learning experience. Prochazka (1985) 
described the levels of learning with memorization being the first level, in which information "enters the brain and is recorded for a short period of time" (p. 174). The second level is when students have a familiarity with the information because of repeated exposure, but they are unable to apply it to anything of practical use. At the third level, there is an experiential component to the learning because students may have an opportunity to use the information, but the experiential learning theory suggests that this opportunity must be established on four sequential stages: (a) concrete experience, (b) observation and reflection, (c) abstract conceptualization and generalization, and (d) active experimentation (Kolb, 1984). These stages are not unique to experiential learning but are essential pieces to the process, for they will lead to an internalization of the information, which is the fourth and final level of learning (Prochazka, 1985). It is at this fourth level that the stage is most primed to allow for learning to become meaningful (Wurdinger, 1994).

Experiential learning theorists are determined not to neglect the human side of learning. They are interested in more than cognition, but acknowledge the role of affect and conation (Henry, 1989). There is an emphasis on student involvement, learner control, and learning activities outside the four walls of the traditional classroom (Henry, 1989). Experiential learning theory focuses on allowing the student to have an experience, reflect on it, and come up with his or her own meaning. This is not a conditioning process of what someone else wants to see learned or an exposure to a certain part of reality through a certain tainted view. Experiential learning is all "about ensuring that a person can ‘do’ rather than merely 'know’...” (Henry, 1989, p.28). What 
matters is what the learner gets out of the experience and experiential learning theorists hope that the experience is meaningful to the student.

Simple participation in a prescribed set of learning experiences does not make something experiential or meaningful. There are guiding principles that should be recognized and incorporated into the situations provided. These principles make experiential education a transformational process (Gager, 1982). They include

1. Mixture of content and process: As Edward Demming instructed managers in business, experience is meaningless unless it is based on theory (Mosley, Megginson, \& Pietri, 1997). One must base the process on theory, which provides direction.

2. Absence of excessive teacher judgment: Teachers provide the situation and create safe working boundaries, but they do not provide the experience unless they impose their own feelings into the situations. Responsibility for finding meaning in a situation is a personal one and that is what makes the experience.

3. Encouraging the big picture perspective: As a person works through situations and has the experience, he should be encouraged to connect what he is learning to other relationships he may have in other situations. The actual situation he may be experiencing is not necessarily the essence of the lesson, but the application of what is learned to similar conditions should be.

4. The role of reflection: Dewey assumes reflection is a major ingredient in the learning process. Although this process may not lead to a meaningful learning experience, it must be a precursor if the experience will have any meaning at all. 
5. Creating emotional investment: This is a critical difference in experiential learning and the other learning theories formerly described. The learner's motivation is not totally based on what he has to do because someone else tells him he must, but he is motivated because he is immersed in the experience and is invested in its outcome for himself.

6. Learning outside of one's perceived comfort zone: Complacency is not the situational model for learning. Challenge and disruption of needs gives new perspectives and possible new potentials. Confronting those situations that make one feel uncomfortable is the only route to returning to a stable state.

7. The presence of meaningful relationships: The learning process cannot be abstract, but should have meaning to the learner. The learner should walk away from the experience feeling he has gained something valuable that he did not possess before the experience (Proudman, 1995).

It is important to note that experiential learning theorists agree with Dewey that the learning process involves more than just being exposed to an experience. All learning is experiential, but not all experiences are very good for learning. What this means is that experiences without at least the opportunity for reflection, are not educative (Dewey, 1938). Therefore, meaningful experiences must incorporate time devoted to reflection, whether that reflection occurs in private or communally. This reflection gives an experience a chance of permanency and relevance. Both are characteristics of meaningfulness (Beard \& Wilson, 2002).

Christian M. Itin (1999) gives a foundation to what exactly experiential education is, how it is defined, the philosophy that underlies its purpose and practice, and an 
argument for experiential education as an innovation for change. Itin distinguishes the difference between experiential education and experiential learning, and he advocates that they are not synonymous terms. He explains that experiential education is best understood as a philosophy of education while experiential learning encompasses the characteristic learning strategies. Experiential education is a holistic philosophy that relies on experiences that are structured to require the learner to take initiative, be involved with decision-making, and be accountable for the results. These experiences become the classroom for developing values and the laboratory for increasing the capabilities of self-efficacy. Experiential education emphasizes that the teacher's role is one of being a facilitator for learning experiences, not a disseminator of facts. There is a sharing of power and responsibility between the teacher and the students for the curriculum, but the teacher does not abdicate his or her authority. A major component of the philosophy of experiential education is the student's participation in the learning process. Experiential education advocates the development of a critically thinking, selfmotivated, problem-solving individual through experiences that support these developments. If Dewey and the constructivist movement were looking for an avenue to fulfill their vision of a contributing member of society, experiential education sets the stage for that to happen (Itin, 1999).

Since this research is focusing on the meaningful experience from the learner's point of view, the experiential learning theory offers a viable point of referencing the qualities of the learning process from the learner's perspective, not solely the teacher's. The experiential learning theory then earns its place as the grounded theory and methodology of this research study. 


\section{Outdoor Education Literature}

The educational use of the outdoors to provide both inspiring and challenging personal experiences is well established and makes for a viable setting to do research studies (Gair, 1997). It provides for a captive group of participants and an arena for a variety of activities that can provide meaningful experiences. Outdoor education is inherently relevant to students because they are personally and experientially challenged by the situation presented (Priest, 1997). In many situations, their comfort level is disrupted and they have to make choices that immediately affect them. Outdoor education creates events that put students into problem solving predicaments and the decisions they make impact them directly and usually quite quickly (Priest, 1997). The setting of outdoor education programs creates situations in which students inherently have a vested interest in what goes on during the program. In many cases, some sense of personal security is threatened during such programs (Garst, 2001). These characteristics make outdoor education programs a likely candidate to provide meaningful learning experiences.

Outdoor education programs must be based on solid learning theories, for they too, must have a learning plan based on proven guidelines. These programs are not just allowing students to escape their traditional four-walled classroom for the experiences of the real world (Bunyan, 1994). Practitioners need to know the reasons for teaching subject matter in the outdoor setting as well as the how to teach in the outdoors. Especially because the outdoors is not specifically designed for comfort and, therefore, more unforgiving than the traditional classroom setting, it is critical that outdoor educators have a well-grounded understanding of what they are doing and why (Phipps, 
1988). Without a learning theory as a guide, the educator may end up doing nothing more than exposing students to the real world in hopes that the process takes place (Bunyan, 1994).

Outdoor education is grounded on the idea that learning is a perpetual quest for adventure and discovery, especially during adolescence when maturing young people are finding their boundaries of abilities through seeking out adventure (Gair, 1997). It is no wonder that youth organizations like the Boy Scouts of America, the Girl Scouts of America, Outward Bound, 4-H Club, Boys and Girls Clubs, Little League, etc., incorporate outdoor experiential activities as part of their education. Youth rehabilitation programs also turn to outdoor education to bring back the adventure and discovery aspect of learning. Even adult leadership and team oriented training may use an outdoor experiential program to enhance and re-vitalize the learning environment through adventure and discovery. These experiences offer a personal exploration of a person's self and expose the weaknesses and strengths that apply to real situations. The application of this self-discovery is used as the springboard for personal exploration and vulnerability. It can be seen that the educational benefits of an outdoor education program can be meaningful and very productive (Gair, 1997).

Outdoor education programs are most effective when they link their learning activities to four psychological foundations: communication, perception, arousal, and motivation (Phipps, 1988). The adventure and discovery aspects of education are developed from these four foundations.

Communication is an integral part of any experiential learning pedagogy since the skills and information taught are subject to feedback and not straight lecturing (Phipps, 
1988). This feedback contributes to the reflective aspect of an educative experience. Communication also exposes students to other people's opinions and views on the same topic or scenario (Phipps, 1988). Communication allows for an outside view of oneself that gives another perspective from which to consider who you really are. It is like hearing yourself sing from a tape recording; it does not sound like what you thought others were hearing from you.

Perception is the process of how one receives and processes information. Perception is based on the continuity of our experiences (Phipps, 1988). Dewey (1938) pointed out that educative experiences must be based on the continuity of experiences of previous learning. Reflection is one part of an educative experience and continuity is what the reflection is based on (Dewey, 1938).

At one extreme, a person in a coma has no activation of the brain's cortex, but on the other extreme, a person who is highly excited or aroused has a very active cortex. To have an experience that activates the cortex of the brain means that the brain is receptive to the information it is receiving. "Arousal is the degree to which the cortex of the brain is activated" (Phipps, 1988, p. 10). Without such an arousal, there is no focusing. Brewer et al. (1991) found that one of the most salient aspects of peak performances, which are meaningful in themselves, is focused attention.

Motivation is the impetus to learning. Maslow (1970) identified a hierarchy of needs and he suggests that this hierarchy influences one’s motivation (see Appendix A). Maslow (1970) advocates that the basis of all needs begins with the physiological needs, such as food, water, air, appropriate temperatures, and sleep. Until those needs are met, the other levels cannot be addressed. Only when one level of needs is satisfied does the 
next higher level of needs come into play. The degree of motivation is most intense at the lowest level and decreases as one moves up the hierarchy (Maslow, 1970). When outdoor education programs allow their activities to involve the lower levels of the hierarchy, then the motivational factor is more influential in the learning process.

These psychological foundations give an outdoor education program a design template from which to create the activities that allow these criteria to be implemented. This sets the stage for outdoor education programs to produce meaningful learning experiences.

Key to this research's study of meaningful learning experiences in outdoor education programs is the ability of the research participants to recognize meaningful experiences. The choice of a university outdoor education program is based on research on executive function that is highly correlated to the frontal-lobe development of the human brain (Caine, 2000). Executive cognitive functioning governs behavior, including planning, focusing, regulating oneself, and reasoning abstractly. "Students with welldeveloped executive functioning think ahead, formulate long-term goals, understand the nature of consequences, and can work with symbols and abstract concepts” (Caine, 2000, p. 60). Students younger than 17-years of age rarely have their frontal-lobe development complete and, therefore, their executive function capabilities are in question (Caine, 2000). The selection of university undergraduates as participants of this research study will reduce the likelihood of this lack of executive function.

Experiential education (e.g. outdoor education) as a vehicle for the development of physical, cognitive, and affective skills is based on a flow from the learner to critical reflection with several intermediate stages (Gager, 1976) (see Figure 2). 
Figure 2. Flowchart for the development for experiential learning.

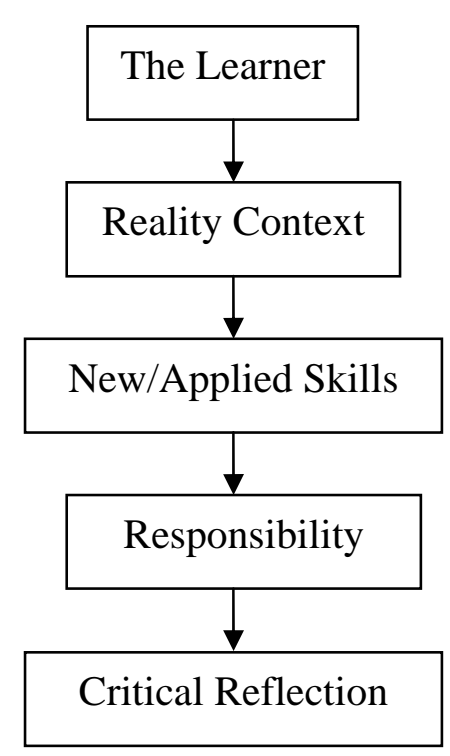

Gager (1982) points out that experiential education differs from other learning approaches in that a student is given the opportunity to carry out an action and see the effects of that action from which he can then generate his own concepts and applications. The focus of outdoor education programs must be on the student undertaking actions in the real environment where the need for making decisions and taking responsibility has real consequences. As Dewey (1938) proposed, an important component to the educative experience is the final stage, critical reflection. Yet, many outdoor education programs falter at this stage because facilitators of such programs are unable to see the importance of this last stage and therefore fail to structure their time to accommodate time for reflection or fail to account for unexpected events, which sometimes leaves little or no time for this last stage (Bunyan, 1994). Another problem concerning this last stage is the inability of facilitators to use this time for reflection effectively (Bunyan, 1994). Too many outdoor education programs have come and gone because their approach was to expose their students to experiences in the real world in hopes that the learning process 
would just take place. Research has shown that if experiential education's potential to contribute to the growth of individuals is to be realized, then the stages outlined by Gager (1976) need to be incorporated.

Research has shown the effectiveness of outdoor education programs. Hattie, Marsh, Neill, and Richards (1997) did a meta-analysis of a large sample of adventure programs and their effects on a diverse array of outcomes, including self-concept, locus of control, and leadership. Their study was based on effect sizes or "the degree to which the phenomenon is present in the population” (Cohen, 1988, pp. 9-10). Even though the effect sizes varied substantially from program to program and outcomes, they were able to show that the effect sizes did improve as the length of the program and the age of the participants increased. They concluded that adventure programs have a major impact on the lives of the participants, especially in the outcome of self-control as it related to regulation of self, responsibility, or an assurance of self. Development of interpersonal competencies, enhancement of leadership skills, self-control, assertiveness, increased sense of empowerment, and better decision-making skills were all attributed to the participation in outdoor education programs, specifically Outward Bound. Another finding indicated that this impact is lasting (Hattie et al., 1997).

The importance of Hattie et al.'s findings is the impact such outdoor programs can have on the development of a contributing citizen of a society. Tyack (1997) reports that our society is losing a civic America because the nation is made up of apathetic civic citizens. Harris (1997) conducted a survey that suggested that voters knew little about what was going on in their state legislatures. Boss (1999) suggests that this trend occurs because citizens feel powerless to affect change and they think that they have little 
influence on their governing bodies. Outdoor education programs can be effective bridges to civic participation when qualities such as those identified in Hattie's study are taught (Boss, 1999).

Outdoor education programs can be one of the most intensive forms of experiential education because of underlying processes that occur in the wilderness setting which can render meaningful experiences (Andrews, 1999). Andrews (1999) incorporates the cultural concept of the rites of passage first proposed by anthropologist Arnold van Gennep in 1909. From the cultural perspective, certain experiences within a societal environment can have meaningful effects on an individual (Gennep, 1960 [1909]). These meaningful effects can produce a transition from one emotional stage of life to another stage (Gennep, 1960 [1909]). This rite of passage is a universal phenomenon that shares three common phases: separation, in which a person is separated from the structure of everyday life in society; transition, the phase in which a person then goes through an intense experience that has different norms and characteristics of everyday life in society; and aggregation, the final phase through which the person reenters the societal life he came from, but in a different frame of mind (Gennep, 1960 [1909]). Andrews (1999) proposes that wilderness experiences provide the settings for transition to occur because the wilderness operates with a different set of norms and characteristics. Having different norms and characteristics from the everyday life a person is familiar with gives the wilderness setting a sense of risk, the risk of becoming involved in a different environment with its own set of norms and characteristics.

Therefore, outdoor adventure programs provide the element of risk involved in the experiential process. Along with the risk comes the sense of anxiety (Yerkes, 1980). 
The notion of anxiety adding to the learning process was studied by Yerkes and Dodson (1980) and resulted in the Yerkes-Dodson Law. This paradigm of learning describes the phenomenon of a student's level of anxiety and its affect on learning. The following figure illustrates the Yerkes-Dodson Law (see Figure 3).

Figure 3. Yerkes-Dodson Learning Curve

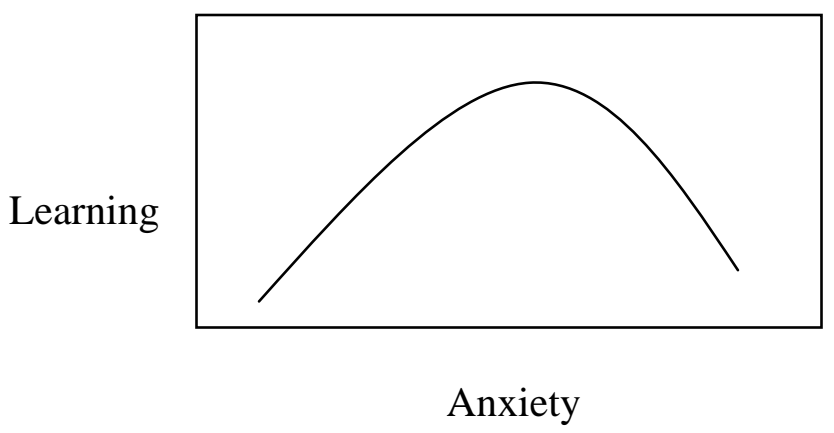

According to this principle, learning gains its greatest potential when the student's anxiety level is moderate. When the student's anxiety level is low, the learning potential is inhibited by poor motivation and when the anxiety level is high, learning is inhibited (Yerkes \& Dodson, 1980). This study reflects the learning influence of educational programs that can provide a controlled environment in which anxiety can be produced with controlled limitations.

Depending on the level of anxiety, anxiety can become more of a sense of fear and one study shows that fear can be a contributing factor to the learning process. Ewert (1987) found that fear played an important factor in the success for learning in outdoor education programs such as Outward Bound, although he did not point out how or why it did.

A study conducted by Debring, Willis, and Genet (1995) looked into the attribute of anxiety in outdoor education programs that offer controlled challenges for the students. 
Basing their research on Yerkes and Dodson (1980), the researchers hypothesized that (a) students with moderate levels of anxiety during the program will learn the most, (b) students will understand the materials taught during the activities based on the same curvilinear manner as the Yerkes-Dodson model, (c) students with moderate anxiety levels will be more involved in the activities than those who have low or high levels of anxiety, and (d) the more experience the student has had with the activity, the lower the level of his anxiety. Thirty-nine participants were studied in a college outdoor program which was based on the concepts of Outward Bound. In this three-week program, students were involved in a variety of outdoor activities including rock climbing, a major expedition, and a three-day solo trek. Anxiety levels were measured using the StateAnxiety Inventory and learning experiences were determined by a questionnaire using the Likert scale. The findings of this study show little support for the first hypothesis. The results showed an inverse correlation between anxiety levels and satisfaction in the learning process. The second hypothesis was supported. Students with moderate levels of anxiety understood their experience more than those with low or high levels of anxiety. The third hypothesis was not supported. Those students who were more involved with the activities had higher levels of anxiety than those who were not so engaged. The fourth hypothesis was supported by this study (Debring et al., 1995). This research points out the need to distinguish between the learning process and the understanding process of an outdoor activity. If meaningful learning experiences are sought in outdoor education programs, this study implies a need to monitor anxiety levels.

The effects of wilderness orientation programs on student success in postsecondary schools in the United States were studied by Gass (1995) and again by 
Galloway (2000). Their research found that these wilderness programs had positive correlations on the retention of first-year students, higher grade point averages, and greater levels of student development than those students who did not participate in such orientation programs. These studies imply that such programs can provide meaningful learning experiences, but it does not identify what attributes of the programs affect this provision.

Phipps and Claxton (1997) investigated the effectiveness of adventure educators by analyzing the use of specific teaching behaviors. They measured ten areas of teaching and learning that Phipps had identified as necessary aspects. Those areas included structure of the course, communication, perception, motivation, arousal levels, feedback, group processing, action and practice, leadership, people skills, and safety. Phipps stresses the necessity of mastering these characteristics in adventure and outdoor education because of the high-risk nature of such programs. The data collected in this study revealed mean scores that were consistently high, showing very effective instruction (Phipps \& Claxton, 1997). By examining the details of this study, one could see that Phipps and Claxton were looking at the characteristics of a teacher who had mastered these characteristics and practiced the synchronizing of disseminating information and facilitating experiences that allowed application. Both of these qualities in a teacher are considered important in the Progressive Education Movement (Itin, 1999). Just as important was that the data were collected from the students involved with the program and observations made by the researchers; therefore, it has significance because it represents how the students perceived their experience. 
Another aspect of outdoor education that contributes to meaningful learning experiences is the leadership training of educators. What skills should they have? Priest (1995) conducted a survey to investigate the approaches to outdoor leadership training conducted from various programs in five different nations (Australia, Canada, Great Britain, New Zealand, and the United States). Fifty programs were studied. Seven skills were identified as common amongst all the programs studied. They included technical activity skills, safety skills, organizational skills, environmental skills, instructional skills, group management skills, and problem-solving skills. The priority of which skills were emphasized in the leadership training programs varied from country to country. Countries, like Canada and the United States with high concerns for litigations, emphasized safety more than any other skill, but problem-solving skills took priority for the other countries. It is interesting to note that instructional skills were usually in the bottom half of the priority list for all countries.

A study conducted by Haluza-Delay (2001) investigated the experience of eight teenage participants on a 12-day adventure trip through observation and semi-structured post-trip interviews. This research found that the teen participants conceptualized nature as being undisturbed, natural, unfamiliar, without people, relaxing and with a sense of freedom. Although the research was not focusing on meaningful learning experiences, the study indicates that the participants found the experiences more fruitful than their experiences in a traditional classroom setting because there was a sense of no limitations or inhibitions to their levels of self-discovery (Haluza-Delay, 2001).

A study on self-perception and outdoor experiences in adolescents found that the novelty of the experience lends itself as an escape mechanism from the usual situations 
students find themselves in day after day (Garst, Scheider, \& Baker, 2001). Participants described how the trip served as an escape from family pressures and negative peer influences. The positive impact of escape on self-perception was supported by Milton, Cleveland and Bennett-Gates (1995), who found that young people who were "placed in a natural setting and released from the pressures of reading, writing, and teacher approbation, discovered new interests and capabilities" (p. 36). Furthermore, participants described how they were able to see a different aspect of the world, a natural environment that they never expected to see. Therefore, outdoor adventure programs may have value because participants experience time away from the usual home and school environment, even if it is only for a few days, to discover new perspectives and relationships from different references.

The transference of what is learned in an outdoor education program to the home environment after a period of time was the focus of a study done in northern Canada (Miller, 2001). Three years after participating in a 35-day wilderness expedition in Canada, five of the young participants were interviewed to find out if any of the lessons learned during their wilderness experience were being used in their personal lives at home. The findings were mixed in that certain lessons still had application, but only if the circumstances were similar to the wilderness experience that generated the lesson. Most of the lessons were overcome by the social influences of their home environments (Miller, 2001). The study recommends that the learning process with wilderness educational experiences be continued with more opportunities to experience the outdoors in an educational setting (Miller, 2001). There is certainly a desire by the participants of this study to continue learning in outdoor environments, but probably due more to their 
personal experiences in such educational settings rather than application to their usual home life experiences. Yet, it could be argued that the more outdoor educational experiences one has, the more similar applications may be realized.

A British study found that outdoor education provided a more democratic approach to learning than traditional pedagogy (Grierson, 2001). British students at all levels are under increasing pressure to perform with respect to targets and objectives that have been dictated to them by school officials. The push to meet government-imposed educational standards has made schools more undemocratic than ever. Outdoor education provides students the experience of making choices and facing the consequences, a way to truly learn about democracy (Grierson, 2001). This study lends support to Dewey’s point of schools being the model for a democratic society and suggests that outdoor education programs are vehicles to accomplish this.

The literature points to a greater possibility that an actual outdoor education program can provide experiences, which are potentially meaningful than experiences usually, found in the traditional classroom setting. This phenomenological study will focus on one such program that has shown this potential for over ten years. This research will use a joint course consisting of an outdoor education class and an English writing class offered at Brigham Young University. Students select and participate in a variety of outdoor recreational activities, including backpacking, cross-country skiing, winter camping, skydiving, horseback riding, mountain biking, participation in a ropes course program, spelunking, and scuba diving. In conjunction with their participation in these activities, the students are given many opportunities to reflect on their participation and also to write about their feelings and thoughts. Through their students' writings, Bennion 
and Olsen (2002), of this joint program, have found that "the trips transform them" (p.

245). Repeated comments from their students about the teachers and the course contents include "relate to my personal emotions", "makes things more interesting”, "more aware of my own feelings", "enjoy life more in general”, "heightens my experience”, "mind is more active”, and “ affected me to think clearer and more critically” (Olsen, 2002). The records of this joint course by the instructors, Bennion and Olsen, established that the program can provide the setting to investigate the attributes of meaningful learning experiences.

Currently, mainstream education fails to provide enough of the meaningful experiences that Dewey, Maslow, and others feel are so critical in developing an educated society of contributing members (Education, 1983). Grounded in the theory of experiential learning and Dewey's pragmatic philosophy of experiences, outdoor education has attempted to provide personal experiences for students. Outdoor education stresses the wholeness of knowledge and the person with emphasis on social and emotional growth (Knapp, 2000). Many outdoor education programs have proven to provide meaningful learning experiences, yet it is unclear what the common attributes of these programs are that provide the meaningful experiences. This phenomenological study attempts to identify what those meaningful experiences consist of. 


\section{Method of Study}

The focus of this research was on identifying possible attributes of meaningful experiences through the participation in an outdoor education program. In trying to learn what makes a learning experience meaningful, the methods used in this study to collect data were qualitative. This chapter outlines the rationale for the qualitative approach for this study, the setting for the study, the makeup of the study's participants, the approach for getting the participants to consent to their participation in this study, the methods for collecting data, and the methods used for the analysis of the data collected.

\section{Phenomenological Study}

Experiences are so personal and, therefore, indescribable through a positivistic science model (Bowles, 1994). The very nature of the human language and the concepts it tries to represent concerning the social world are problematic because of probable difficulties in expressing them in quantifiable terms. Instead, Geertz (1975) refers to thick description as a qualitative methodology to study human experiences. This approach goes beyond the numbers and looks to describe what individuals are going through; what they are thinking, how they feel, the context their view is coming from, and the environment they are a part of. This approach applies to the understanding of meaningful learning experiences in the social realm of education. Numbers may imply what may be happening, but a qualitative description tells what is happening to the individual. Therefore, experiential learning is a phenomenological study (Bowles, 1994).

The study of interpretive practice must include the discovery of subjective assumptions about the nature of the lived experience and the social order (Holstein \& Gubrium, 2000). Husserl (1970) insisted that to understand the experiential 
underpinnings of knowledge, one must consider the human consciousness that actively constitutes the objects of the experience. Therefore, "subjectivity is paramount as the scientific observer deals with how social objects are made meaningful” (Holstein \& Grubium, 2000, p. 262).

The expression of this human consciousness is the language of the individual having the experience (Holstein \& Gubrium, 2000). Language is the central medium for the transmitting of consciousness and the understanding of what the language is conveying requires careful recording and questioning. The use of conversation and written accounts of individual and personal perceptions becomes the main source of data for analysis.

\section{The Study's Setting}

This phenomenological study is interested in meaningful learning experiences in an outdoor educational program. Such a program, with a history of feedback from students who felt that they had meaningful learning experiences from this program, is Brigham Young University’s (BYU) Wilderness Writing Program (WWP) (Bennion, 2002).

The WWP consists of two courses that must be taken together in the same semester. One of these courses is offered through the Department of Recreation Management and Youth Leadership (RMYL) in BYU's College of Health and Human Performance. This course is RMYL 123: Introduction to Outdoor Recreation, in which students are exposed to a variety of outdoor activities. They are required to participate in some of the activities; others they may choose to participate in. The second course is offered through the English Department in BYU's College of Humanities. This course is 
Honors 203R/ English 368: Wilderness Writing, in which the students are expected to write about their experiences in the outdoor activities. The writing course offers 3.0 semester credit hours and the outdoor recreation course offers 2.0 semester credit hours. The WWP has been offered at least one semester a school year for the past ten years at BYU with Dr. Burton Olsen, from the RMYL Department, and Dr. John Bennion, from the English Department, team teaching the two courses. The WWP is an adventure-based education program with an emphasis on self-definition of the students and formation of an environmental ethic (Bennion \& Olsen, 2002). Self-analysis through journal and personal essay writing is at the center of the WWP (Bennion \& Olsen, 2002). The goals of the WWP include

(a) to teach students the skills of non-competitive lifetime recreation in the out-ofdoors; (b) to teach them the process of using journal and polished personal narratives to meditate on their experiences, using outdoor activity as a catalyst for self-exploration and discovery; and (c) to help them make decisions about their relationship to the environment. (Bennion \& Olsen, 2002, p. 242)

The WWP used in this study was offered during the 2003 Winter Semester at the BYU Provo campus. The Winter Semester began January 6, 2003 and ended April 23, 2003. The Honors 203R/ English 368 classes met twice a week on Tuesdays and Thursdays from 2:00 to 3:15 in the afternoon. The RMYL 123 class met on Thursdays from 4:00 P.M. until 7:00 P.M., with additional time scheduled to accommodate the outdoor activities the students needed to participate in. Both classes regularly met on the Provo campus of BYU, unless the students were participating in a scheduled outdoor activity. Dr. Bennion was the lead instructor and facilitator of the English writing course 
and Dr. Olsen was the lead instructor and facilitator of the Outdoor Recreation course. One graduate teaching assistant participated in helping with the facilitation of both classes.

\section{The Study Participants}

The participants for this phenomenological study made up a convenience sample of willing and volunteer students. The participants were enrolled in the 2003 Winter Semester WWP at BYU.

That semester's WWP's enrollment was 15 undergraduate students. Of these 15 students, 13 of them would be involved as participants of this research study $(N=13)$. The two students who did not continue to be a part of this study had originally agreed to participate. One of these students was a member of a National Guard unit that became involved with the 2003 war against Iraq in March 2003 and had to drop out of the WWP. The other student had personal reasons, unrelated to the research study, for dropping out of the WWP two weeks before the end of the semester. The two students who had dropped their enrollment in the WWP had their collected data removed from the study's collection to maintain a consistency of all of the participants having experienced the entire program and avoiding any possible major influences not associated with the outdoor activities.

\section{Consent to Participate}

On the third class meeting of the WWP (held on January 9, 2003), all of the WWP students were informed, both orally and in writing, of the purpose and the methods used for this research study (see Appendix B). The research study's participants were given the opportunity to ask questions and receive clarification on any matter concerning this study 
before making any commitments. They also were informed that they could withdraw from the study at any given time before the end of the semester, and they could also have their collected personal data removed from the study upon their request when they withdrew from the study without any penalties for doing either. They had to agree to participate in discussions that would be tape recorded, with the understanding that only the researcher, a hired transcriber, the professors of the WWP, the teaching assistant, and the members of the researcher's doctoral dissertation committee would be allowed to review the recordings and/or the transcribed copy. All participants were required to sign the Consent to Participate form in order to participate in this study (see Appendix C). The participants were informed of the researcher's assurance of confidentiality concerning their identity and their responses to questions and discussions. The confidentiality of the participants was accomplished by assigning each participant a number and using that identification number as their personal label throughout the analysis of the study. From that point on, for the purpose of this study, the participants were identified by their corresponding ID number and their gender references. This allowed the researcher to identify participants with their responses and use the ID number for bookkeeping purposes only. Only the researcher had access to the student's name and corresponding ID number. The WWP's professors and teaching assistant did not have any knowledge of the ID number's correspondence. In the results of this study, references to names were not used.

Students were made aware that the researcher had no role or influence in the grade determination for the courses. They were also assured that their decision of whether or not they decided to participate in this research, it did not influence their 
instructors concerning any student's position or grade in their respective course. The students were informed that the instructors received no extrinsic benefits from this study.

The students of the WWP were given 12 days to consider the proposition to participate in this phenomenological study. The researcher made himself available during that time to answer questions and address concerns, but no student took advantage of discussing concerns or questions with the researcher during that 12-day period. At the seventh class meeting (held on January 21, 2003), the researcher asked those who had chosen to volunteer to sign the consent form. All 15 WWP students agreed to participate and signed the consent to participate form.

\section{Introduction to Outdoor Recreation Course}

The RMYL 123 course is an experiential course designed to allow students to participate in a variety of outdoor activities with emphasis on introducing the student to a wide variety of outdoor recreation possibilities. The course followed Olsen’s (2003) objectives:

(a) to experience and learn basic outdoor techniques through participation in a wide variety of outdoor activities, (b) to learn and apply fundamental outdoor ethics (minimum impact/leave no trace), and (c) to learn and practice fundamental outdoor safety skills related to common practices in adventure programming. (p. 1)

The course instructor, Dr. Olsen, required that the students attend the first class for the introduction of the course. This first class meeting was used to discuss course requirements, class and applicable BYU policies, safety issues and risk management issues, and to allow students, instructors, and teaching assistants to be introduced to each 
other. Students were also required to attend scheduled classes when the details of an upcoming required activity were being discussed (see Appendix D). Part of each of these four required activities was the respective preparatory lesson of required skills and basic knowledge that students needed to be exposed to in order to participate in each activity with minimal calculated risk (Bennion \& Olsen, 2002). For example, before the crosscountry skiing activity, students were introduced to the equipment used, proper clothing to be worn, winter survival issues, basic skiing techniques, and the area and terrain where the activity would take place. Each student was also required to help in planning, organizing, leading, or carrying out one of the various required activities (Bennion \& Olsen, 2002).

The students were all required to participate in four outdoor recreation activities. The instructors found that several short and relatively easy outdoor activities were better suited for the majority of the students instead of one long and rigorous one (Bennion \& Olsen, 2002). The required activities included an overnight winter campout in which the students had to build and sleep in their own snow cave, a three-day backpacking trip in the San Rafael River drainage in central Utah, a one-day ropes course seminar, and a cross-country skiing activity. In addition to these four activities, each student had to select two to six other outdoor activities to participate in, depending on how much time the activity involved. Some examples of the options available were scuba diving, rock climbing, paragliding, ice skating, bear tagging, horseback riding, and sky diving. These optional activities were all introduced and taught by certified professionals in their respective fields and the students participated through the professional's instructional services. 
For the purpose of data collection, this research focused on the four required activities for all the students in the class. These activities gave a variety of long- and short-term outdoor experiences, as well as different levels of challenge and different skill performances.

The first of the four required activities was the cross-country skiing held on January $23^{\text {rd }}$, during the class's regular meeting time. The activity occurred at BYU's Aspen Grove Family Camp, located approximately 20 miles northeast of the BYU main campus in Provo, Utah. It is in the Wasatch Mountains at an elevation of about 6,000 feet. This camp had a maintained cross-country ski area. The cross-country ski trail was about one-and-a-half kilometers in length and was groomed and maintained by the staff of the facility. The students received some basic instructions on the use of cross-country skis on a flat and open field. After the brief instruction and practice session, they were given the opportunity to ski on the ski loop for approximately one hour. All of the students ventured out to the ski loop, which was located in a spruce tree forest with hills and flat areas. All the students made it around the loop at least once, with some of them going around a second time. With a little daylight left after the ski loop adventure, the instructors took the students up a trail for about a kilometer to view some different scenery of the mountainous area.

During the cross-country skiing activity, the researcher skied along with the students, observing those participants who could be recognized by the researcher at various times and locations during the activity, recording observations onto a portable miniature tape recorder as soon as privacy allowed. Key observations that warranted recording were falls (who fell, seriousness of the fall, how long it took them to get up, did 
anyone assist them back up), participants having difficulties (slow, slipping, signs of fatigue, complaining and/or swearing), participants who seemed to be enjoying the experience (laughing, singing, making causal conversation, stopping to look at the scenery), participants who were assisting others (stopping to help, asking if anyone needs assistance, constantly skiing with someone having difficulties), participants who appeared to be competing (racing to a point, skiing fast to get back to the start, verbally challenging others), and participants who were in a world of their own (skiing frequently alone, ignoring others around them, leaving the road to take a side trail).

At the end of the cross-country skiing activity, the students, instructors, and the researcher went over to the camp’s lodge to relax, warm up, have a snack and warm drink, and participate in a focus group debriefing of this activity, moderated by the researcher. This debriefing session was held about a half-hour after the skiing activity was completed.

The environment for this group debriefing provided a comfortable and relaxing environment in which the students had the opportunity to ask questions of the instructors and amongst themselves. They had the opportunity to evaluate their participation in the activity with regards to level of difficulty. They discussed their association with each other, their enjoyment level, and the value and relevancy of the activity for them personally. They reflected on their ability to overcome difficulties and they discussed the relationship of the environment to their experience, and application of the experience to other life situations. The group’s discussion during this debriefing was tape-recorded (see Taniguchi, 2004 for additional information). The researcher observed and took notes during the debriefing session. The debriefing session lasted approximately one hour. 
To enhance individual participation during these debriefing sessions, a processing sheet with a few questions related to the activity was given to each student so that they could jot down some answers of their own before the debriefing session began (see Appendix E). These questions for thought were piloted with five RMYL graduate students for review and evaluation. Their input as to the validity of each question was incorporated to produce the questions that were given to the participants of this study.

The overnight winter camping/snow cave experience followed a few weeks later on February $7^{\text {th }}$ and $8^{\text {th }}$ at the snow fields along Skyline Drive in Sanpete County, Utah, approximately 100 miles to the southeast of Provo, Utah. This was the only location close enough to BYU that had enough snow to facilitate the construction of snow caves. This area is approximately 8,000 feet above sea level. The researcher participated in the building of the snow caves and also slept in one of them. Observations of the participants and the interactions that took place while preparing to build the snow cave, while building the snow cave, and using the snow cave were made by the researcher by recording the observations on a tape recorder. The researcher was particularly interested in those observations that indicated that participants were having difficulties building their snow cave, participants who were complaining of the cold, participants who were giving up with their building process, participants who were helping others build their caves, participants who appeared to be having a good time with the activity, and participants who were not participating. The focus group debriefing was held the following morning after the students had an opportunity to sleep overnight in their snow caves. The debriefing session was tape-recorded (see Taniguchi, 2004 for additional information). 
The ropes course seminar was scheduled during the regular course time on March 6th and held at the CLAS Ropes Course in Provo, Utah. This facility is privately owned. The ropes course utilized an outdoor area with a variety of structures that facilitated experiential activities focusing on problem-solving, decision-making, trusting, building teamwork, and overcoming fear scenarios. The facilitators of this ropes course were trained and certified in the supervision of the various activities and were employees of the CLAS Ropes Course facility. The activities included some problem-solving scenarios using lengths of rope and each participant blindfolded, a decision-making scenario using an obstacle course, an overcoming fear scenario using a giant swing, and a trust-building scenario that required the participant to leap from a small platform, about 20 feet above the ground, to a ring which was suspended at the jumper's eyelevel height approximately ten feet away from the platform. The researcher observed the participants and their interaction with the situations presented by the facilitator. The researcher recorded his observations in writing as he saw key observations, such as frustration, fear, exuberance, joy, celebrations of success, reactions of failure, quitting, strong and persistent determination. After all the activities were completed, the WWP instructors hosted a Dutch oven dinner at the facility. While the participants were eating, the researcher facilitated a final debriefing session and tape-recorded what was said (see Taniguchi, 2004 for additional information).

The fourth outdoor activity was a three-day backpacking hike in the San Rafael River canyon in central Utah. This activity was on March $27^{\text {th }}, 28^{\text {th }}$, and $29^{\text {th }}$. Each participant had to carry his or her gear in a backpack and hike a specific route to a designated destination each of the three days. The two WWP instructors and the 
researcher accompanied them. Two nights were spent outdoors during this hike. This hike follows a dirt and sandy walking trail along the San Rafael River for about 10 miles in. The first day was a short hike covering four miles to a sandy wash. The next day was a longer hike of about six miles, which included hiking over a steep pass. The third and final day was hiking back out all the way. Again, the researcher observed the participants and their interactions. He recorded key observations through a tape recorder. Key observations include fatigue, complaining, difficulties, helpfulness to others, signs of enjoyment, signs of impatience, and indications of quitting or perseverance. The debriefing sessions were held at the end of the first two days of hiking, after everyone had eaten dinner and could relax around a campfire. These debriefings were tape recorded by the researcher (see Taniguchi, 2004 for additional information).

This outdoor recreation course exposed the participants to a variety of outdoor environments and activities that were unfamiliar to most, if not all, of the participants of this study. The course offered opportunities for the participants to face their individual challenges that the activities in those environments provided and allowed for time to reflect on these experiences.

\section{Wilderness Writing Course}

The wilderness writing course was the segment of this study where much of the critical reflection took place. This class met twice a week. The earlier class period was spent in a traditional classroom setting. During this time, students read and discussed journal entries from their reflection on their participation in the outdoor activities. They also discussed reading assignments about outdoor and environmental experiences and issues from various published authors. The second weekly class period was spent in a 
computer lab classroom on the BYU campus where students worked through exercises that stimulated thought and ideas for essays, drafting essays, editing essays in peer groups, and critiquing essays as a class (Bennion \& Olsen, 2002).

This phenomenological study did not collect and analyze all the written work assigned during this course because some of the assigned work was not related directly to the actual outdoor experiences of RMYL 123. Many of the lessons and activities of this wilderness writing course were for teaching writing skills and teaching the various ways to express emotions, perceptions, and reflective thought concerning personal experiences. The emphasis of this research study was to identify attributes that appear to be expressed in association with meaningful learning experiences in an outdoor education program. There were some writings that were personal essays about family situations, church missions, boyfriends, and girlfriends. They had no connections to the outdoor activities and, therefore, were not part of this study. This phenomenological study focused on those written essay assignments and daily journal records that reflected personal thoughts concerning each participant's involvement in the outdoor activities of RMYL 123, specifically concentrating on whether those experiences were meaningful to the individual participant and what made them so.

Each research participant was assigned to write three personal essays during the semester. The first essay was a personal autobiographical account of the student's own encounters with the non-human other (e.g. mountains, animals, trees, snow, etc.) and his or her own perceptions about those encounters. This written piece of work was used as a supplemental source of insight to the student's thoughts and perceptions concerning his or her relationship to the perceived environment. Some of these second essays were used 
in the analysis for this research study because the topics chosen by some participants dealt with reflections on one or more of the RMYL 123 required outdoor activities. Those personal essays that did not deal with one of the required outdoor activities were not included in the data analysis. The students were allowed to choose their topics for the second personal essay. The third essay was specifically assigned as a personal synthesis essay concerning their reflective thoughts about the three-day backpacking hike in the San Rafael River Canyon. Each essay assignment was a process of drafting thoughts, writing a rough draft of the essay, verbalizing the written thoughts and explaining meanings to a group of two to three classmates, editing and producing a revised draft of the essay, having the class professor critique the second draft, and finally editing and producing a final copy. During one of the essay processes, each student was expected to present his or her second draft to the entire class for a class peer review and critique before producing the final copy. Another essay process included a discussion of the individual student's essay with the class professor.

The course professor introduced exercises to help students practice techniques of writing personal essays and guided the students in learning how to constructively critique each others' writings. In his one-on-one interview with each student for one of the assigned essays, he critiqued the student's draft, but also asked for explanations that he and/or the researcher felt could lead to a better understanding of the student's feelings or perspective.

During the small-group peer reviews, with two or three other students, the focus was on clarifications, but correcting spelling and grammatical errors and giving praise for worthy writing was also encouraged by the course professor. 
The researcher observed all class essay reviews and all discussions between the class professor and the individual student. The researcher also observed selected small group reviews of individual essays. Copies of the final essay product for each of the three assignments were collected by the researcher for data resource (see References section under the author's name for information to obtain copies of the essays).

Throughout the semester, another required assignment was keeping a journal of personal thoughts and descriptions of personal experiences. These writings were not critiqued by fellow students or by the professor of the course. The emphasis was on writing down immediate and reflective thoughts about anything, in a personal and carefree style. The purpose of this assignment was to give the students a non-punitive format of expression and to be another source of research data. These journal writings were collected by the professor for verification that each student fulfilled the assignment. The researcher also received copies of the participants' journal entries as another source of data.

\section{Data Collection Procedures}

The pertinent written works from this study’s participants were collected on an IBM/DOS formatted floppy computer disk. All collected works were identified by a numerical ID code.

The written work was saved on the computer disk both as a Microsoft Word document and in a Rich Text Format. Both formats were copied and pasted onto a computer database associated with the qualitative data analysis software program called QSR NVivo. Each written work was catalogued according to the subject's numerical ID, 
the outdoor experience the writing was about, and whether the writing was a journal entry or an essay.

The tape recorded sessions were transcribed by the researcher and a hired transcriber to the same computer database for use with QSR NVivo. Each recording entry was catalogued by the outdoor experience that was being discussed. The transcribed entries were reviewed for transcription errors by the person who did not do the original transcription. Errors were corrected by the original transcriber.

Memos, created by the researcher concerning perceptions of what was recorded and observed from the participants of this study, were also used as part of the data and the analysis. This information was transcribed, but not for the purpose of analysis by the computer analysis software.

\section{Data Analysis Procedures}

Analysis of the data collected was coded through a process described by Strauss and Corbin (1991). Initial analysis of the data began with a microanalysis using detailed line-by-line analysis of tape recording data and written data. This generated initial categories of properties and dimensions found in the discussions and participants’ writings (Strauss \& Corbin, 1991). This conceptualization of identified phenomena assisted the researcher in the open coding of the data. In general, coding is a method for analyzing qualitative data whereby the data is fractured based upon similarities, then conceptually grouped into codes which become the theory to explain what is happening in the data (Glaser, 1978). Open coding consisted of fracturing transcribed data according to words, phrases, sentences, or paragraphs that represented one thought on a line-by-line basis. Sample codes included trip activities, weather, challenging experiences, perception 
of group, perception of self, interaction with instructors, interaction with classmates, teamwork, and novel experiences. Codes were then sorted to identify preliminary categories as suggested by Glaser (1978).

Axial coding was utilized as subcategories were identified and their relationships to larger categories were linked through the levels of properties and dimensions (Strauss \& Corbin, 1991). Strauss and Corbin (1990) defined axial coding as "a set of procedures whereby data are put back together in new ways after open coding, by making connection between categories" (p. 96). Axial coding consisted of sorting again by category to identify relationships between the categories (Strauss \& Corbin, 1990). Using the axial coding process, a preliminary list of categorical relationships emerged through a semantic comparison of coded categories.

In qualitative research, "trustworthiness" is conceptually related to reliability and validity (Guba \& Lincoln, 1985). Several trustworthiness procedures were used in this study to establish reliability and validity among the qualitative data. Credibility, which is the qualitative equivalent of internal validity, involves the extent to which the interpretations that have resulted from data analysis are credible to the participants. Credibility was established using member checking. Five of the research study's participants were located in the fall semester of 2003 and each was asked to review the researcher's data and the analysis for validity (see Appendix F). All five of the research study’s participants agreed with the interpretations made by the researcher in the analysis. Dependability and confirmability, the qualitative equivalent of reliability, was achieved through the use of an inquiry audit, whereby a RMYL graduate student and two individuals, not affiliated with BYU or the research in anyway, were used to examine and 
confirm the qualitative data analysis process and the codes and categories that were produced (Lincoln \& Guba, 1985). With this triangulation of the researcher's interpretations, the members' checks, and the three individuals' feedback, the resulting analysis was agreed upon. (see Appendix F)

To reduce the chances of misinterpretations of the data, the collection of data using both verbal (through interviews and focus group discussions) and written (through journals and writing assignments) reflection were used as a redundancy of the data gathering procedure. This redundancy allowed for triangulation in which multiple perceptions were used to clarify meaning and verify reliability of the observation or interpretation (Stake, 2000).

Constant-comparative methods of analysis, as described by Guba and Lincoln (1985), were used to continually refine the descriptive categories and the axial coding process. The researcher's memos were analyzed as supplemental interpretations of the processes observed, in conjunction with the participants' collected data.

The use of the QSR NVivo computer software program was an aid in the organization, categorization, coding identification, and initial identification of reoccurring codes within the collected data. The final analysis was still determined by the researcher's interpretations of all analyses done.

\section{Phenomenological Analysis}

The study of experiences must depend on the individual's perception of the experiences he has had or is currently having. The experiential underpinnings of knowledge are the relationship between the perception of the experience and the experience itself (Husserl, 1970). "The human consciousness actively constitutes the 
objects of experience” (Holstein \& Gubrium, 2000, p. 263). Schulz (1964) argued that social scientists must recognize the subjective point of view to understand social reality and the meaningfulness of experiences. To ignore such would open doors for scientific explanations that would only create a fictional, non-existing reality (Schutz, 1964).

Individuals approach their experiences with stocks of knowledge that are composed of commonsense constructs and categories derived from social associations (Schutz, 1970). These stocks of knowledge are comprised of an individual's ideas, values, theories, images and attitudes that are applied to experiences and this application is what makes experiences have meaning. Stocks of knowledge are the resources from which interpretations of an experience are made and they help make the world a familiar place (Holstein \& Gubrium, 2000).

This familiarity of shared experiences is a categorization of stocks of knowledge and allows for typifications. Typifications make it possible to recognize experiences as a particular type and produce categories that allow interpretive application to specific experiences (Holstein \& Gubrium, 2000). Typifications are also adaptable and indeterminate (Holstein \& Gubrium, 2000).

This research found typifications that were identified in the data collected and labeled them as the attributes of the construct of meaningful learning experiences. Attempts to identify the stocks of knowledge that are common and frequently shared amongst the participants of this study were accomplished through interviews between the researcher and the individual participants. The characteristics that appeared to be common for the experiences were analyzed in conjunction with the stocks of knowledge identified in order to form typifications. 
These typifications were then identified as the characteristics that this research

proposes as the attributes of meaningful learning experiences in outdoor education programs. 


\section{Findings}

This research study was interested in finding common attributes of meaningful learning, expressed by the study's participants, in an outdoor education program. The participants’ demographics illustrated a group of collegiate students with varied backgrounds which helped to link certain attributes to the meaningful learning experiences. Some similarities amongst the participants were identified because these similarities might influence the rationale of some of this study’s findings.

Five central themes were identified by this study to be common in meaningful learning experiences: (a) risk, (b) awkwardness, (c) fractional sublimation, (d) reconstruction, and (e) growth. These themes, with their attributes, were drawn from the BYU WWP, but may have a much wider value in reviewing learning experiences.

The themes and their respective attributes are substantiated by the writings and comments from this study’s participants. Some examples of participants' statements are given in this chapter to illustrate their perspectives, and additional examples from the participants can be found in Appendix G under the themes and attributes they represent.

\section{Participants’ Demographics}

A questionnaire was given to each of the study's participants at the beginning of the 2003 winter semester in order to obtain the following demographic information (see Appendix H). The convenience sample of this study was made up of 13 participants $(N=13)$. There were four male participants (30.8\%) and nine female participants $(69.2 \%)$. Four of the participants held a freshman class standing (30.8\%), one held a sophomore class standing (7.7\%), one held a junior class standing (7.7\%), and the other 7 participants held senior class standings (53.8\%). The students' major areas of study at 
BYU varied from the social sciences (e.g. English and psychology) to the natural sciences (e.g. botany, physics, and biostatistics). One of the male students was married with no children; the other 12 students were not married. The ages of the participants ranged 6 years, with the youngest being 18 years and the oldest being 24 years. The average age was 20.42 years $(\sigma=1.94)$ (see Appendices I \& J).

The study participants were a mix of different backgrounds, different areas of interest, and different amounts and types of experiences in outdoor settings. Even though all participants grew up in the United States, there were a few differences in each of their upbringings. Two of the participants grew up in rural environments, while the others were raised in urban or suburban environments. Twelve of the participants came from the traditional two-parent household, while one participant came from a single-parent home. Twelve participants were raised in a Caucasian family environment, one participant was of Asian ancestry and was raised with a Chinese cultural influence, and one participant had some American Indian ancestry, but admitted that there was little exposure to that particular culture. Some of the participants had extensive outdoor recreational backgrounds, a few of them having actually worked with outdoor recreational programs. There were also a few with a very limited previous exposure to outdoor recreational activities and one participant had told the group that she had no previous experiences with outdoor recreation except bike riding. As one participant stated during the debriefing discussion after the ropes course activity,

I just have a thought. I don't know if it has anything to do with anything, but I'm just kinda [sic] watching people today, and sitting around watching the discussion 
on different things and you can actually see everyone’s different background, different personalities. We are a random group of people. (male participant ${ }^{1}$ )

The study's participants did have a couple of noteworthy common characteristics. First, all of the participants were high academic achievers. Most of the participants were members of BYU's Honors Program which they had earned through their high academic achievement records (see Appendix H). This Honors Program offered courses in the general education requirements and had smaller class sizes and, therefore, more opportunities for individualized mentoring by the course's instructor. Expectations in the Honors courses were usually set at higher standards than the non-Honors courses. The second commonality among the study's participants was that all of participants were active members of The Church of Jesus Christ of Latter-day Saints. This second common characteristic established some common ground for all the participants to associate with, including the understanding of certain behaviors and general behavioral guidelines.

\section{Themes of Meaningful Learning Experiences}

The outdoor environment provides unique and different challenges from the usual routines that most civilized people experience on a daily basis. Conveniences, usually taken for granted, are either missing or much different in the outdoors and comfort is a commodity that takes on a very relative definition when coping with the challenges of the outdoor environment. Priorities must be shuffled around and personal goals become more short-term rather than long-term plans for the distant future. Because this outdoor

\footnotetext{
${ }^{1}$ When a quotation is identified by just the gender of the participant who made the statement(s), the specific participant's identification was not obtained because the quotation was taken from the transcription of the focus group discussion and the specific participant's identification was not possible to determine from the tape recordings.
} 
environment is different from the usual for most people, it creates disruptions for individuals. In order to regain the homeostasis that is a part of the natural order of things, there must be some common avenues that everyone follows to recapture what the laws of thermodynamics calls stability.

There were differences in the participants' perceptions of the four outdoor activities that were observed and many of these differences stemmed from the background of each participant. Some felt that the ropes course activity was not that challenging because they had done similar activities before, and there were a few participants who enjoyed the winter campout because they knew what to expect and had prepared for the experience. Yet, it was also obvious that some common threads ran through all of their writings and comments. For one participant, these common threads occurred in the cross-country skiing activity and the winter campout, and for another, the threads appeared during the experience in the San Rafael hike. These common threads are identified as the themes of meaningful learning experiences.

The researcher observed and identified five major themes of meaningful learning experiences which developed from the analysis of this research study: (a) risk, (b) awkwardness, (c) fractional sublimation, (d) reconstruction, and (e) growth. Each of these themes was redundant for those participants who found meaningful learning experiences from the outdoor activities identified in this study.

The sequential presence of these themes was critical for the process of having a meaningful learning experience to progress. There were several activities that did not provide a meaningful learning experience for some of the participants because of the absence of a theme or themes. For example, “...that just didn’t seem that exciting, you 
know it wasn’t going to change our lives” (female participant). If a participant’s reflections did not produce any evidence of the theme of risk, the rest of the themes were not evident for the participant either and the meaningfulness of the experience was absent. Another example would be the absence of reconstruction, even though the participant perceived the elements of risk, awkwardness, and fractional sublimation.

Group discussions bother me. I feel as though everyone is trying to out introspect the others. And in this search for meaning, I feel as though meaning is forced into existence. It is given an unnatural birth. Meaning comes from application. I don’t know what this winter camping meant. I don't know what the cut I gave myself on my nose bridge meant, or the meaning behind my spontaneous yet effective decision to super-glue it shut means. I will only find out what they mean when I can apply them to something new. The true meaning of an experience itself is sucked out of it by later experiences. And sometimes injected as well. (Participant \#3)

Without the reconstruction theme, meaning may be found in other areas unrelated to personal meaningful learning experiences.

Each theme was identified by attributes common to the theme and these attributes became the results of this study. The themes and their attributes are both considered integral to the presence of a meaningful learning experience.

Risk

This study defines risk as the chance that a state of awkwardness may result. As exemplified by the following participant's written entry, risk and awkwardness seem to be related, "Although I try to avoid awkward situations, I have a tendency to land in 
the middle since I take risks” (Participant $\# 1^{2}$ ).

The perception of risk could be as extreme as a life-threatening situation or, at the other extreme, a potentially embarrassing situation. Most of the risk perceptions experienced by the study's participants were somewhere in between these two extremes, such as the participants having a sense of not having full control of a particular situation. This was usually due to their lack of aptitude of the situation, illustrated by the following comment, "For some, the risk was just that the experience would be something new for them. I was going to experience something new to me” (Participant \#1). There was also a sense of risk due to a lack of physiological abilities to overcome the problems presented, and/or an uncomfortable sensation or sensations due to environmental factors. Examples of such perceptions are "I have never been a huge fan of the cold so getting prepared for the winter camping trip was not an exciting thing for me” (Participant \#12), and "I have never built a snow cave in below-freezing temperatures” (Participant \#6).

Their sense of risk was one of excitement and anxiety. Because they had little to draw upon to know what the experience would really be like for them, there was a sense of excitement to try something new, but anxiety was also part of the equation, especially if something about the experience had possible similarities to previous experiences. Implied in their reflections is the possibility for awkwardness. "I am scared of heights, terrified of heights. But for some reason, when the opportunity presented itself, I took it” (Participant \#7).

\footnotetext{
${ }^{2}$ When a quotation is followed by a participant's number, the specific identification of the study's participant can be made because the quotation was taken from that participant's writing, which was identified by that participant's ID number.
} 
For others, the risk was more of a sacrifice of committing to an experience that was known to bring about a personally awkward situation. There was more at stake for this type of risk. The following example illustrates this type of perception of risk: "I dreaded this snow-caving activity the entire week leading up to it” (Participant \#9). Another participant was even more explicit in their perceptions:

Leading up to the trip, I had many fears. I get cold quite easily. I wasn’t sure how I would do. As I bid farewell to my friends and family, I added “if I don’t die” or “if I ever see you again”. (Participant \#7)

An important note is that the level of awkwardness that the risk had the potential to produce determined the level of risk. Each level of risk was an important consideration for the participants, but relative to each level of risk, some were considered greater challenges. The likelihood that a situation could probably produce a life-threatening potential was considered a huge risk because the level of awkwardness could produce very severe consequences. A lesser risk was one that could produce injury, but not death. Risks that could have the potential to produce physical discomfort without injury were even considered lesser risks than the risks of injury and risks of embarrassment or loneliness were less of a risk compared to the others mentioned.

These comparative levels of risk seemed to have an influence on the potential of how meaningful the experience could end up being for the participant.

In fact, the more traumatic it seems like this is horrible but like the things I learned the most from were like about myself and about trusting people and about trusting myself and about my strengths and my weaknesses and things like that 
were the ones that I was terrified and I wasn't sure if I was going to wake up in the morning in the (snow) cave ...

And like the most traumatic moments like what would most people say would be traumatic were the moments I learned the most. (female participant) The snow cave campout in minus $14^{\circ} \mathrm{F}$ temperature was considered a higher level of risk than the ropes course activity because the awkwardness felt by many of the participants at the winter campout was at the level of physical discomfort: "We were just freezing" (female participant). For some, the experience was perceived as life threatening or possibly resulting in injury. Comments, such as "It's just that it’s such a dangerous activity" (female participant), or "I think this is the closest I have ever had to a survival experience" (female participant) illustrate this point.

When comparing the comments from the ropes course debriefing concerning the level of risk, it is evident that the level of risk was considered lower than the winter campout. Examples of this would be "I wasn't hesitant at all to get up there and to make an attempt at jumping the ring, but once I was up there, I knew I was safe and that nothing was going to happen to me" (male participant), and "When I got up there, I wasn't worried about falling, because I knew I'd get caught by the ropes and I'd be okay" (female participant).

But the perceived level of risk had no bearing on whether the experience resulted in a meaningful learning experience. Just the perception of risk in an outdoor activity seemed to lead to the process of having a meaningful learning experience. The following statement from a participant exemplifies this point: 
...like the alligator thing (the group all having to cross over ten stumps by connecting them with two boards without touching the ground about a foot below) was the thing that meant the most to me today. It is something that I can contribute to and that not that it wouldn't happen without me, but that I was able to take an active role in it. (female participant)

All participants who had a perception of risk seemed to find a pathway to having a meaningful learning experience. Therefore, the perception of risk appears to be an important ingredient for the experience to become meaningful.

\section{Awkwardness}

The second theme in the sequence of having a meaningful learning experience in the WWP was awkwardness. Awkwardness is the state of being uncomfortable due to the unfamiliarity of the situation and having a difficult time changing this state in a timely manner. This state may involve a sense of inconvenience, ignorance of what is happening and/or what to do, a lack of ability to perform necessary actions, feeling out-of-place, being in a situation that is unmanageable and/or out of personal control (Guralnik, 1966). Some may assume that this awkwardness is synonymous with danger, but it is important to note that there are degrees of awkwardness, many of which are not necessarily perceived as dangerous. Even though some of the more extreme degrees of awkwardness, such as an unmanageable situation, may be perceived as dangerous, the terms used here are not synonymous. Inherent in this study's definition of risk is that the state of awkwardness must follow the taking of the risk.

This study's use of the term awkwardness came from one participant's essay that vividly illustrates the point in her reflections of past experiences and the experiences she 
had during this Program. The following are excerpts from Participant \#1's essay on awkwardness:

Although I try to avoid awkward situations, I have a tendency to land in the middle since I take risks. I honestly do not know how most of these awkward situations happen, but I must confess that I have been known to initiate a few. This past school year has been a pivotal time for me. For the first time I stopped just believing what Joyce Brothers said; I started living it. Taking risks became important. I realized that although I was not failing, I wasn't doing anything either. I did not want to come to the end of my life and discover I had not lived. Still--I constantly struggle with awkwardness.

The awkwardness will just continue to build until I snap and confess my feelings in a constant stream of unintelligible phrases that do not accurately describe my feelings.

I used to think that awkwardness stemmed from others hacking at the plaster and cement holding my emotional barricade together. Now I know that it is more than that. It happens when they try to tear down the wall, and you can't stop them, but you are too afraid of their response when they finally reach the other side and see who you really are.

I never meant to become emotionally connected to my friend. I just wanted to go to his apartment and study. It was supposed to help my anti-social desires. If I was never in my apartment, I wouldn't become attached and it would be easier to leave when I had to move. It didn't happen that way. I became attached, not to my roommates but to him and his roommates. I was emotionally 
dependent on them. I loved talking to them, especially with him. I could tell him almost anything. He seemed to have the same level of comfort when talking to me. Still, within the comfortable confines of our friendship was the awkward silence. I couldn’t tell him everything about how I felt, then when I did, I couldn’t find enough courage to listen to his response. It was how I tried to avoid the awkwardness.

Awkwardness, that feeling has occurred several times throughout my life. When I could not control the reaction others had when I fell on my cross-country skis... When I could not trust my fellow winter campers with my life, even though I obviously could not care for myself... When I could not change my friend's reaction to my confession...the feeling was there. Awkwardness is the result of unbalance between fear of failure and faith. I did not want to fail, but I was unable to control the outcomes, I was personally dependent on others. The lack of faith in another person, feeling unconfident that things will work outknowing that you can do nothing about it, is awkward. It comes when you lose faith and struggle to free yourself from the bonds of failure, even when it is impossible to do anything more.

Participant \# 1 expresses her perception of awkwardness as an uncomfortable feeling of "unbalance". This unbalance disrupts the homeostasis that makes us believe that our facades are truly who we are. Awkwardness sets us up to let go of some of our facades. 
All 13 participants gave many examples of awkwardness. There were awkward situations that came about due to inconvenience, such as, "I was not able to do all of the digging, since I broke another shovel on the trip” (Participant \#1).

There were awkward situations due to ignorance, as illustrated by the following two examples: "This was so far out of my life's context up to this point that when I was actually confronted with my shovel and the task of shoveling it, I was somewhat baffled” (Participant \#4), and “I do not even know how to put the skis on” (Participant \#1).

There were awkward situations due to lack of ability. An example of such awkwardness is

Continual embarrassment, but even worst, the biting defeat that clenched me when I made it half way down a hill, saw most of the class waiting at the bottom, and decided just to clip off my skis and just walk down to prevent myself from flying uncontrollably into a mess of tangled legs and poles and skis (Participant $\# 10)$.

There were awkward situations due to feeling out-of-place. The following comment illustrates this type of awkwardness: "Right now, when I go do an activity in the outdoors I feel awkward and out of place” (Participant \#1).

There were awkward situations due to a sense of an unmanageable situation, as illustrated by the following participant’s comment: “I had begun my journey with a small group of people, but as the path continued, paces changed and I found myself alone. I often find myself alone and lonely” (Participant \#7). Another participant had a sense of anxiety due to an unmanageable situation: 
...the thought of descending brought no relief since, looking back down the ridge

to where we had come from, the decline was so steep that forward motion down it might start a momentum I could not stop. (Participant \#11)

Some participants may have had a perception of risk before participating in certain outdoor activities, but may have discovered afterwards that they had no sense of awkwardness while participating in the activity. A perceived lack of awkwardness in an outdoor experience tends to disrupt the process of leading to a meaningful learning experience. Participant \#3 on the winter campout had a cold experience but seemed capable of managing his situation. He said, “I don’t know what this winter camping meant. I don't know what the cut I gave myself on the nose bridge meant, or the meaning behind the spontaneous yet effective decision to super-glue it shuts mean.”

There may be some notions that the duration of a challenging or awkward situation builds character or makes a more meaningful learning experience; the longer the duration of awkwardness, the more meaningful the experience. This study supported the Yerkes-Dodson Law where the amount of anxiety experienced does reach an optimal learning curve and exceeding that anxiety level can decrease the learning experience (Yerkes \& Dodson, 1980). This study did not find a relationship between the length of time of an awkward situation and the quality of the meaningful learning experience. A person could suppose that a prolonged period of awkwardness could lead to a very meaningless experience due to the awkwardness causing the individual's demise.

Even more detrimental to the meaningful learning process than duration of the awkward state is the redundancy of the same awkwardness state over and over again in a short period of time. Several of the study participants noted that repeating the same 
situations of awkwardness led to a boredom of finding meaning in the activity. For example, after hiking for several days, some of the participants felt that the only meaning there was in the red rocks of the San Rafael Canyon was that the rock was red and that is all the meaning there is to that. Participant \#1 made the written comment in her essay On Awkwardness, "I am tired of this; the initial excitement has worn off. I no longer feel adventurous ... I have fallen too often.” This statement reflects a much different attitude than what the participants had on the first day of the hike when they were overwhelmed with the immensity and beauty of the area.

The important aspect of the awkward state that makes it a precursor to fractional sublimation and the rest of the process of meaningful learning experiences is that there is recognition of this state and the individual's vulnerability while in this awkward state. There are challenges with no quick fixes. "Doing, feeling, and experiencing are part of learning; the mind may require the stimulation of the awkward moments” (Participant $\# 1)$.

\section{Fractional Sublimation}

There appears to be a tendency to fabricate an image of ourselves based on how we perceive what society expects of us or how we desire society to perceive us. "Also, there's kind of a public face that people put on. You want people to perceive you this way” (male participant). This alienation of self (AFS) begins during a person's infancy stage and is a compensatory action to cope with the detachment of baby from mother (Rosenthal, 1983). Clinical evidence shows that infants will develop a false self-image in order to be acceptable to the mother (Rosenthal, 1983). As Participant \#1 stated in her winter campout journal, "I worry too much about what other people think.”, she 
continues, "Many of my concerns, inadequacies, embarrassment, feelings of failure, and unhappiness stem from this desire to impress others and make them happy.” This image fabrication involves the creation of facades or coverings over the true self that is the sublime. These facades can be physical items, such as dress, coiffure, cosmetics, and adornments. Many of the facades are manifested through behavior, such as the way a person interacts with others by how that person speaks and what he or she says, the person's projection of body language, and the attitudes projected at a particular time. This image is usually fabricated on a more grandiose scale than what is reality, but facades projecting an inferior image still hide the sublime.

Fractional sublimation was the third theme found in this research study. Sublimation describes the process of shedding some of these facades. Since this process does not totally expose all of the facades an individual has created in one occurrence of sublimation, but can expose some of them, it is a fractional process or a process done in stages.

This research coins this term fractional sublimation as the process of finding the sublime of one's self. Again, this study adapts the insights of one of the participants (Participant \#8) from her essay, On the Sublime, which hints to this process:

Immanuel Kant believed that the sublime was actually our taking pleasure in pain. His basic scenario is this-you go up to the top of a mountain (in France, preferably) and look out at the view. What you see is so immense, so breathtaking, so incredible that you just can’t comprehend it all. So your mind and soul have a seizure, and internally scream "WHOA!" Not because of the sheer beauty of the sight, but because the immensity of what you're seeing is too 
much to comprehend, and the overload hurts. And in that pain is a secret indulgent pleasure. You like that your brain can't handle it all. You like the masochistic feeling of vastness. Your pain breeds pleasure.

True, there was pain involved. And that, for Kant, is the first step: pleasure from pain. But my soul didn't ache with longing and my mind didn't reel from immensity. My ankle hurt from being twisted and my hip ached from being bruised. My pain-derived pleasure was the sweet realization that I still had extremities, because I could feel them throbbing.

Maybe there's some special requirement that is needed to trigger a sublime experience, like an outline of requirements that list what you have to do. It's kind of like those numbered footprints on the floor that teach you how to tango.

Is there something I'm missing before the experience? Or is it during the experience...should I take a step back from the situation and contemplate its meaningfulness as it happens? I could be missing steps in what I do after the experience.

Does that mean, then, that my experiences are not sublime because I don't take time to understand them beforehand or during the experience, and only look at the rather pathetic aftermath? Or merely that I'm too self-centered and/or completely under impressed that I don't ever get the chance to experience the sublime to begin with? Perhaps it's a little bit of both.

The participants' recognition of this phenomenon, which occurred during their outdoor experience, seemed to prepare and allow them to create a meaningful learning 
experience. Therefore, fractional sublimation was one of the most essential phases in this process of having a meaningful learning experience for the participants in the WWP.

The following entry, taken from a de-briefing session while on the three-day hike in the San Rafael Canyon, metaphorically illustrates how one participant perceived this process:

Thanks [Participant \# 12 ${ }^{3}$ ]. (Laughter) I'm going to move so I can talk. But just the different types of erosion and stuff. A lot of my essays and a lot of my things that I've been thinking about this semester are the same and for that I apologize to all you guys. But, thinking about how just how [sic] rocks like build up and just how it takes so long to build up this rock in these canyons we have here. And that they're beautiful but they weren't always this kind of beautiful. They weren't always like this and they're constantly changing and they take a long time to build up and then erosion happens and their weaknesses become more prevalent and then eventually their weaknesses break off and it changes who they are. And I just thought about this class and this semester and college and the experiences that I'm having are showing my weaknesses and I think in some ways, it sounds horrible, but making them like worse. But at the same time, I'm becoming more aware of those and then like my strengths and just how things are beautiful to begin with but over time they change and they can turn into some other kind of beautiful.

\footnotetext{
${ }^{3}$ When the identification of a participant is given within a quotation and printed in italics, this is to recognize that this participant is being referred to by the one making the statement. This was necessary to keep the participant's name from being revealed and, therefore, keep the statement's owner anonymous.
} 
And how when this canyon started it was probably a field of some sort or some range and kind of some flat area and just over time it kind of turns into you know like, and it may have been, well it probably was beautiful before but it's more beautiful now because we appreciated the time and all the things that have happened to it to make it like interesting to look at. (female participant) Other comments from the participants of this study showed the recognition of this fractional sublimation:

Well, a couple of feelings that I've had and I don't know if it fits this or not, but I find when people go in the out of doors, all of the sudden there's a facade that is broken down, (male participant)

and

To go on that, I think that maybe it hasn't brought out a different personality, but it's brought out our real personality, sort of uncovered layers that we usually make and sort of help us see ourselves as we really are. (female participant) Something in the environment or in relationship to the environment seemed to trigger this process of sublimation. This connection to the awkwardness created by the environment was linked in every comment of letting down a facade. It is apparent with these participants that the outdoor environment provides the setting for the first two themes to establish themselves so that the fractional sublimation may occur. The following quotations from the participants illustrate this point: "I have found that when I am out in the wilderness, I can’t hide from my true self” (Participant \#7), and 
It was not about snow caving, despite the specificity of it, because the meaning I took away from it is that I can be calm in rather volatile situations. I learned more about me than about how to build a snow cave. (Participant \#4)

Fractional sublimation was not a pleasurable experience for the study’s participants because the result was to confront the kinds of facades and how many facades were fabricated. This study points to the phenomenon of fractional sublimation as the process that Kant (1892) referred to as the painful aspect of realizing the sublime. "For a man who has snow-skied all his life, to not be able to snowplow correctly was painful (Participant \#5), and "Maybe people should be made out of sandstone, too. Maybe we’d break down a lot faster, and with less pain” (Participant \#8). The realization of what the process of removing the facades revealed created some emotional statements about this pain:

I kind of dislike writing about these activities because I find that I am learning some things about myself that I do not like. It was a painful self-discovery I had but it has helped me to become more aware and discover my areas of improvement. (Participant \#12)

The pain that is mentioned by the participants was more of a psychological pain, such as an emotional discomfort or grief. Even though this psychological pain can manifest itself as a physical problem, "I realized that I had also been hyperventilating the entire time” (Participant \#7), the Kantian pain of the realization of this overwhelming discovery of true self has its origins in the psyche. Much in the same way as depression can be the cause of excessive sleep or lack of appetite. 
It can be easy to build these facades as circumstances dictate what a person should fabricate to survive in society. But the facades do not break down just because another facade is fabricated. One facade layers over another one, just like a painter stripping off the layers of paint that have been applied on the walls of a house, one coat over another. To see the original color of the wall, the outer-most coats of paint need to be removed first. More layers of these facades mean more fractional sublimation needs to occur in order to shed the facades and be able to see what the base layer is and, therefore, confront one's true color.

Some of the study's participants found the environment to be a metaphor for their shedding of facades. As they viewed the beauty and immensity of their natural surroundings, especially in the San Rafael Canyon, they seemed to connect their sublimation process with the erosion of rock and dirt. They viewed the process as a slow and arduous task, but one that was necessary to reveal what was hidden underneath the facades. "In my breakage, like the hoodoos, I can become beautiful. What makes them beautiful? Their crags and crevices created from fracture. Their intrigue lies in their striking demise. So must mine” (Participant \#8).

Fractional sublimation was accompanied with a variety of emotions. Some expressed surprise. "It surprised me how scared I was” (Participant \#13). Others mentioned honesty. "I liked this honest feeling" (Participant \#10). There were those who even expressed giving up, even though the truthfulness of their statements was not validated. "I could feel the cold now ... and I literally longed for death" (Participant \#7). Frustration was another emotion mentioned by some of the participants. "I became 
frustrated with others in my group” (Participant \#12). These emotions were indicators that the fractional sublimation process was taking place or had already taken place.

Fractional sublimation was present for all those participants that felt that an experience in the outdoor setting became a meaningful learning one. To create meaning, there should be a true and solid foundation on which to build on, leaving the facades behind. "I was myself; at least I was discovering what that meant by pealing [sic] off the layers one by one” (Participant \#2).

\section{Reconstruction}

In this research study, reconstruction was a decisive theme in the process of having a meaningful learning experience because this was the production phase of making an experience meaningful. This phenomenon was characterized by the participant's recognition and acceptance of what was discovered in the fractional sublimation stage and by the participant's attempt to make changes based on this selfrealization awareness.

I think there was one thing that I learned. Like, my capabilities are a lot more than

I thought. Because I would get tired and then something kicks in that this has to be done, there's no time for rest and there's something about being out here and having those pressing needs that kind of, I know there's a certain point, but it pushes you farther to be able to accomplish more because you realize what needs to get done... (male participant)

Without the recognition of what fractional sublimation attempts to reveal, the process of creating a meaningful learning experience is stifled. It would be as if just another experience has happened with no reflection to gain meaning from it. If there is 
recognition, but no acceptance of what was discovered or realized in the fractional sublimation stage, the experience may be an educative one, but not necessarily a meaningful learning one. The acceptance is essential to making the experience meaningful because acceptance translates the experience into a personal realization of some aspect of a person's true self and this leads to reconstructing oneself based on what was learned.

There were several participants who pointed out that the outdoor environment had an influential role in their meaningful experience of self-discovery. Their presence in the outdoors and interacting with it gave them a reference point from which to compare and contrast themselves.

Obviously we don't live in geologic time, but the trials that plague our lives are exactly similar to those of the canyons. If we can compare the periods of hurt and betrayal to the immense space of eternity, it is just like the rocks fracturing from the walls of the cliff. It has to happen. It is the hand of God molding us into monolithic fortresses of stone that will eventually be impenetrable and will last for eternity. (Participant \#5)

At this point of the phenomenon, several participants concerning the difference between loneliness and solitude made an important distinction. This distinction described loneliness as an unwanted condition in an outdoor setting, whereas solitude was a welcomed condition. No participant in this study ever wanted to feel lonely, left behind, or excluded from the rest. But, there were times when being alone helped a participant to personally reflect on an experience he just had. Loneliness was considered awkward and undesirable. Solitude was reconstructive and desirable. 
But, when I come out into the non-human other, and I did quite a bit of walking by myself today, too, but I didn’t feel alone at all, I just I don’t know, something about looking up and (now it feels like testimony meeting) being surrounded by God's creation, I felt comforted and at one with my surroundings. I didn’t feel by myself, even though I couldn’t see anyone else (female participant).

This distinction between loneliness and solitude helped to identify two sub-phases contributing to the reconstruction stage. Solitude was characterized as a beneficial way to reflect about experiences and consider what the experiences were revealing. On the other hand, the changes that may need to be made were usually identified by those around a person during and after such revealing experiences. These two situations, solitude and being around others, characterize the two sub-phases: reflection and reformation.

Reflection. The first sub-phase was the reflection phase. After being exposed by fractional sublimation, there seemed to be a period of reflection to consider what had just happened and how a person was to deal with it. This was the time when recognition and acceptance of what fractional sublimation revealed about a person played a crucial role in the reconstruction process.

The exercises of writing and having a dialogue with others who have gone through the same experiences seemed to enhance this reflection. By reading what these participants wrote and talked about, one can see that they are thinking about their experiences, trying to tie experiences of the present to experiences in their past, and trying to make sense of all of them.

The water was deeper than I thought. Everything is deep here. It reaches deeply. To the soul I guess. My conversations with people surpass the shallow 
commentary on everyday life. Instead of tests and roommates, we think on those who made their marks on rock walls and He who made the slate of rocks. I wonder out loud how the rain washed bold streaks down immense rock walls, making its own pictographs, inviting the rich colors of minerals out that streaked and disappeared like the end of a rainbow. Yes, everything is deeper out here. It reaches to some familiar yet unexplored part of me. (Participant \#7)

Reformation. The second sub-phase to reconstruction was the reformation phase. At this point, the participants were taking their reflective thoughts and reforming themselves on the foundation of what was exposed through fractional sublimation. This could be done in solitude, but it is interesting to note that two important aspects of the reforming process of reconstruction, which kept re-occurring throughout the verbal and written reflections of the participants, were the interaction and relationships with others during the WWP. There were repeated references to how others helped shape the new perspectives a person was realizing about himself or herself. The added viewpoints from others seem to broaden the paradigm from which individuals could assess themselves. The following are examples: "This class has helped me to see how important other people are in adding meaning to my life” (Participant \#9), and

But, while this is what I internalized, the color of the rock, the sound of the San Rafael, the paradox is that I know that I could not have faced this nonhuman other without our class. I needed humans in order to establish a relationship with the nonhuman other. (Participant \#4)

Pete Allison (2004), of the University of Edinburgh, Scotland, commented on this research study's reconstruction theme and the views from relationships with others by 
citing an Antarctic explorer who said that he needed to step outside of himself to get a really good view of who he was. For these participants, they relied on their classmates and instructors to give them that out-of-body perspective.

There was a distinction made by Participant \#10 between the moment and the reflective experience. “Now I realize what I’ve always known; rarely is life defined by moments, but more so by experiences, and this may help shape some part of me.” This distinction seemed important to this participant and her comment implied that, for her, reconstruction was a very cognizant process. This cognition was a common attribute of reconstruction throughout the group as they wrote or verbalized their feelings. "Situations and experiences shape us and make us who we are” (Participant \#7).

Reconstruction created the sense of a meaningful learning experience. This theme filled in the framework that the other previous three themes helped to wipe a clean spot on the canvas. The new image is painted on the sublime or that indescribable essence of the individual.

Growth

Growth is the final theme in this phenomenon of meaningful learning experiences. Growth is the recognition that a personal change has occurred and that the process yielded results that can be memorable and worthwhile. This theme is not a part of the process of making meaningful learning experiences because it is more of the result of the meaningful experience, not a part of the actual process. Yet, it was still essential for the participant to know that they had a meaningful learning experience.

Growth was the result of the previous four themes of a meaningful learning experience. "I think I learned about myself that I have so much room for growth and 
improvement” (Participant \#13). At this stage of the experience, the participant not only recognized that something influential happened but could identify what that something was. The participant can be specific as to what was learned and may even be able to express how that has changed him or her. For some, the growth was in building friendships. "Nature for me is a tool I can use to create meaningful relationships with others" (Participant \#9). Some participants learned to trust others. "I think that is what I really started to learn from this class, how to allow others to reach out their arm to help and how to reach back” (Participant \#7). Growth was also a realization of the facades one creates. "It was also instructive to learn that it’s not really important in other people's eyes how tough I am” (Participant \#5). Specific weaknesses, strengths, and potentials were identified for individuals. "I discovered that I'm not really the leader type, but I'm a good like team worker, and stuff like that. I'm okay with that and I can focus on being a good team player" (female participant). Some discovered their relationship with their environment. "I have learned to love this "non-human other" not because it is divinely beautiful, unbelievably intricate, and overwhelmingly expansive $\ldots$ but because it has become my workshop; a place of discovery ... a place of worship ... a place of change” (Participant \#1).

The participants found and expressed positive learning experiences. Before this study began, there was a concern that a negative result, which could also be a meaningful learning experience, could occur. Such was not the case in this study. All the participants who felt that they had meaningful learning experiences in the WWP expressed positive growth as the result of their experiences. "I feel that my quality of life has been improved from meeting the people in the class. I really feel that” (Participant \#12), and 
...I truly feel that something that I have learned this semester is forgiving yourself, for lack of a better phrase. Like trying and failing and forgiving yourself. And like maybe it seems like, no, failure is not okay, failure is sad, you know, you don't want people to fail, you want people to try and you want them to succeed, and then learn big, huge truths about themselves, but there's value to learning how to try and fail and forgive. Try, fail , forgive. It's not a bad thing. (female participant)

Growth was the final verification that meaningful learning had taken place. The participants' expressions of growth at the end of the WWP were more than just the checked off excellent class rating on an evaluation form. All but one participant found the experiences meaningful and emotionally expressed their feelings about the program in very powerful words.

Thank you Dr. Bennion (and Stacey [sic] and Dr. Olsen if you are reading this) for a wonderful class. I do not know what I would have done without it. It has kept me sane. It has caused me to believe that I can do more than I think I can do. I feel more connected to my environment; I want to learn more about it. It has given me a sense of place, a sense of belonging. I am terrified of losing this. I am afraid that now that my forum for outdoor learning is gone, I will find myself flailing, not knowing how to continue on my own (Participant \#4).

and

Why does it all have to end? [Participant \#4] and I talked about the possibilities of class reunions, an idea that will most likely remain an idea. No one is ready for change. I didn't cry at my high school graduation, but I might cry at this one, and 
it is just the end of another class. We have been there for each other through pain and sorrow and joy of each activity. Someone said earlier that although we don't know much about each other's personal lives, we know each other. (Participant \#6)

The one participant, Participant \#3, who kept mentioning that looking for meaning in these WWP experiences was futile and implying that meaningful learning had not taken place for him, was also the one individual who found little risk and, therefore, hardly any awkwardness in the activities done in the WWP. He had done most of the activities before and was adept at performing the skills required. For those activities in which he found awkwardness, there were expressions of fractional sublimation, but the recognition and acceptance of what was exposed was quickly covered back up by more facades and not admitted to.

I have to leave the fire. I go to my hammock, take off my shoes, and try to wrap up. Most of the night is spent trying to warm my feet. Little time is spent sleeping, and the dawn's arrival is gratefully accepted as a chance to leave again for the fire. The coals are still hot, and in short order, I have started the flames again. My feet began the several hour thawing process ... Passing over uneven, steep terrain is second nature for me. (Participant \#3)

He did allow himself one comment that was taken as a growth statement, "Meaning comes from application” (Participant \#3), so there is a slight assumption that meaningful learning did take place for him also. 


\section{Summary}

In summary, the research found that five major themes evolved out of the phenomena of meaningful learning experiences in an outdoor education setting. They were risk, awkwardness, fractional sublimation, reconstruction, and growth. These themes occurred in a specific sequence, as previously listed, and this sequence seemed to be crucial in the process of creating meaningful learning experiences. Within each theme, this study found attributes that were repeated by multiple participants, which included the following:

1. Risk

a. There are degrees of risk.

i. Risk based on something new.

ii. Risk based on a commitment to experience a known awkward situation.

iii. Risk based on high potential of a very awkward situation.

b. The degrees of risk influenced the potential of how meaningful the experience could be.

2. Awkwardness

a. Different causes of awkwardness.

b. Duration of awkwardness.

c. Recognition of this awkwardness and the vulnerability.

3. Fractional sublimation

a. The outdoor environment stimulates this fractional sublimation process to develop by providing environmental challenges. 
b. Fractional sublimation is characterized as a painful process.

c. There is emotion that emanates from this theme which may reflect the sublime.

4. Reconstruction

a. Recognition and acceptance of what was revealed through fractional sublimation.

b. Outdoor setting's influence.

c. Reconstruction is composed of two steps:

i. Reflection

ii. Reformation

d. Reflective experience vs. moment.

5. Growth
a. Recognition and specificity.
b. Positive
c. Constructive
d. Emotion 


\section{Discussion}

Something happens when you share experiences with others in an outdoor setting, where challenge naturally is placed before you. Challenges mean more than climbing a rock face or kayaking down a class five white water river, even though those count too. A challenge means that some sort of risk has to be taken, like backpacking in a new area or learning how to canoe for the first time. By sharing these kinds of experiences with others, you get to know them, not in a demographic way, but you really get to know them. You see and hear things that make them appear vulnerable, pure, teachable, and even sublime. But if you see and hear things that give you those impressions about them, maybe they are seeing you in the same light. And if they see you that way, can you step outside yourself for awhile to see yourself in that same view? And what do you see? In the surrounding environment, whether it be a desert canyon, the alpine mountains, a boreal forest, a flowing river, or the ocean, does the immense backdrop do something to you? In the grand scheme of this overwhelming environment, with its potential power to squash you like a bug or swallow you up so no one might ever find you or your group again, your existence may not seem so important or even noticed. You find yourself no longer at the top of the food chain and all that talk of man being the superior life form, well, nature does not seem to be buying into that notion right at this point. Yet, you know that you and your companions do matter, to yourselves. Maybe you are vulnerable in this outdoor environment, but not defeated. Your survival instinct demands that you adapt. You take what you have seen about yourself and others, even that vulnerable self with weaknesses, and the strengths that others point out to you and you deal with the situation. For some reason, you emerge with a meaningful learning experience. You have 
discovered a new image of yourself and the people you are with like what they see. You reciprocate the feeling for them. The experience has become something special, learning has taken on a new dimension of interest, and personal meaning from an experience is formed and cherished.

This type of phenomenon gets people excited about being in the outdoors and it is what currently has turned the commercial outdoor recreation world into a ten-digit revenue business each year (Russell, 2002). There are people who are excited about sleeping on the ground, getting sweaty and sore, getting dirty and wet, and even living with self-imposed challenges that they did not have to encounter. It seems counterintuitive to all the modern conveniences that exist today.

This phenomenon of a meaningful learning experience is not new and educators are well aware that this type of learning can exist. It is recognizable and personal. Yet the current trend in education is what can be measured and what can be tested. Positivistic ontology, even post-positivism, still dominates education today and the empirical numbers and data are relied on to tell of the successes and failures of educational systems existing in the United States.

The real interest that educators, political leaders, and every citizen of society should have is not how many students graduated from high school or what was the mean aptitude score of a particular grade level, but what did they learn. What were their experiences? Are they interested in education for life? Are they excited to be contributing members of society?

The parameters for the WWP showed 13 students successfully completing the program out of 15 students who started in the program. In the outdoor recreation class, 
seven students who completed the course earned a grade of A, two students earned an A-, while there was one student each for a grade of a B, C, and C-. That results in a class GPA $\mu=3.58$ with a $\sigma=0.78$. In the wilderness writing course, 12 participants received a grade of $\mathrm{A}$ and one participant received a $\mathrm{B}+$. In the wilderness writing class, the GPA $\mu=3.97$ with a $\sigma=0.11$.

BYU offers an opportunity to the students to rate and evaluate a course they have taken at the end of the semester or term they have taken that particular course. The student's evaluation is done voluntarily online. Seven of the participants of this study evaluated Dr. Olsen’s class and 9 students evaluated Dr. Bennion’s class. The evaluation summaries of both Dr. Olsen’s class and Dr. Bennion's class show a very high overall rating of their courses involved with the Winter 2003 WWP (see Appendix J). Dr. Olsen received a rating of 7.7 for his overall course rating and a 7.9 for his overall instructor's rating out of a possible maximum rating of 8.0 for each. Dr. Bennion received an overall course rating of 7.9 and an instructor's rating of 7.8. These ratings can be compared to the University’s overall course mean of 6.6 and the overall instructor mean of 6.9.

Based on these data, a person can assume that the program was a success, but grades and ratings, such as these, usually reflect the skill development and the satisfaction level of the student, not the meaningfulness that each student may have experienced. This data does not tell the whole story of the success of the program. The personal changes, the paradigm shifts, the emotions, and the desire to continue to learn this way are not described by the statistical data.

This research study has found one example of opportunities offered for meaningful learning experiences to flourish. The WWP, offered at BYU in the 2003 
winter semester, gave ample examples of students leaving that program with such experiences. The students of this program had insights about themselves and their relationships with others which resulted in their learning of their weaknesses, strengths, and potentials. This study identifies this result as meaningful learning.

The five themes, (a) risk, (b) awkwardness, (c) fractional sublimation, (d) reconstruction, and (e) growth, appeared in almost all of the participants' reflections. Risk or awkwardness appeared to set the progression of these themes to occur. When either one of these early themes was not identified through the participant's reflections, the other themes did not develop. One participant could not accept what was being revealed about him during the fractional sublimation and, therefore, did not find a reason for reconstruction, a crucial theme in the creation of a meaningful learning experience.

The meaningful learning experience has attributes that this study identified under the five themes associated with such an experience. These attributes appeared in multiple reflections of the participants on the four outdoor activities studied, so they were not onetime occurrences. They seem to fit Holstein's \& Gubrium's (2000) typifications for this phenomenon.

Under the theme of risk, the identification of the attribute of which degree of risk was taken by the participant played two important roles. One role was for the participant to decide if the risk was worth taking in the first place, and the second role was for the determination of how much potential for meaning could come from the experience. Some higher degrees of risk might be too awkward for the participant to become involved and, therefore, they chose not to participate. The potential for meaning was never a consideration before choosing whether to participate for those in this study, but upon 
reflection after the different activities, it seemed clear that the degree of risk directly influenced how meaningful the experience was to the participant. Yet, it was interesting to note that the degree of risk did not determine whether or not a meaningful learning experience could take place. Since meaningfulness is a personal phenomenon, there were different types of meaning coming from different conceptions of the degree of risk produced by the same activity. Whether a participant considered the activity a high risk and another considered the same activity as a low risk, meaning still developed for both.

Awkwardness had several attributes that re-occurred for many of the participants. First, the causes of awkwardness were attributes that appeared to be important for the participants to identify. Five causes of awkwardness were identified in this study: (a) inconvenience, (b) ignorance, (c) lack of ability, (d) feeling out-of-place, and (e) having little or no control of the situation. They helped establish reference points for future determinations concerning the degree of risk one might be willing to take during a different or similar outdoor activity. Second, an interesting attribute of awkwardness was that this study found that with these participants, the duration of the awkwardness did not influence how meaningful the experience was for each of them. For example, during the ropes course activity, one of the experiences was jumping off a small platform about 20 feet off the ground to a suspended ring hanging at about eye level six feet away from the platform. The meaningfulness of that experience was found to be in the cause of the awkwardness of the situation and not how long the participant stood on the platform. The participant who stood on the platform for 15 minutes contemplating whether to jump or not could find that the experience was meaningful just like the next participant who stood on the platform for five minutes before jumping. Finally, the third attribute of 
awkwardness was the recognition of the awkwardness and the vulnerability to it. This attribute was important because in order for the participant to move on to the next stage of the phenomenon of creating meaningful learning, this recognition was essential.

Fractional sublimation had five attributes that appeared in this study. The first two attributes were that the outdoor environment was a common influence of this stage of the phenomenon. Here, the existentialist's view of man's existence being compared and contrasted by his natural surroundings became evident through the reflections of the study's participants. Many of them used the metaphor of the erosion of the earth as a reflection of their own sublimation. The outdoors also enhanced the recognition of fractional sublimation occurring. Many of the participants knew that facades were being peeled off because the outdoor environment required them to deal with this right then and now. The outdoors rarely provided a comfort zone from which a person could delay reactions to this shedding of facades for a later time away from the outdoor environment. A third attribute of this theme was that fractional sublimation was not a pleasurable experience. The participants realized some unpleasant characteristics about themselves through the sublimation process. This led to the fourth attribute which was that the pain experienced during this sublimation was psychological. It could manifest itself later as a physical pain, but not often. The final attribute of fractional sublimation is the emotion that was expressed as part of the recognition of this process. Whether it was surprise, disappointment, or frustration, emotions ran high at this particular stage of the phenomenon.

The reconstruction attributes were important because they contributed to the actual creation of the experience being meaningful for the participant. First, the 
recognition and acceptance of what resulted from the fractional sublimation was essential for the reconstruction to proceed. One participant in this study refused to accept what he was facing from the fractional sublimation and, for him, the process stopped there. The participant commented, “Overall, the class was a very enjoyable experience. I never felt never pushed beyond where I could comfortably go, and so I don’t feel like I had any major life changing experience” (Participant \#3).

The second attribute, again, turned to the outdoor setting that was used as a reference point from which the participants visualized their own personal reconstruction process. To see a river slowly carving out its own niche in a canyon helped the participants realize that all that they had been going through during the activity was similar to this natural erosion process.

The third attribute was the two sub-phases of reconstruction that seemed to occur during the process. The first was the reflection phase which allowed the participant to process all that had occurred up to then and put the important experiences into a context that could create meaning. Some of the participants pointed out that this phase could be done in solitude and some preferred to be alone when reflecting on experiences. The second sub-phase was the reformation phase during which the participant could use his strengths, recognize his weaknesses and decide what to do about them, and, with the help of others (which was considered crucial for this phase) discover the potentials of the participant. Finally, reconstruction was an experience that caused one to be reflective on what had happened during the experience; it is not just an unnoticed moment in time. This was Dewey's educative experience taken to the next level of creating a meaningful learning experience. When you are taught how to do a quadratic equation in an algebra 
class that usually occurs in a moment in time. You remember a vague period when that happened, but little else. A meaningful learning experience is memorable and details remain for a long time because you learned something valuable and applicable to your life.

The final theme of growth differed from the other four themes in that it verified the phenomenon of a meaningful learning experience; it did not create it. Growth is the product of the previous four themes. But, it, too, had attributes. First, the participants recognized that something was learned and they could identify exactly what was learned. It was not a vague concept. Second, growth seemed to be a positive experience for the participants. It was constructive. Finally, growth was an emotional experience. There are deep feelings that sometimes cannot be written or verbally expressed, but can be emotionally expressed. A tear, a laugh, or a smile tells you that something good happened out of all this.

The phenomenon of meaningful learning experiences can be likened to a painting that is priceless. The original may have been vivid and sublime at one time, but, through the years, many environmental factors wore on the painting. To liven it up again, fresher paint was added to cover up the faded and damaged areas, but as these attempts continued, the true essence of the original painting is hidden under the layers of facades. To get back to the painting's original masterpiece, a painter has to take the risks to peel away the added layers of paint. The paint thinner and scraper used to remove the layers creates the awkwardness because of the potential of ruining the masterpiece beyond repair. Fractional sublimation occurs as the layers of paint are carefully removed to bare the original paint. This is what the restorative painter wants to find so that he can paint on 
the original masterpiece. Kant (1892) expressed that the discovery of the sublime was an emotional experience. A painter looking for that original masterpiece knows he has found it through an emotional experience of discovery. The painter carefully reflects on what he has done so far and also what he sees in his own mind that is the masterpiece he is trying to restore. Then, he paints to reform this painting to a different masterpiece, similar to the original and yet different. This is the sublime discovered through a meaningful experience.

This study found what was expressed by the participants of this study as the common attributes that made meaningful learning experiences emerge from the outdoor education program, WWP. This study also showed that such experiences had a powerful impact on most of the participants and they desired more of it. 


\section{Conclusion and Implications}

This study proposes that the meaningful learning experiences that occurred during the WWP can occur again and again with outdoor education programs that can offer the same attributes identified in this study. These attributes can be replicated and duplicated in various outdoor programs that offer relative risks and awkwardness for their students. Many outdoor programs already offer opportunities for these attributes to take place due to the challenges that the outdoor environment presents. That is why they work and produce excited, successful, and contributing students of learning.

The implications of this study can be far-reaching for education because the focus is on learning and learning about self. If what education needs to produce are the contributing citizenry that Dewey (1916) and Posner (2003) advocate for in a democratic society, then education will need to create similar meaningful learning experiences. These identified attributes can be the template for outdoor education programs to model and also add their own variations to. It may even be suggested that these attributes may be used to model vicarious outdoor educational experiences to educational programs that might not have outdoor wilderness settings close by. Through stories of those who have been in the outdoor setting, struggling, and surviving, or through programs that focus on providing appropriate risks and models to reference, the meaningful learning experience may still be possible by emphasizing the themes identified in this study.

If meaningful learning is the goal, not testing and measurement statistics, then a case can be made that concerns for liability or financial support for outdoor education programs can be risked to allow this goal to develop. The reality of such an attainment is a meaningful learning experience in itself. 
A participant of this study verbalized best the importance of what this research found:

The wilderness draws that sweat and blood out of our souls that makes us who we are and shapes our lives to be people of meaning and purpose. Most, if not all, of us found out who we are and what we are made of this year. Some sacrificed comfort, others sacrifice safety, and in return we found majesty and a nobility that will bond us together forever. (Participant \#6) 


\section{Questions for Further Research}

This study was an exploratory one; therefore, the purpose was to identify the essential characteristics of meaningful learning experiences, the first step in the research approach. The results of this study have now generated many more research questions that warrant investigation. The next research question that needs answering is if there are statistically significant correlations between these identified attributes of meaningful learning experiences in this specific outdoor program, the WWP, and other outdoor education programs. A significant correlation could lead to the identification of indicators of this study's themes, which could be used to create a causality study. The findings from such a study could yield some very interesting applications in a variety of educational settings. Could the attributes found in this study be applicable to traditional classroom environments? Could meaningful learning experiences be developed without the outdoor environment?

Another question that has implied answers from this study, but would need its own research to back up the implications, is if there is a connection between meaningful learning experiences and memorable ones. If there is a connection, or several, then what are they and how do they affect one another?

Implications from this research can also impact research conducted in other academic areas other than education. In the field of recreation, should there be a link between recreation and education? Do the patterns of social behavior in recreation have application or correlation to other fields of study? Can recreation research, especially outdoor recreation, have an impact on the studies of other academic disciplines? Some 
research in this area is already being done, but the research is limited on which disciplines are tied to recreation.

Meaningful learning experiences are also very important within the institution of families. Research in this area would be just as important, if not more so, as in the educational settings. Are meaningful learning experiences the same in classroom settings as in family settings? Are the attributes identified in this study applicable to the aggregate of family situations? Could these experiences be re-enacted in family settings and would the results be similar?

Further research in the area of meaningful learning experiences can only enhance the educational process at any level and in any aspect of life, since we are here to experience and learn. 


\section{Epilogue}

"I [have] learned that my gift as a teacher is the ability to dance with my students, to cocreate with them a context in which all of us teach and learn” (Palmer, 1998, p. 72).

In light of what this research has discovered, I think back now to the experiences I have had as a wilderness guide and the experiences I have had as a teacher in the classroom. Even though many of my guided clients expressed their appreciation of providing a meaningful learning experience, interestingly, I now think that not all of my students from the classroom setting failed to get a meaningful learning experience studying the facts of introductory biology. I am sure that some students must have seen my course as a risk and felt the awkwardness of experiencing at least something new. Were they fractionally sublimated? I may make a case that some were. In my biology class, it did not matter whether you were the star football player for the high school or the grand thespian of the drama department to learn the course's material. I do not think that any of my students gained an advantage in my class if they came from a wealthy family or a not so wealthy family. In other words, the social facades that the students may have been carrying around probably did not help them learn biology. But I do think some recognized and accepted their weaknesses and strengths in learning the material, and by reforming through some degree of diligent studying, they realized their potentials by achieving success in the class. Occasionally, but not often, I have received letters from former students expressing gratitude for what they learned in my class and some of the letters let me know that they are practicing medicine or doing work in the biological sciences now. 
The difference between those who might have had a meaningful learning experience in my classes, like many of my guided clients, and those who did not is probably focused on the lack of following through the sequence of risk, awkwardness, fractional sublimation, and reconstruction, as outlined in this study. I think many of my students started off on this path of a meaningful learning experience, but either through my inadequacies as a teacher or their own inadequacies, the sequential process never was completed. Maybe the students failed to recognize or accept what they were being exposed to concerning themselves, or I, as their teacher, did not give them a chance to reflect or reform. Whatever the reason, an opportunity to have a meaningful learning experience was missed and it was missed because I did not know what to look for or how to offer it to them then. I hope that it would be different now with what I have learned about myself as a teacher and what I have learned through this research study.

I believe that Kant's sublime points to the acknowledgement that we do have an $a$ priori self that is hidden beneath facades that we, along with the society we live in, have created. There is sublimity about each one of us that I believe has existed long before we arrived here on this earth. That sublimity is our intelligence, and through our experiences, we have opportunities to rise to our full potential that our sublime nature offers. Education provides us with experiences that have boundaries that control some of the risks that we take in life. These risks set the stage for meaningful learning experiences. Teachers become part of the experience and share the experience with the student and facilitate the opportunities for making experiences meaningful. But teachers need to know the attributes of such meaningful experiences in order to provide those opportunities. 
Christian religions state that we should become like a child in order to humble ourselves and become teachable. Without the facades, this child-like state is the sublime of man. We fail as educators to help students realize the sublime when the education process follows the set agenda of experiences defined by others. Education is not about minimal standards, pre-set aptitudes or statistically significant scores. Education is all about helping individuals realize who they are and what they can become through the contributions they make for the benefit of the society in which they live. Education must provide the bounded settings that allow students to come face-to-face with their weaknesses, their strengths, and their potentials. This is what I have learned through this study and it has been very meaningful to me. It is my hope that this will have meaning for you as well. 


\section{References}

Allison, P. (2004). Thoughts and reflections on the second annual symposium on experiential education research. The Journal of Experiential Education, 26(3), 214-218.

Andrews, K. (1999). The wilderness expedition as a rite of passage: Meaning and process in experiential education. The Journal of Experiential Education, 22(1), 35-43.

Audi, R. (Ed.). (1999). The Cambridge dictionary of philosophy ( $2^{\text {nd }}$ ed.). New York: Cambridge University Press.

Bacharach, S. B., \& Mundell, B. (Eds.). (1995). Images of schools: Structures and roles in organizational behavior. Thousand Oaks, CA: Corwin Press, Inc.

Beard, C., \& Wilson, J. P. (2002). The power of experiential learning: A handbook for trainers and educators. London: Kogan Page Limited.

Bennion, J., \& Olsen, B. (2002). Wilderness writing: Using personal narrative to enhance outdoor experience. The Journal of Experiential Education, 25(1), 239-246.

Bigge, M. L., \& Shermis, S. S. (1999). Learning theories for teachers (6 ${ }^{\text {th }}$ ed.). New York: Addison Wesley Longman, Inc.

Boss, J. A. (1999). Outdoor education and the development of civic responsibility. ERIC Digest. Charleston, WV: Appalachia Educational Laboratory.

Bowles, S. (1994). Glorious enchantments. The Journal of Adventure Education and Outdoor Leadership, 11(4), 15-17.

Brewer, B. W., Raalte, J. L. V., Linder, D. E., \& Raalte, N. S. V. (1991). Peak performance and the perils of retrospective introspection. Journal of Sport and Exercise Psychology, 13(3), 227-238. 
Bruner, J. S. (1973). The relevance of education. New York: Norton.

Bruner, J. S. (1990). Acts of meaning. Cambridge, MA: Harvard University Press.

Bunyan, P. (1994). Adventure activities as an exemplar of experiential education. Journal of Adventure Education and Outdoor Leadership, 11(4), 7-8.

Caine, R. N. (2000). Building the bridge from research to classroom. Educational Leadership, 58(3), 59-65.

Chaplin, J. P. (1985). Dictionary of psychology ( $2^{\text {nd }}$ ed.). New York: Dell Publishing.

Clawson, J. G. (1999). Level three leadership: Getting below the surface. Upper Saddle River, N.J.: Prentice-Hall, Inc.

Cohen, J. (1988). Statistical power analysis for the behavioral sciences $\left(2^{\text {nd }}\right.$ ed.). Hillsdale, NJ: Erlbaum

Coleman, J. S. (1979). Experiential learning and information assimilation: Toward an appropriate mix. Journal of Experiential Education, 4(1), 6-9.

Daft, R. L. (1999). Leadership: Theory and practice. Fort Worth: The Dryden Press.

Debring, C. E., Willis, S. C., \& Genet, B. (1995). Anxiety and the Outward Bound process. In K. Warren \& M. Sakofs \& J. Jasper S. Hunt (Eds.), The Theory of Experiential Education (pp. 357-364). Dubuque, IA: Kendall/Hunt Publishing Company.

Dewey, J. (1916). Democracy and education. New York: The Macmillan Company.

Dewey, J. (1920). Reconstruction in philosophy. Boston: Beacon Press.

Dewey, J. (1938). Experience and education. New York: Collier Books.

Dewey, J. (1960). The quest for certainty: A study of the relation of knowledge and action. New York: Putnam. 
Dreyfus, H. L. (2001). On the internet. London: Routledge.

Drucker, P. F. (1999). The discipline of innovation. In F. Hesselbein \& P. M. Cohen (Eds.), Leader to Leader: Enduring Insights on Leadership from the Drucker Foundation's Award-Winning Journal (pp. 53-56). San Francisco: Jossey-Bass Publishers.

Education, N. C. o. E. i. (1983). A nation at risk. Washington D.C.: U.S. Department of Education.

Elmore, R. F. (1996). Getting to scale with good educational practice. Harvard Educational Review, 66(1), 1- 26.

Estes, W. K. (1975). Introduction to concepts and issues, Handbook of Learning and Cognitive Processes (Vol. 1). New York: Lawrence Erlbaum.

Etzioni, A. (1993). The spirit of community: The reinvention of American society. New York: Simon \& Schuster.

Ewert, A. (1987). Fear and anxiety in environmental education programs. Journal of Environmental Education, 18(1), 33-39.

Frankl, V. E. (1984). Man's search for meaning (4 ${ }^{\text {th }}$ ed.). New York: Pocket Books.

Gager, R. (1976). An introduction to the learning process underlying various modes of experientially based education. Unpublished M.Ed. Thesis, University of Colorado, Boulder.

Gager, R. (1982). Experiential education: Strengthening the learning process. In D. Conrad \& D. Hedin (Eds.), Youth Participation and Experiential Education. New York: Howarth Press.

Gair, N. P. (1997). Outdoor education: Theory and practice. London: Cassell. 
Galloway, S. P. (2000). Assessment in wilderness orientation programs: Efforts to improve college student retention. Journal of Experiential Education, 23(2), 7584.

Garst, B., Scheider, I., \& Baker, D. (2001). Outdoor adventure program participation impacts on adolescent self-perception. Journal of Experiential Education, 24(1), 41-50.

Gass, M. A. (1995). The effects of a wilderness orientation program on college students. In K. Warren \& M. Sakofs \& J. Jasper S. Hunt (Eds.), The Theory of Experiential Education (pp. 365-372). Dubuque, IA: Kendall/Hunt Publishing Company.

Geertz, C. (1975). Interpretation of cultures. London: Hutchinson.

Glaser, B. (1978). Theoretical sensitivity. Mill Valley, CA: Sociology Press.

Greenaway, R. (1983). Active reviewing. Paper presented at the National Conference on Education and Development in Organization, University of Lancaster, UK.

Greene, M. (1978). Landscapes of learning. New York: Teachers College Press.

Grierson, P. (2001). Learning about democracy - Democractising learning. Horizons, 16, 25-26.

Guba, E. G., \& Lincoln, Y. S. (1985). Naturalistic inquiry. Thousand Oaks, CA: Sage Publications.

Guralnik, D. B., \& Friend, J. H. (Eds.). (1966). Webster's new world dictionary, College edition (11 ${ }^{\text {th }}$ ed.). Cleveland, OH: The World Publishing Company.

Haluza-Delay, R. (2001). Nothing here to care about: Participant constructions of nature following a 12-day wilderness program. Journal of Environmental Education, 32(4), 43-48. 
Hammersley, M. (1992). What's wrong with ethnography? London: Routledge.

Harris, D. (1997, March). The making of good citizens. State Legislatures, 29-32.

Hattie, J., Marsh, H. W., Neill, J. T., \& Richards, G. E. (1997). Adventure education and Outward Bound: Out-of-class experiences that make a lasting difference. Review of Educational Research, 67(1), 43-87.

Hemingway, E. (1964). The snows of Kilimanjaro and other stories by Ernest Hemingway. New York: C. Scribner's Sons.

Henry, J. (1989). Meaning and practice in experiential learning. In S. W. Weil \& I. McGill (Eds.), Making Sense of Experiential Learning: Diversity in Theory and Practice (pp. 25-37). Philadelphia, PA: Open University Press.

Hillocks, G., Jr. (2003). Fighting back: Assessing the assessments. English Journal, 92(4), 63-70.

Holstein, J. A., \& Gubrium, J. F. (2000). Phenomenology, ethnomethodolgy, and interpretive practice. In N. K. Denzin \& Y. S. Lincoln (Eds.), Handbook of Qualitative Research (2 ${ }^{\text {nd }}$ ed.), pp. 262-272. Thousand Oaks, CA: Sage Publications.

Husserl, E. (1970). Logical investigations. New York: Humanities Press.

Itin, C. M. (1999). Reasserting the philosophy of experiential education as a vehicle for change in the $21^{\text {st }}$ century. The Journal of Experiential Education, 22(2), 91-98.

Joplin, L. (1995). On defining experiential education. In K. Warren \& M. Sakofs \& J. Jasper S. Hunt (Eds.), The Theory of Experiential Education (pp. 15-22). Dubuque, IA: Kendall/Hunt Publishing Company. 
Kant, I. (1892 [1790]). Kant's kritik of judgment (J. H. Bernard, Trans.). London: Macmillan and Co.

Kaplan, S., \& Talbot, J. F. (1983). Psychological benefits of a wilderness experience. In I. Altman \& J. F. Wohlwill (Eds.), Behavior and the natural environment (Vol. 6, pp. 163-203). New York: Plenum.

Kolb, D. (1984). Experiential learning. Englewood Cliffs, NJ: Prentice-Hall.

Kuhn, T. S. (1996). The structure of scientific revolutions ( $3^{\text {rd }}$ ed.). Chicago, IL: The University of Chicago Press.

Maslow, A. (1970). Motivation and personality. New York: Harper.

Maslow, A. H. (1971). The farther reaches of human nature. New York: The Viking Press.

Mayes, C. (2002). Three perspectives on recent research in conceptual change theory.

Mayes, C. (2003). Seven curricular landscapes: An approach to the holistic curriculum. Dallas, TX: University Press of America, Inc.

Miles, J. (1987). Wilderness as healing place. Journal of Experiential Education, 10(3), $4-10$.

Miller, S. (2001). The transference from wilderness to the home environment. The Ontario Journal of Outdoor Education, 13(2), 26-30.

Milton, B., Cleveland, E., \& Bennett-Gates, D. (1995). Changing perceptions of nature, self, and others: a report on a park/school program. The Journal of Environmental Education, 26(3), 32-39. 
Mosley, D. C., Megginson, L. C., \& Pietri, P. H. (1997). Supervisory management: The art of empowering and developing people. Cincinnati, $\mathrm{OH}$ : South-Western College Publishing.

Oliver, M. (Ed.). (1999). History of philosophy: Great thinkers from 600 B.C. to the present day. New York: Barnes \& Noble, Inc.

Olsen, B. (2002). Student value statements. Provo, UT: Brigham Young University.

Olsen, B. (2003). Recreation management and youth leadership 123: Introduction to outdoor recreation syllabus. In R. students (Ed.). Provo, UT: Brigham Young University.

Olsen, B., \& Bennion, J. (1996). Experiencing Utah's natural heritage: Outdoor experience and creative writing. Utah English Journal, 24, 21-28.

Paige, R. (2003). Remarks of Secretary Paige before the Greater Houston Partnership, [Webpage]. U.S. Department of Education [2003, December 15, 2003].

Palmer, P.J. (1998). The courage to teach: Exploring the inner landscape of a teacher's life. San Francisco: Jossey-Bass.

Payne, D. C. (1987). Psychological theories of learning and teaching. Bloomington, IN: Eastern Press.

Phipps, M. (1988). The instructor and experiential education in the outdoors. Journal of Environmental Education, 20(1), 8-16.

Phipps, M. L., \& Claxton, D. B. (1997). An investigation into instructor effectiveness. The Journal of Experiential Education, 20(1), 40-46, 50.

Piaget, J. (1952). The origins of intelligence in children. New York: The Norton Library, Norton \& Company, Inc. 
Posner, R. A. (2003). Dewey and democracy: A critique. Economic Education Bulletin, 43(1), 1-6.

Priest, S. (1995). An international survey of outdoor leadership preparation. In K. Warren \& M. Sakofs \& J. Jasper S. Hunt (Eds.), The Theory of Experiential Education (pp. 373-382). Dubuque, IA: Kendall/Hunt Publishing Company.

Priest, S., \& Gass, M. A. (1997). Effective leadership in adventure programming. Champaign, IL: Human Kinetics.

Prochazka, L. (1985). Internalizing learning: Beyond experiential education. In R. Kraft \& M. Sakofs (Eds.), The Theory of Experiential Education. Boulder, CO: Association of Experiential Education.

Proudman, B. (1995). Experiential education as emotionally engaged learning. In K. Warren \& M. Sakofs \& J. Jasper S. Hunt (Eds.), The Theory of Experiential Learning (pp. 240-247). Dubuque, IA: Kendall/Hunt Publishing Company.

Rosenthal, H. M. (1983). On early alienation from self. American Journal of Psychoanalysis, 43(3), 231-243.

Russell, R. V. (2002). Pastimes: The context of contemporary leisure ( $2^{\text {nd }}$ ed.). Champaign, IL: Sagamore Publishing, Inc.

Sartre, J.-P. (1993). Being and nothingness: A phenomenological essay on ontology. New York: Simon \& Schuster.

Schutz, A. (1964). Studies in social theory. The Hague: Nijhoff.

Schutz, A. (1970). On phenomenology and social relations. Chicago: University of Chicago Press. 
Schwartz, S. (1986). Classic studies in psychology. Mountain View, CA: Mayfield Publishing Company.

Senge, P. M. (1999). The practice of innovation. In F. Hesselbein \& P. M. Cohen (Eds.), Leader to Leader: Enduring Insights on Leadership from the Drucker Foundation's Award-Winning Journal (pp. 57-68). San Francisco: Jossey-Bass Publishers.

Skinner, B. F. (1938). The behavior of organisms. New York: Appleton-Century-Crofts.

Skinner, B. F. (1969). Contingencies of reinforcement. New York: Appleton-CenturyCrofts.

Smoot, R. C., Smith, R. G., \& Price, J. (1995). Merrill chemistry. New York: Glencoe Division of Macmillan/McGraw-Hill School Publishing Company.

Stake, R. E. (2000). Case studies. In N. K. Denzin \& Y. S. Lincoln (Eds.), Handbook of Qualitative Research (2 ${ }^{\text {nd }}$ ed., pp. 236-247). Thousand Oaks, CA: Sage Publications.

Strauss, A. L., \& Corbin, J. (1991). Basics of qualitative research: Grounded theory procedures and techniques. Newberry Park, CA: Sage Publications.

Swenson, L. C. (1980). Theories of learning: Traditional perspectives/ contemporary developments. Belmont, CA: Wadsworth Publishing Company.

Taniguchi, S. (2004). [Dissertation research transcription and participants' essays]. Outdoor education and meaningful learning experiences: Finding the attributes of meaningful learning experiences in an outdoor education program. Unpublished raw data. To obtain copies of the transcriptions and essays, contact 
Department Secretary, Educational Leadership and Foundations, Brigham Young University, 306 McKay Building, Provo, Utah 84602.

Tyack, D. (1997). Civic education - What roles for citizens? Educational Leadership, 54(5), 22-24.

Vygotsky, L. S. (1978). Basic theory and data. In M. Cole \& V. John-Steiner \& S. Scribner \& E. Souberman (Eds.), Mind in Society: The development of higher psychological processes (pp. 19-57). Cambridge, MA: Harvard University Press.

Wurdinger, S. D. (1994). Philosophical issues in adventure education. Dubuque, IA: Kendall/Hunt Publishing Company.

Yerkes, R. M., \& Dodson, J. D. (1980). The relation of strength of stimulus to rapidity of habit-formation. Journal of Comparative Neurological Psychology, 18, 459-482. 
Appendix A

Maslow’s Hierarchy of Needs

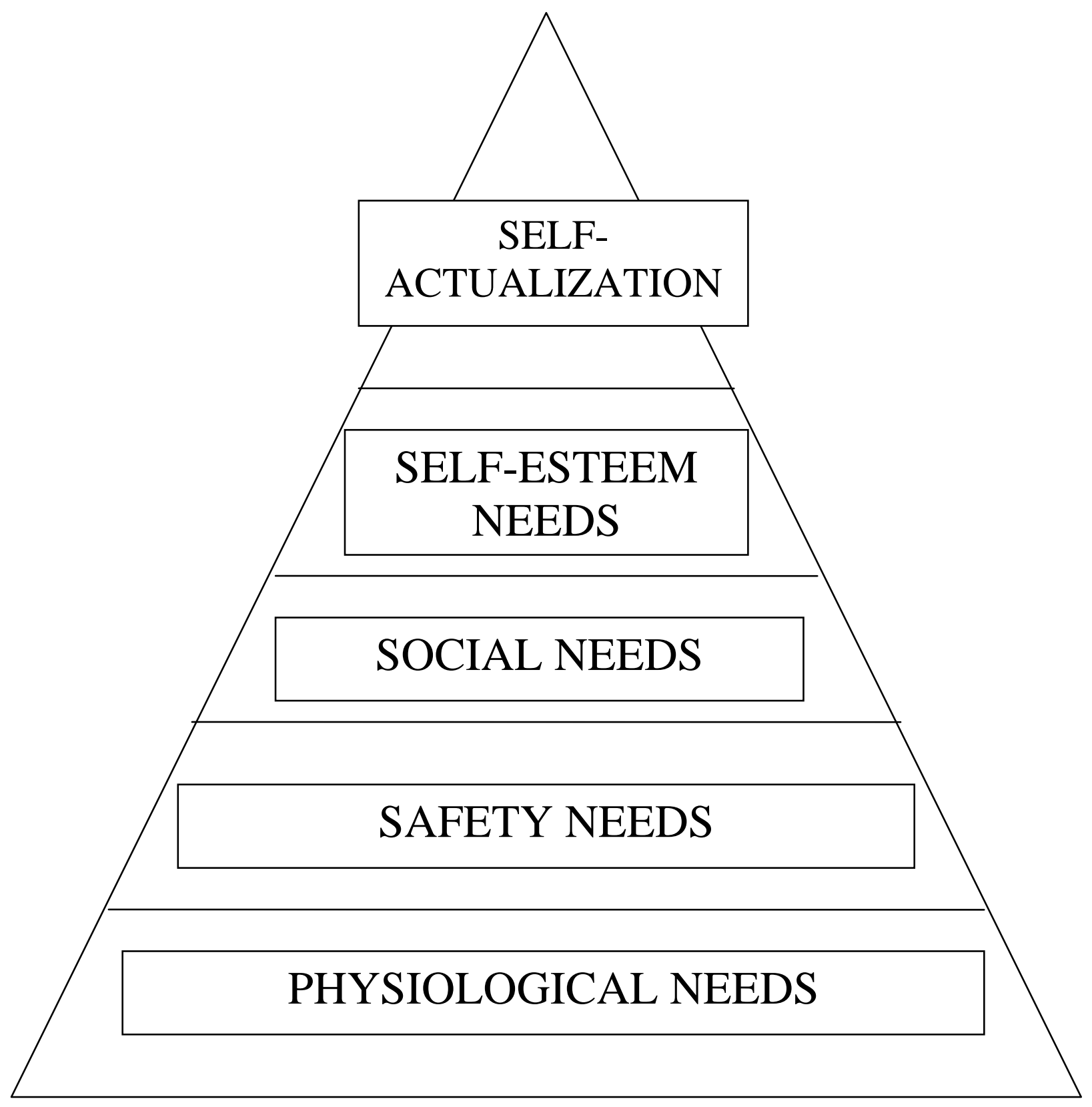

(Daft, 1999) 
Appendix B

Written Purpose and Expectations of Research Study

BRIGHAM YOUNG UNIVERSITY

Stacy's Research Project: Participation Expectations

Data Collection Methods

The research study that you are being asked to participate in is interested in discovering the attributes that are common and frequent with meaningful learning experiences in an outdoor education program, such as the Wilderness Writing Program.

The following outline will describe the proposed methods for data collection in this research study. There may be revisions and changes due to unforeseen circumstances, but changes and revisions will not affect the contract of the Consent to Participate form you may sign.

\section{EXPECTATIONS:}

1. Participate in four required outdoor activities for the RMYL 123 course. These activities include the following:

a) 2-4 hours of cross-country skiing at Aspen Grove.

b) Overnight snow cave experience (location yet to be determined)

c) Half-day (afternoon) ropes course activity (CLAS Ropes Course in Provo)

d) 3 days and 2 nights backpacking trip (location yet to be determined) Observations, by the researcher, will be made and recorded during each of these activities.

2. Participate in group discussions scheduled either right after or during the latter part of each of the 4 required RMYL 123 activities. These will be focused group debriefings that will allow time for personal, as well as shared reflections of the outdoor activity just completed or soon to be completed. These group debriefings will encourage verbalization of your reflections but can also be a time for written reflection. Observations and tape recordings of these group discussions will be made.

3. Keep a personal journal that records, in writing, your thoughts, feelings, perspectives, descriptions, and anything else you want to record during and soon (within 1-2 days) after each of the 4 required RMYL 123 outdoor activities. The entries, you write concerning each activity, will be transcribed onto a floppy disk and given to Dr. Bennion by the following Monday right after the activity's completion. It will be requested that you transcribe your journal entry exactly as you wrote it in your journal. During the following Tuesday's writing class meeting, you will share your journal entries, concerning the recent outdoor activity, with a classmate for review. Your journal transcriptions and the classmate's review will be used for analysis for this research study. 
4. You will write 3 personal essays, as per Dr. Bennion's instructions. Each essay will be about your connection with a personal experience and its meaning to you. One of the essays must be about the 3-day backpacking trip. All 3 essays may be used for analysis in this research study. You will be asked to present one of these essays to the class for review. You will also have a one-on-one interview with Dr. Bennion concerning one of these 3 essays. The researcher will be present at this interview and the class review of one of your essays to make observations and tape record the session.

5. You may be asked to discuss your thoughts, writings, feelings, etc. with the researcher at various times throughout the semester. These requests will be to clarify questions about your writings and/or your verbalizations made during various times of the classes. Your participation in these requested discussions is voluntary and will always be done in a public setting.

6. You may be contacted by the researcher after the current Wilderness Writing Program is completed for additional information.

7. You will be asked for personal demographic information during and, maybe, after the current Program is completed.

If you have any questions or concerns about this research study, please feel free to ask or comment to the researcher at anytime. 
Appendix C

Consent to Participate Form

Phenomenological study Project: A Doctoral Dissertation Research

Consent to be a Research Participant

This research project is part of the requirements of a doctoral program in the Department of Educational Leadership and Foundations in the College of Education at Brigham Young University. The research study is being conducted by Mr. Stacy Taniguchi, a Ph.D. candidate in this Department.

The purpose of this research is to identify attributes of an outdoor education program that are commonly recognized by the participants of this study as characteristic of meaningful learning experiences. The outdoor education program, under study, is the Wilderness Writing Program at Brigham Young University.

As a research study participant, you will be asked to be enrolled, as a student, of RMYL 123: Introduction to Outdoor Recreation and Honors 203R/ English 368: Wilderness Writing in the Winter Semester 2003 at Brigham Young University. Your participation as a subject of this study must be of your own volition and understanding that you are under no obligation to participate. You understand that you will not be penalized in any way, as a student of the Program, for choosing not to participate in this study. You understand that you may withdraw from this study at anytime during the Winter Semester of 2003 without any penalties and that you may request to have your input be completely or partially removed from the collected data of this study.

As a research study participant, you will be expected to participate in four outdoor activities that will require you to be outdoors in a variety of weather conditions and temperatures. Some of these activities will be in snow conditions. These activities will require you to cross-country ski, hike with a full backpack, climb, and sleep outdoors. Some of these activities are an hour long while others will be as long as three days. All of these activities are requirements of the Program, whether you are a subject of this study or not. All of these activities are under the instruction and supervision of the Program's instructors. This study carries some potential risks, which include, but are not limited to, bodily injury due to your participation in the outdoor activities, hypothermia, and fatigue. Although these risks will be minimized by instruction, preparation, and supervision, there cannot be a guarantee to alleviate any of them all together.

As a research study participant, you will be expected to participate in discussion groups to vocalize your personal feelings and perceptions of each of the activities. You will also be expected to participate in writing assignments, of the Program, that will ask you to write about your feelings and perceptions of the required activities. You will be expected to be honest and forthright with your contributions. 
Your identity as a subject of this study will be kept anonymous to all outside of this study, but the researcher, Stacy Taniguchi. You will not be personally identified in any publications, text, presentations, or conversations dealing with this study.

Confidentiality will be maintained by the researcher concerning personal information given out, by you, in this study. There is a risk that the confidentiality of what you share amongst others in the Program may be violated by others. To minimize this risk, all students of the Program will be asked, by the Program instructors, to respect this confidentiality.

If you have any questions about this research study, you may contact: Stacy Taniguchi, Department of Recreation Management and Youth Leadership, Brigham Young University, 273F Richards Building, Provo, Utah 84602, telephone number: (801) $422-$ 1286.

If you wish to speak to someone regarding your rights as a research subject, you may contact:

Chair of the Institutional Review Board of Human Participants, Brigham Young University, Provo, Utah 84602.

"I herby affirm that I will not disclose information discussed during the Program or this research study to anyone other than other members of the Program and the researcher of this research study. My signature below indicates that I have read, understood, and willingly comply with this consent form and have also received my personal copy of it. I desire of my own free will to participate in this research study.”

NAME:

(Please print your full name)

SIGNATURE:

WITNESS:

(Please print your full name)

SIGNATURE:

DATE: 


\section{Appendix D}

RMYL 123 Class Schedule for 2003 Winter Semester

\section{DATE}

January 9, 2003

January 16, 2003

January 23, 2003

January 30, 2003

February 6, 2003

February 7 - 8, 2003

February 13, 2003

February 20, 2003

February 27, 2003

March 6, 2003

March 13, 2003

March 20, 2003

March 27 - 29, 2003

April 3, 2003

April 10, 2003

April 17 - 23, 2003

\section{$\underline{\text { SUBJECT MATTER }}$}

Course Orientation

In class lessons: Personal Safety Issues \&

Description of Course Activities

Cross-country Skiing Activity

In class lesson: Camping Skills, Snow Caves, \& Winter Considerations

No class due to upcoming campout

Winter Campout

Indoor rifle target shooting activity in Springville

In class lesson: Sky diving lecture

In class lesson: Paragliding lecture

CLAS Ropes Course

In class lesson: Hiking Skills

In class lesson: Backpacking Skills \& Equipment

Backpacking Trip

Dutch oven cooking and meal

Course Review

Final Examinations Week 


\author{
Appendix E \\ Focus Group Debriefing Questions
}

Questions for Thought

The following questions are for you to consider before you participate in the upcoming debriefing of the outdoor activity you have just participated in. You may refer to your journal entries to reflect on your previous thoughts, but these questions are to stimulate an on-going thought process that should continue through the debriefing and your writing assignments for this activity. You should write down thoughts as soon as possible.

- Were you apprehensive about this activity before you started? Why or why not?

- Did you enjoy participating in this activity? How much? Why? Would you do this activity again? What would you change about it?

- Were there any specific moments or situations during this activity that you remember vividly? What were they, if any (Describe them in as much detail as you can remember)? Why do you think that these particular moments or situations stand out? 
- Did you find any associations with classmates or Program staff effective towards your personal feelings about this outdoor activity? What were they, if any? Why?

- Do you feel that you were adequately prepared for this outdoor activity? Why? Would you suggest any modifications to the outdoor activity's instruction? List them, if any.

- What did you learn from your participation of this activity? Anything about yourself? Did your participation in this outdoor activity enhance the learning of the material given in class? How so?

- Would you consider this outdoor activity and the associated lessons meaningful to you, as the term meaningful has been defined in class? Why? 


\section{Appendix F}

Triangulation: Supporting Sources for Validity and Relaibility

Study Participant A:

I really enjoyed reading your study. It sure did make me miss the class. It has been too long since I've done anything outside. Then again, it's FRIGID outside, so I feel a little validated. I didn't see anything that needed to be changed or that I didn't agree with aside from one thing: not everyone in the class was part of the honors program. Most were, but I was not, and I think there were a few others that weren't as well. I was in the honors class, but it was only the second honors class that I had taken in four years. Anyway, that's not too big of a deal. I think that you've done some fine work, and I wish you the best for your dissertation completion and defense. If you need a supportive audience, let me know.

\section{Study Participant B:}

It is a good thing that you caught be just before I left on my mission. I leave in less than a week. I read over your work, I am impressed with the common themes. I thought that I was the only one who felt some of the negative feelings that I did during that class. It is really wonderful to know that I changed and grew with the other class members. I guess each of us learned what we needed to. It was different from other classes because we learned in a group experience our individual lessons.

I think that you are right on. I just finished the class for the second time and my experiences in the class help me better understand what happened to me the first time and the second time. I would have to agree with you completely on what you have written.

\section{Study Participant C:}

I was reading along and decided that it was difficult for me to decide whether the study eventually proved that meaningful experience came from the outdoors or if meaningful experience came because the outdoors is a great way to break down boundaries, and that seems sort of a crucial thing since there was that one student who didn't get all that much out of it. I think that variable needs to be taken into consideration. It is only one student, but why? Because I guess that would determine how you set up the classes of the future.

I like the stages alot. I think the growth stage should be used more than it is used because I wanted some more culminating analysis of the other 4 in the context of the $5^{\text {th }}$. I've read through everything else pretty quickly and then read Growth fairly carefully, and what I was looking for (for me personally) was an academic sort of breakdown of the different contributing factors of the participants plus the outdoors equals these 4 stages equals growth, because reading through risk and fractional sublimation and reconstruction made me think that PERHAPS we could 
shut us all up in a ropes course and get the same thing? BUT I don't think that's true. I think that the outdoors has something SPECIFIC about it that makes the risk, etc unique. The comments you added from us reflected that, but I kinda wanted it mentioned as well.

Study Participant C:

Your themes made me reflect back on my experiences during the course. I could vividly see particular experiences that related to each of your themes. Your findings actually made sense out of what I was going through and helped me remember things that I had actually forgotten. I especially like the analogies that we made with our surrounding environments. I do believe that our existence is defined by the non-human surroundings that we live in, even if for just a moment. Maybe, that realization of our relationship with our environment changes the moment into an experience.

I see your findings as important discoveries for learning who we really are, which is meaningful. Thanks for the insight!

Study Participant D:

What interesting reading! Of course, I'm a lowly undergraduate, so what do I know, but I think your themes are right on. It is important to note that our friendships helped build meaning out of our experiences. I think without having others to discuss what we feel and have gone through would make us miss a lot of the meaning we eventually found out of our experiences. I wish more of my classes would incorporate what you found out and make my learning experiences meaningful.

RMYL Graduate Student :

The findings flowed for me and I could see the sequence being very important. What made this research meaningful for me is that I could see myself making similar statements as the participants of this study. The themes made sense to me and I agree that the growth theme is a result of a meaningful learning experience. The Discussion chapter helped make each theme and its attributes very clear. Some of the participants' comments needed to be put into context, but as we reviewed them, it all made sense.

Outside Reviewer \#1:

I think the really important aspect of this study is how much people can relate to the experiences the subjects of this study had. We may not have done exactly the same things, but I think most of us can remember experiences very similar to what they went through and that makes this research so significant. Meaningful experiences teach us something about ourselves and the outdoor experiences seem to do that quite nicely. Not that I'm willing to go out to discover who I am in that 
way now, but I think the themes you identified can help us look for them in other experiences. Especially, in education where I do agree that meaningful learning experiences are important.

I did have a couple of questions. First, do you think that these kinds of experiences can happen indoors as well? I don't see many schools taking their students outdoors to duplicate your activities. And another question, how do we know that this is actually how it all happens? By having risk, awkwardness, and the rest, does that mean you will have a meaningful learning experience? It would be very interesting to see how these students look back on this study years from now and how they feel it really impacted their lives. I think you're on to something here.

Outside Reviewer \#2:

I'm not that familiar with phenomenological research that you say this one is, but I like the so-called thick description. It adds so much insight to what these students are going through. Is the bonding process that seems to go on in this study between the students any part of the meaningfulness? I think the sequential themes are identified very well and I like the term fractional sublimation. As a former chemist, I think the use of the term is more appropriate than Freud's, although I'm not all sure how he used it in psychology or whatever.

I think your defining risk as more than just a physical thing is important to identify. The mental risk is just as dangerous sometimes.

Will you be following up on this study in the future with these same subjects? I think the verification of what you found will be more meaningful if you can get feedback from these subjects a couple of years down the road. 


\section{Appendix G}

\section{Additional Comments from Participants Relating to Themes}

\section{Risk}

\section{Personal Awkward Situation}

Then I had to walk across the face of the rock to a more even part. I inched along its face with my stomach and chest as close to the wall as possible. At one point, I had to let go of my hand hold, take a step, and reach around to another hand hold. I stood looking at what I had to do and then looking down at my old running shoes that didn't have great traction, and then looking down the thirty feet or so to the ground. I realized that if I fell, I would hit rock ledges on the way and it would be really painful, and I'd most likely seriously injure myself. (Participant \#13)

\section{Physical Discomfort, Injury, or Life Threatening}

“I like hyperventilated for an hour and shivered” (female participant).

"Fifteen below is real scary” (male participant).

“I learned a lot. A lot of stuff was kind of painful” (male participant).

\section{Lesser Degree of Risk}

"We were talking and neither of us were [sic] going to try for the ring that just didn’t seem that exciting” (female participant).

"With the snow cave, it's either you dig it or you freeze... but I didn't see any purpose in jumping off a ledge and catching a rope or a ring” (female participant).

\section{Awkwardness}

\section{Inconvenience}

“I just sat there thinking about how much I didn’t want to be there, struggling in the wild for something as silly as building a snow cave, when a nice warm bed was only an hour away. It wasn’t fun” (Participant\# 6).

\section{Lack of Ability}

"Each time I so awkwardly fell that I had to unclip one ski to stand up" (Participant \#11). 
“...balancing is a challenge” (Participant \#12), "Frustration frequently mixed with anger as I fell over and over and over” (Participant \#6).

Feeling Out of Place

"As I look around at the rocks and dirt, and then down at my own legs, I wonder what has brought me here. Even here I do not belong” (Participant \#7).

\section{Unmanageable Situation}

"And then for the first in a long time I felt really really scared” (Participant \#13).

"I think there were many things against us; these circumstances we were unprepared to face caused us to struggle for the whole trip" (Participant \#1).

\section{Fractional Sublimation}

People are so much more likeable when their facade comes off too. Dr. Bennion said, I've always thought that you ought to take your potential wife or husband backpacking before you marry them, just to see what they are really like. (male participant)

\section{Influence of Outdoor Environment}

"Nothing else matters when you have to work so you'll have a shelter to keep you alive in a couple hours. Not work, not school, not friends, not family" (Participant $\# 11)$.

"I was admittedly scared to go down it. I knew I would die. It was an important lesson in humility” (Participant \#5).

\section{Painful Experience}

"Nothing can make me aware of how small I am better than staring up a cliff" (Participant \#9).

I push myself hard in every facet of my existence - but I guess when I am out of my element, and things get rough, I lose that characteristic - A lot of who I am, or who I thought I was, was lost on me that night in the darkness ... when the sun went down and the temperature plummeted [sic], I lost all that I knew about myself. I thoguth [sic] that I was strong, I thought that I was sharing, I had though [sic] thtat [sic] I could make it on my own - but I couldn't - I can't - and I wasn't who I thought I was. (Participant \#7) 


\section{Environmental Metaphors}

I lifted my head from the trail more often and enjoyed the raw beauty. The red rocks are my heart, I thought. Rough. Exposed. Slowly wearing away by the elements. All the cracks visible. The cracks cut deep and wind tears through them. They are widened, and unsealable. (Participant \#10)

The canyon did not start that way, it started small and over time turned into something magnificent and breathtaking. In that moment, I started to think about me, about who I am, about who I want to become. After several miles, I concluded that God had his hand in my life. I, too, was to become his creation, his masterpiece. It will take time ... it will take work. I will have to withstand years of rain and wind. But it will be worth it. (Participant \#1)

\section{Reconstruction}

\section{Environmental Influence}

"Together, the rock and I shed our former selves and drift upward” (Participant \#8).

"I strongly believe that as I write about my experiences in nature, I am not writing as much about nature as I am about myself” (Participant \#7).

"I felt the value of being in nature was this function of knowing your environment and finding your place in it” (Participant \#4).

"The earth allows us to feel what we see, and in that gives us emotion" (Participant \#11).

"I would watch the experts a little closer and not get so excited about being a big mighty man that could build a palace rather than a dinky little snow cave" (Participant \#12).

"[Participant \#12] made a comment about how the desert helped him learn about himself” (Participant \#10).

He also told us about the desert soil that was on both side of the narrow path we walked on. I forgot what the technical term of it was, but he said that it takes hundreds of years to form - he said it after [Participant \#4] had stomped on it. I found it inspiring, as if I should take lessons from the soil and be willing to persevere. (Participant \#13) 


\section{Reflection}

It is difficult to separate what I have learned specifically from this class and other things that happened in my life this semester. I think I learned about myself that I have so much room for growth and improvement. I realized that I have a long ways to go before I'll be really comfortable in any new social situation. I guess this has to do with community. But I learned too that despite many surface differences, eventually people can learn to mesh with each other and be happy together. (Participant \#13)

I think it's also really interesting with this activity that some of our strengths came out and some of our weaknesses came out that wrecked havoc in our activities. Some people led where other people haven't led before, and vice versa. (female participant)

\section{Reformation}

"I am convinced that I wouldn't have made it through the night if I had been alone” (Participant \#7).

"In a sense, it was a rewarding experience to learn that if you need help, it's not really that degrading to let others help you” (Participant \#5).

“The pictographs just weren't interesting until others arrived to see them, too. I feel like I could witness the most amazing phenomena, but if I had no one to see them with me, it would be meaningless” (Participant \#9).

\section{Growth}

A meaningful learning experience? Is that what is meant by the sharp pain in my bruised knees as I hobble slightly back to my dorm room? Yes, I grew. My physical awkwardness forced me to reveal my social awkwardness and the result was rewarding (Participant \#10).

\section{Positive Results}

"I learned more about the value of a human being” (Participant \#1).

I remember the cross-country trip and journal abstract. I was so worried about what the assignment was and doing all that was required and so worried about doing it just right, and not sounding like an idiot that I wasn't able to open myself up. I wasn't really able to enjoy the trip, because I was so focused on what I would write and how it would sound and what I would say. I don't think I really learned all that much or got all that much out of it because I was so focused on what people would think and what message there was, that I missed it all. Since then, I have learned to enjoy the moment and focus on the activity. And later, as I 
write my journal, I have found the meaning or what I learned. It's been an interesting journey. (Participant \#7) 
Appendix $\mathrm{H}$

Demographic Questionnaire

\section{BRIGHAM YOUNG UNIVERSITY \\ Wilderness Writing Program \\ Demographic Questionnaire}

DIRECTIONS: Read through the following questions and answer each one as honestly and accurately as you possible can. Your responses to the following questions will be recorded and used for data analysis in Stacy's research study.

Participant's ID \#

Your gender (Circle one): $\quad$ Male $\quad$ Female

Your current age (in years):

Your current class standing (Circle one): $\quad$ Freshman

Sophomore

Junior

Senior

Marital Status (Circle one):

Single

Married

Divorced

Widowed

Total number of years of formal schooling:

(Count pre-school \& kindergarten, if applicable)

Your high school cumulative GPA:

Your current post-secondary cumulative GPA:

Your current major area of study:

Your current minor area of study: 


\section{Appendix I}

Research Participants’ Demographic Parameters

\begin{tabular}{|c|c|c|c|c|c|c|}
\hline PARTICIPANT & AGE (yrs) & CLASS $^{1}$ & COGPA $^{2}$ & HSGPA $^{3}$ & TOTSCH $^{4}$ & GENDER $^{5}$ \\
\hline 1 & 20 & 3 & 3.75 & 3.86 & 15.00 & 2 \\
\hline 2 & 20 & 4 & 3.60 & 3.75 & 16.00 & 2 \\
\hline 3 & 18 & 1 & 3.84 & 3.95 & 14.00 & 1 \\
\hline 4 & 21 & 4 & 3.76 & 3.87 & 16.00 & 2 \\
\hline 5 & 24 & 4 & 3.46 & 3.99 & 17.00 & 1 \\
\hline 6 & 20 & 2 & 3.53 & 3.98 & 16.00 & 2 \\
\hline 7 & 19 & 1 & 3.90 & 3.96 & 14.00 & 2 \\
\hline 8 & 22 & 4 & 3.85 & 4.10 & 17.00 & 2 \\
\hline 9 & 23 & 4 & 3.25 & 3.71 & 15.00 & 1 \\
\hline 10 & 18 & 1 & 3.80 & 4.10 & 13.00 & 2 \\
\hline 11 & 22 & 4 & 3.76 & 4.30 & 17.00 & 2 \\
\hline 12 & 18 & 1 & 3.37 & 3.70 & 13.50 & 1 \\
\hline 13 & 21 & 4 & 3.76 & 4.40 & 17.00 & 2 \\
\hline
\end{tabular}

${ }^{1}$ Class Standing at BYU: $\quad 1=$ freshman

$2=$ sophomore

$3=$ junior

$4=$ senior

${ }^{2} \mathrm{Co}$ GPA $=$ Cumulative GPA at BYU (based on $4.0=\mathrm{A}$ ).

${ }^{3}$ HSGPA = Cumulative GPA upon graduation from high school (based on 4.0 = A)

Some have a GPA greater than 4.0 due to Advanced Placement courses.

${ }^{4}$ Tot School $=$ Total years of school to date (as of January 2003).

${ }^{5}$ Gender: $\quad 1=$ Male

$2=$ Female 


\section{Appendix $\mathrm{J}$}

Descriptive Analysis of Demographics

Table I1

Participants' Statistics

\begin{tabular}{lcccc}
\hline & AGE & COLGPA & HSGPA & TOTSCH \\
\hline Mean & 20.5 & 3.66 & 3.97 & 15.42 \\
Median & 20.0 & 3.76 & 3.96 & 16.00 \\
Mode & 18.0 & 3.76 & 4.10 & 17.00 \\
SD & 1.94 & 0.20 & 0.21 & 1.44 \\
Range & 6.0 & 0.65 & 0.70 & 4.00 \\
Minimum & 18.0 & 3.25 & 3.70 & 13.00 \\
Maximum & 24.0 & 3.90 & 4.40 & 17.00
\end{tabular}

Table I2

Class Distribution

\begin{tabular}{lcc}
\hline CLASS & FREQUENCY & PERCENT \\
\hline Freshman & 4 & 30.8 \\
Sophomore & 1 & 7.7 \\
Junior & 1 & 7.7 \\
Senior & 7 & 53.8
\end{tabular}


Table I3

Gender Distribution

\begin{tabular}{lcc}
\hline GENDER & FREQUENCY & PERCENT \\
\hline Male & 4 & 30.8 \\
Female & 9 & 69.2
\end{tabular}

Table I4

Age Distribution

\begin{tabular}{lcc}
\hline AGE (years) & FREQUENCY & PERCENT \\
\hline 18 & 3 & 23.1 \\
19 & 1 & 7.7 \\
20 & 3 & 23.1 \\
21 & 2 & 15.4 \\
22 & 2 & 15.4 \\
23 & 1 & 7.7 \\
24 & 1 & 7.7
\end{tabular}


Appendix K

BYU Online Student Ratings Report

Table J1

Student Rating for RMYL 123: Introduction to Outdoor Recreation

OVERALL

STD DEV SEC MEAN COLL MEAN UNIV MEAN

Course

0.49

7.7

7.0

6.6

Instructor

0.38

7.9

7.1

6.9

Amt Learned

0.76

7.7

6.8

6.6

Active Stud Involvement

0.76

7.7

7.2

6.9

Valuable Time in Class (\%)

12.54

92.9

84.7

78.5

Period: Winter 2003

Responses/Enrolled: 7 / $15=47 \%$

Instructor: Olsen, Burton K

College: Health and Human Perform

Table J2

Student Rating for Honors 203R: Wilderness Writing

\begin{tabular}{lcccc}
\hline & & & & \\
OVERALL & STD DEV & SEC MEAN & COLL MEAN & UNIV MEAN \\
Course & 0.33 & 7.9 & 7.1 & 6.6 \\
Instructor & 0.67 & 7.8 & 7.3 & 6.9 \\
Amt Learned & 1.00 & 7.7 & 7.0 & 6.6 \\
Active Stud Involvement & 0.67 & 7.8 & 7.4 & 6.9 \\
Valuable Time in Class (\%) & 10.54 & 88.9 & 82.4 & 78.5 \\
\hline
\end{tabular}

Period: Winter 2003

Responses/Enrolled: 9 / $15=60 \%$

Instructor: Bennion, John S

College: Undergraduate Education 